University of Rhode Island

DigitalCommons@URI

Open Access Dissertations

2016

\title{
An Explanatory Case Study of the Implementation of Co-Teaching as a Student Teaching Method
}

Karen L. Capraro

University of Rhode Island, kcapraro@ric.edu

Follow this and additional works at: https://digitalcommons.uri.edu/oa_diss

\section{Recommended Citation}

Capraro, Karen L., "An Explanatory Case Study of the Implementation of Co-Teaching as a Student Teaching Method" (2016). Open Access Dissertations. Paper 527.

https://digitalcommons.uri.edu/oa_diss/527

This Dissertation is brought to you for free and open access by DigitalCommons@URI. It has been accepted for inclusion in Open Access Dissertations by an authorized administrator of DigitalCommons@URI. For more information, please contact digitalcommons-group@uri.edu. 
AN EXPLANATORY CASE STUDY OF THE IMPLEMENTATION OF

CO-TEACHING AS A STUDENT TEACHING METHOD

BY

KAREN L. CAPRARO

A DISSERTATION SUBMITTED IN PARTIAL FULFILLMENT OF THE

REQUIREMENTS FOR THE DEGREE OF

DOCTOR OF PHILOSOPHY

UNIVERSITY OF RHODE ISLAND

\author{
AND \\ RHODE ISLAND COLLEGE
}

2016 


\section{DOCTOR OF PHILOSOPHY DISSERTATION}

OF

\section{KAREN CAPRARO}

\section{APPROVED:}

Dissertation Committee

Major Professor:

RIC:

URI:
Patricia Cordeiro

Lorraine Cotti

David Byrd

Theresa Deeney

Donald Halquist

Dean, Feinstein School of Education - RIC

Nasser H. Zawia

Dean, The Graduate School - URI

\section{UNIVERSITY OF RHODE ISLAND \\ AND \\ RHODE ISLAND COLLEGE \\ 2016}




\begin{abstract}
The purpose of this qualitative, single-case study was to examine the implementation of co-teaching as an alternative student teaching method across seven elementary and early childhood classrooms to determine how it was implemented and, if differences in implementation were found, to develop substantive theories as to why those differences were present. The study was conducted at an elementary, laboratory school located on a college campus. Three sources of data were collected including interviews, observations, and documents. During data collection and throughout my analysis, I adhered closely to the methodology of grounded theory analysis as presented by the discoverers of grounded theory, Barney Glaser and Anselm Strauss (1967/2008), and as presented in subsequent texts which further detailed the methodology, as provided by Strauss and Corbin (1998), and Glaser (1978; 1992). My initial analysis aided me in establishing substantive codes relative to the data and to establish a core variable, Transitioning from Student to Teacher Alongside the Teacher, which was further separated into two-sub-categories, Becoming a Teacher While Co-Teaching and Taking the Lead While Co-Teaching. I then selected a theoretical coding family and three properties of status passage-temporality, desirability, and reversibility - to further analyze the data. My findings indicate that how co-teaching was implemented, in terms of Becoming a Teacher, occurred in much the same way as the more traditional model would have been implementedembedded in the larger context of student teaching where temporal expectations were regularly scheduled and coordinated and key agents prevented reversals. Differences in implementation were more closely related to Taking the Lead and were due to
\end{abstract}


undefined temporal expectations, the desirability or undesirability felt by participants toward the passage, and reversals in the passage relative to structural and/or personal conditions experienced by participants. 


\section{ACKNOWLEDGEMENTS}

This dissertation, while bearing my name, is the result of many. I must first acknowledge my committee, David Byrd, Rainy Cotti, Terry Deeney, and, of course, Pat Cordeiro. You generously gave of your valuable time and your vast experience and you kept me focused. Words cannot fully express my gratitude. I had each of you in my mind throughout my research, and, especially, during the preparation of this dissertation. I hope I will make you proud.

I also would like to recognize the Rhode Island College and University of Rhode Island doctoral faculty. You opened my eyes to new ways of looking at education, the world, and perhaps most importantly, myself.

Many members of the Rhode Island College community were also instrumental in this work. To Dean Halquist and Jeannine Magliocco, as well as the second graders and their families I left behind mid-year, thank you for allowing me to fully immerse myself in my work while on sabbatical and for enthusiastically supporting that work.

Many thanks to the my research site's Office of Partnerships and Placements for helping me to establish my "case," and to all of my respected colleagues who participated in my study by opening their classrooms and offering me their precious time and valuable insights.

A sincere thank you, as well, to Robin Montvilo, for agreeing to read my work and for making the milestones feel a little less intimidating. And, I would also like to thank my treasured colleague (and treasured friend), Michelle Nonis, for her continued 
help both in and out of the classroom as I made my journey from my first qualitative analysis class to this qualitative dissertation.

To my family, Mom and Dad, you instilled in me a growth mindset (way before it was trendy) and the work ethic that I needed to accomplish this work. You also taught me to "pull up my bootstraps" when things weren't going well or when life took an unexpected turn. The lessons you taught me made me push through when I was tired, accept that life is unpredictable, and know that there is always more to learn if we just listen.

To my daughters, Liz and my Liv-I hope you saw me more as a role model than a missing mother. I also hope that through watching my journey you will understand that you, too, can achieve anything.

And finally, to my husband who supported me every step of the way, I thank you for encouraging me to go after my dreams and for reminding me often to "relax." You helped me to bring this work to life and my life to this work. Thank you. 


\section{DEDICATION}

To my sister. 


\section{TABLE OF CONTENTS}

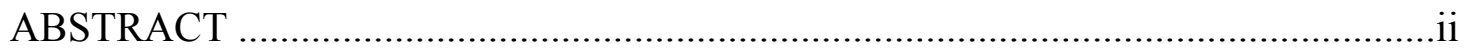

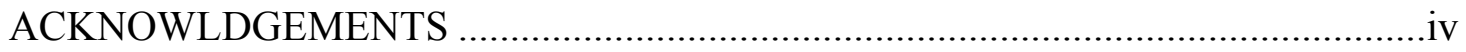

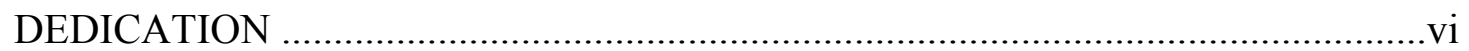

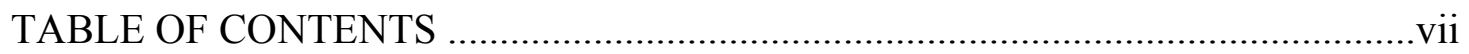

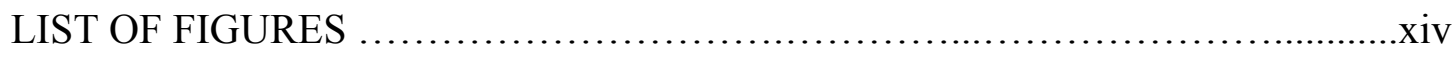

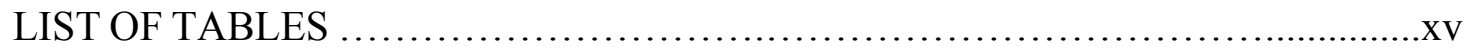

CHAPTER 1: INTRODUCTION …………………...............................................

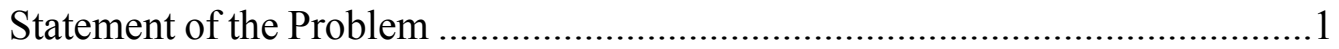

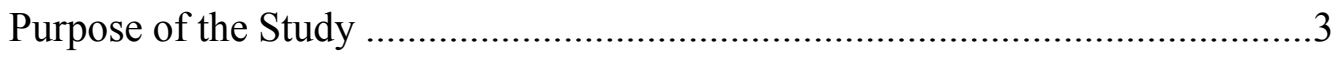

Significance of the Study ……………............................................................

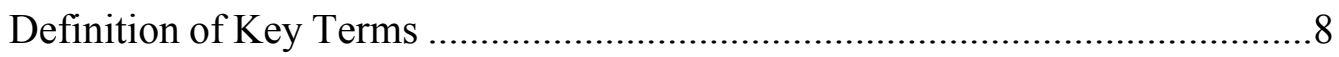

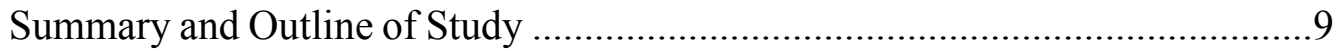

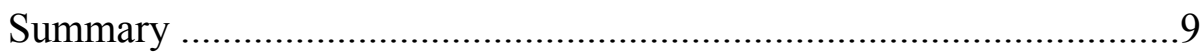

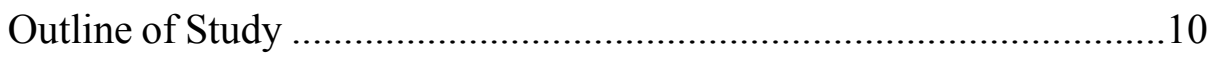

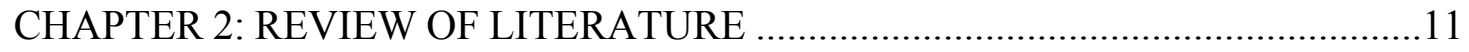

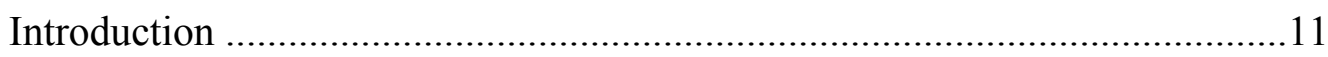

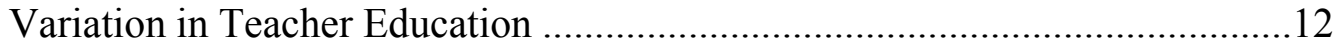

Differences Between Traditional Student Teaching and Co-Teaching ............13

Traditional Student Teaching ...........................................................13

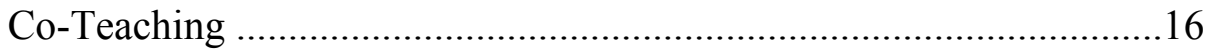

Placing Teacher Candidates ......................................................18

Improved Communication and Collaboration ...........................19 
Teacher-to-Student Ratio ......................................................22

Student Achievement .......................................................23

Preparation and Implementation $=$ Enhanced Student Teaching Experience....24

CHAPTER 3: METHODOLOGY AND PROCEDURES.........................................26

Rationale for the Use of Case Study as Research Method..............................26

Conceptual Structure............................................................................22

Theoretical Framework..................................................................28

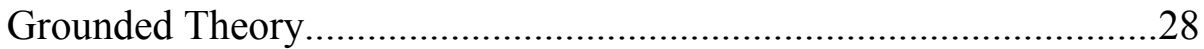

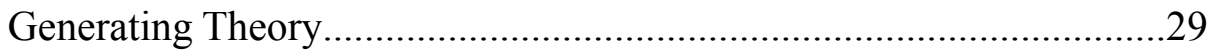

Categories and Properties.....................................................30

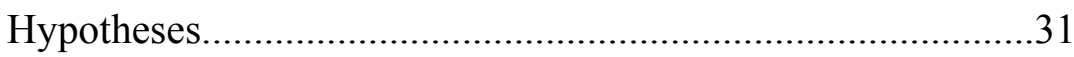

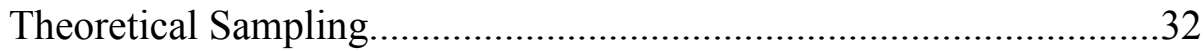

Substantive and Formal Theory.......................................................33

Constant Comparative Method...................................................... 34

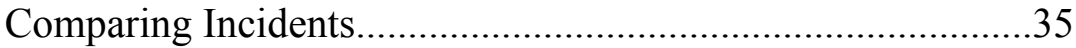

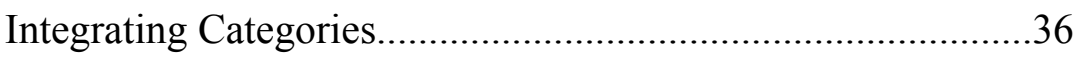

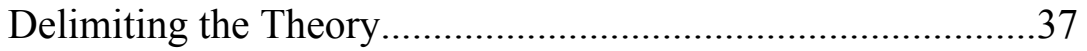

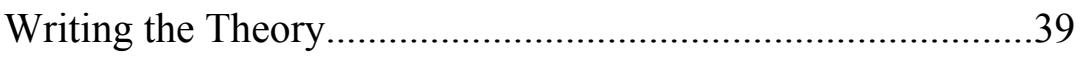

Credibility of Grounded Theory .................................................... 39

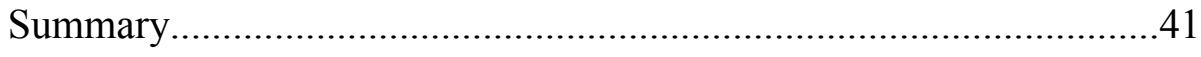

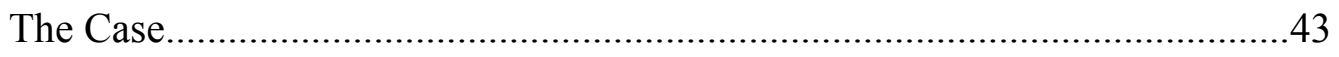

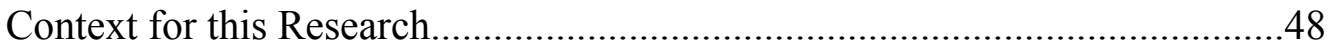




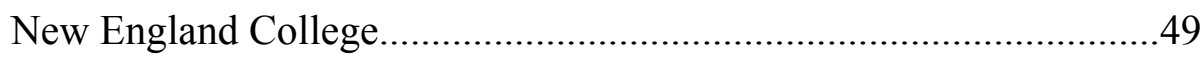

Harold Shipyard School......................................................................50

Relationship of Researcher to Context...........................................................

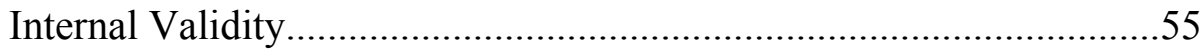

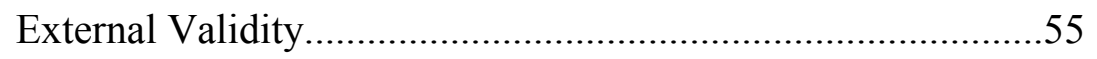

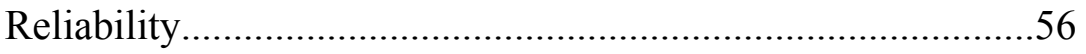

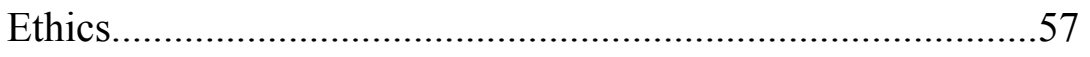

Preparatory Workshops..................................................57

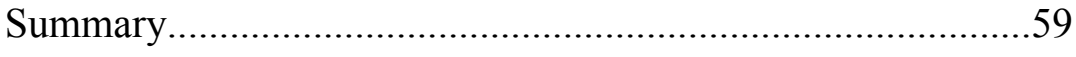

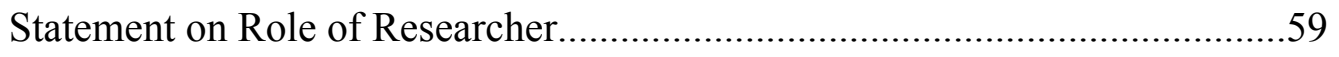

Characteristics of Grounded Theorists..................................................60

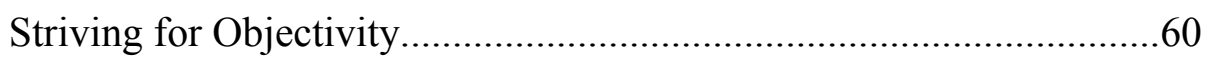

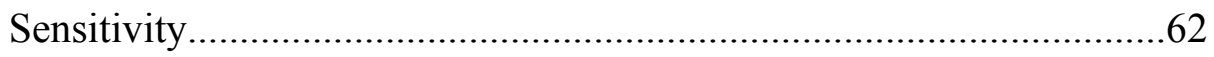

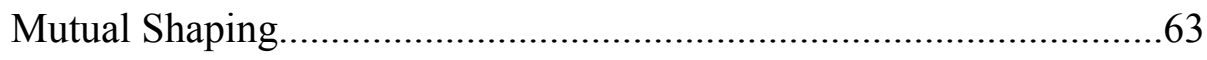

Data Collection: Sources and Procedure............................................................64

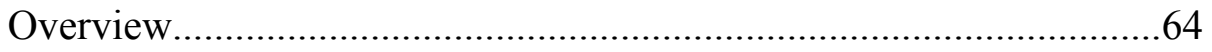

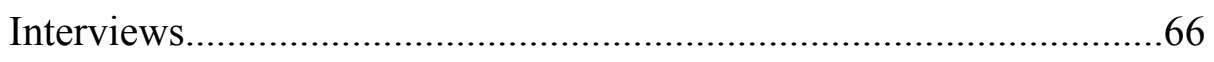

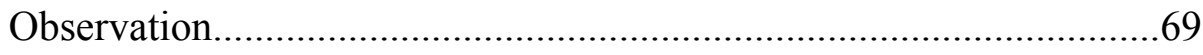

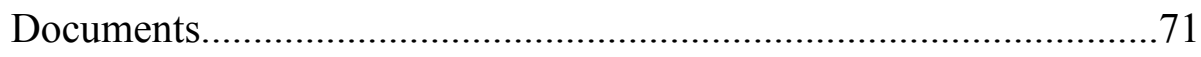

Extant Texts............................................................................

Elicited Texts........................................................................

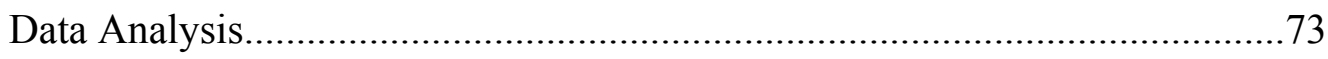

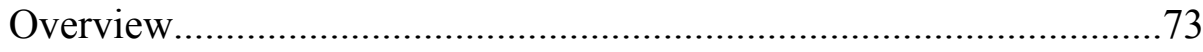


Labeling to Establish Initial Concepts............................................. 74

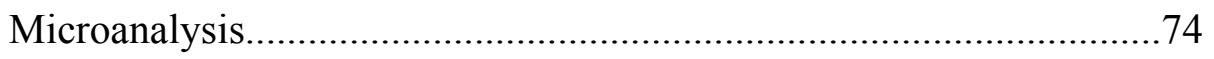

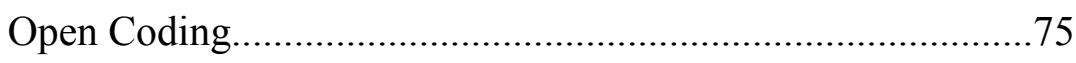

Summary of Microanalysis............................................. 76

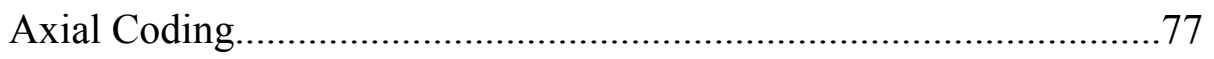

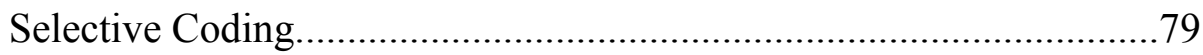

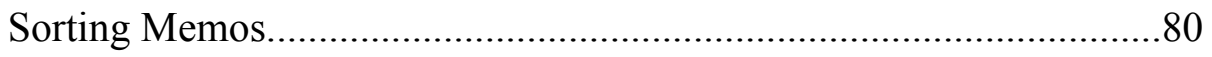

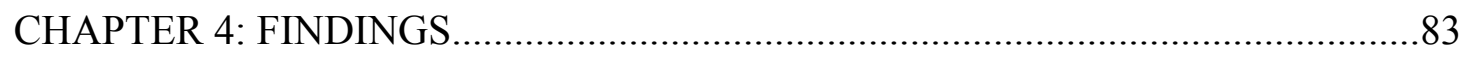

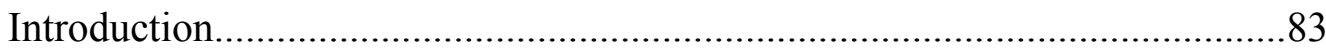

Becoming a Teacher Versus Taking the Lead.................................84

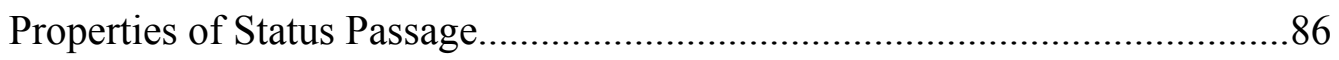

Question 1: How is Co-teaching Implemented in Seven Elementary and Early

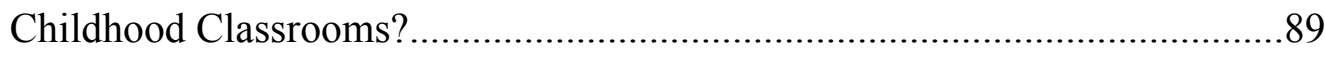

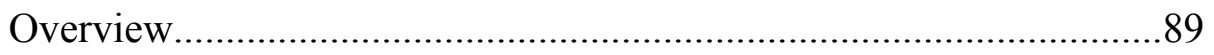

A status passage analysis: Becoming a teacher while co-teaching......92

Temporal Expectations.................................................92

Student Teaching...................................................93

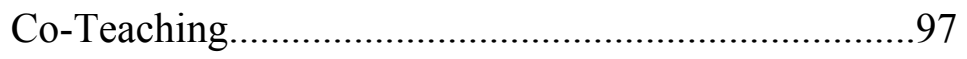

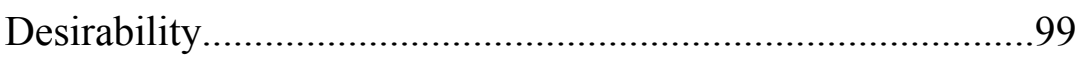

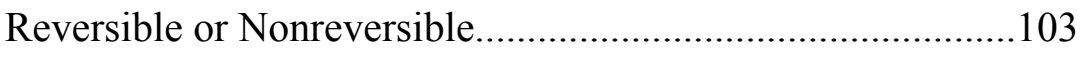

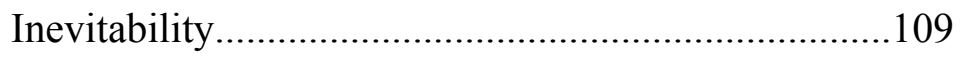

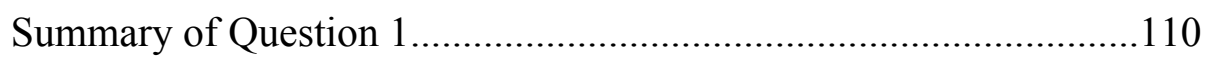


Question 2: If differences in implementation are found, why do these

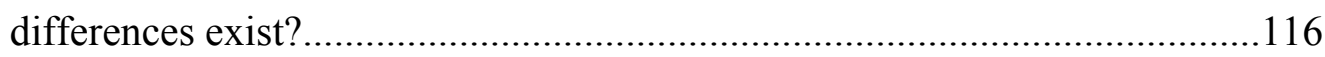

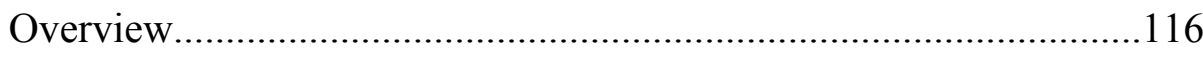

A status passage analysis: Taking the Lead While Co-Teaching........119

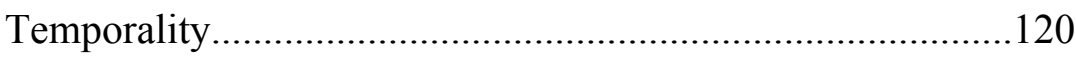

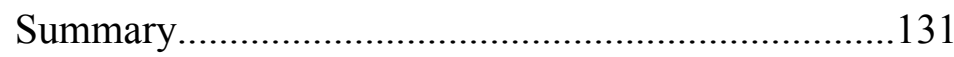

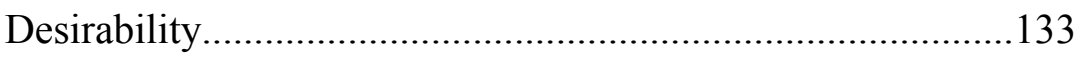

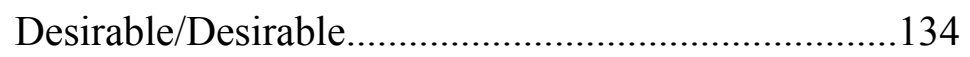

Desirable/Undesirable.................................................135

Undesirable/Desirable...............................................137

Undesirable/Undesirable............................................138

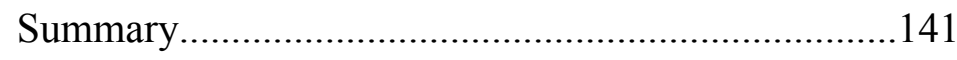

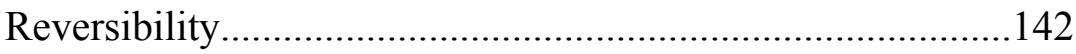

Others in the Building...............................................144

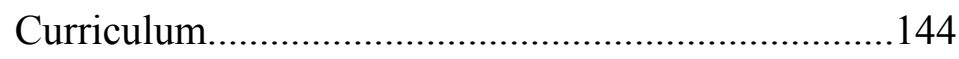

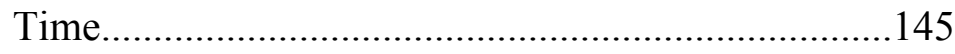

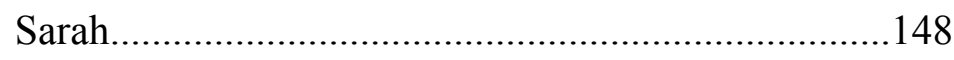

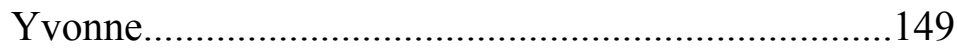

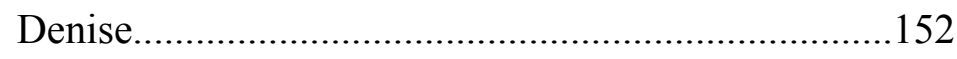

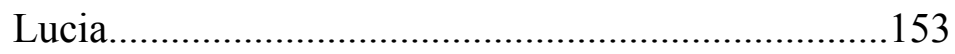

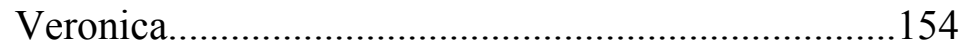

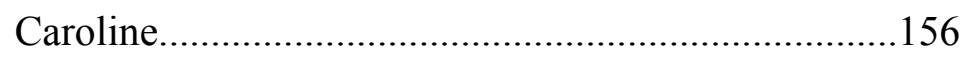

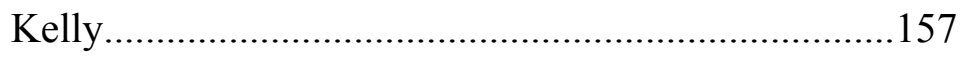




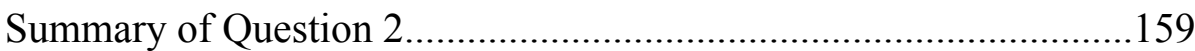

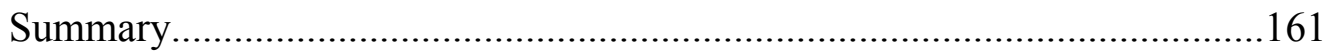

How is co-teaching implemented in seven elementary and early

childhood classrooms?

If differences in implementation are found, why do these differences

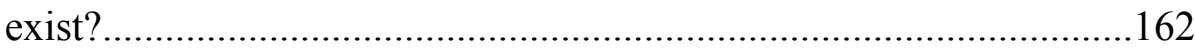

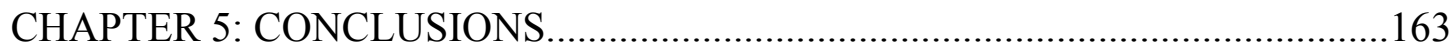

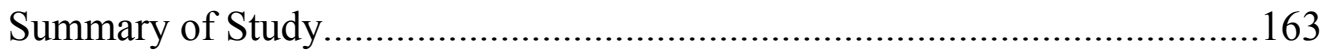

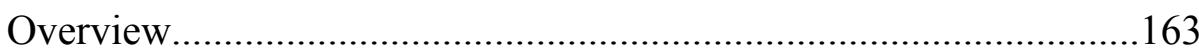

How is co-teaching implemented in seven elementary and early

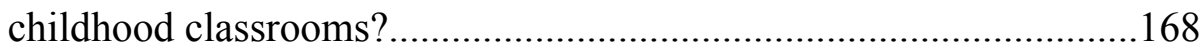

If differences in implementation are found, why do these differences

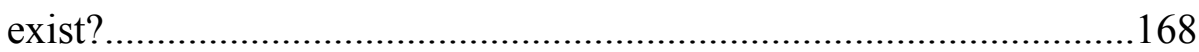

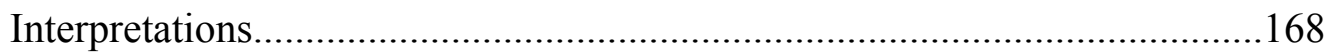

Identifying the Core Variable...............................................................

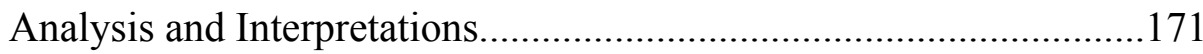

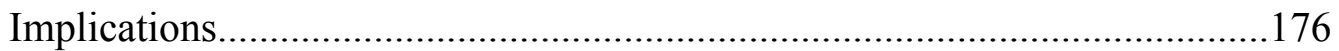

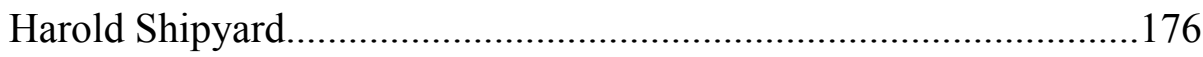

New England College....................................................................178

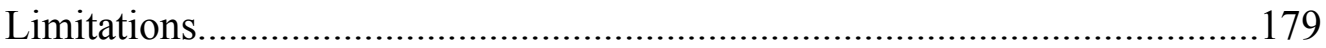

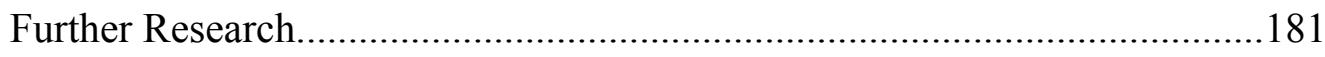

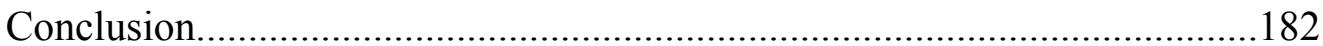


Appendix A: Definition of Co-Teaching Approaches..

Appendix B: Permission Document...............................................................184

Appendix C: Consent Document....................................................................186

Appendix D: Case Study Protocol.................................................................188

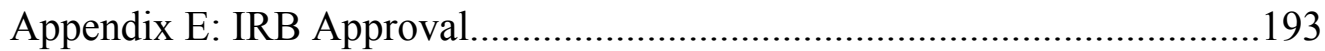

Appendix F: Individual Interview Questions \#1...........................................194

Appendix G: Individual Interview Questions \#2 ...........................................195

Appendix H: Individual Interview Questions \#3...........................................196

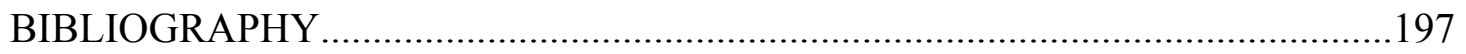




\section{LIST OF FIGURES}

FIGURE

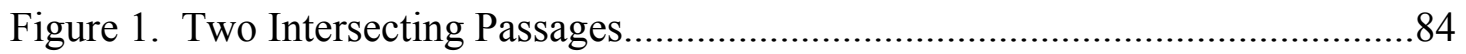

Figure 2. Co-teaching Within the Larger Context of Student Teaching......................91

Figure 3. Temporal Expectations: Co-Teaching Within Student Teaching.................93

Figure 4. Cooperating Teachers: Cooperation With Agents and Passagees...............100

Figure 5. Shape of Becoming a Teacher While Co-Teaching: View of Agents........114

Figure 6. Shape Becoming a Teacher While Co-Teaching: The Preservice Teacher's

View.

115

Figure 7. Taking the Lead: Preservice Teachers Placed on the Continuum...............119

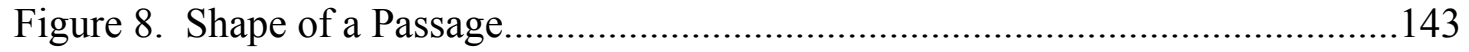

Figure 9. Shape of a Passage With Reversal...........................................................143

Figure 10. Shape of a Passage with Reversal, Re-Reversed.......................................143 


\section{LIST OF TABLES}

\section{TABLE}

Table 1. Sample of Statements Related to the Identification of "Taking the Lead "as a

Passage

Table 2. Becoming a Teacher and Taking the Lead: A Side-by-Side Comparison.....86

Table 3. Preservice Teachers' Expectations of Student Teaching.............................95

Table 4. Cooperating Teachers: Evidence of Cooperation.....................................101

Table 5. Preservice Teachers: Evidence of Cooperation.........................................103

Table 6. Excerpts from Transcribed Interviews: Preventing Reversibility...............105

Table 7. Holding Back Aspects of Teaching: Personal Reasons Why......................107

Table 8. Evidence of Positive Working Relationships........................................111

Table 9. Evidence of Acceptance of Hierarchy................................................... 112

Table 10. Use of Co-Teaching Strategies Across Classrooms................................117

Table 11. Cooperating Teachers on Preservice Teachers Taking the Lead................121

Table 12. Cooperating Teachers on Viewing Preservice Teachers as Capable...........123

Table 13. Desirability or Undesirability of Taking the Lead: Possible Combinations of Viewpoints by Cooperating and Preservice Teachers.........................................133

Table 14. Time Together and Time in the Classroom.............................................. 145 


\section{Chapter 1: Introduction}

\section{Statement of the Problem}

Demands on teachers in the $21^{\text {st }}$ century continue to rise as standards for learning and accountability swell amidst a population of school children with increasingly diverse needs (Darling-Hammond, 2006). While states scramble to adopt and implement the Common Core Standards in an attempt to make our nation's neediest students college- and career- ready, research has continually shown that the "biggest influence on student academic growth is the quality (emphasis added) of the teacher - not socioeconomic status, not family background - but the quality of the teacher" (Duncan, 2009, p. 15). In fact, teacher quality surpasses a multitude of classroom variables including "previous achievement level of students, class size as it is currently operationalized, heterogeneity of students, and the ethnic and socioeconomic makeup of the classroom” (Rivers \& Sanders, 2002, p. 17).

The U.S. Department of Education (2011) estimates that schools and departments of education produce about 220,000 certified teachers each year (Duncan, 2009) with $90 \%$ of those educated in universities (Levine, 2010). Remarkably, despite evidence related to teacher quality, and the changing needs of the student population, teacher education programs at the college and university levels have remained largely unchanged (Council of Chief State School Officers [CCSSO], 2012) and conspicuously ill-defined (Bacharach, Heck, \& Dahlberg, 2010; Darling-Hammond \& Baratz-Snowden, 2007; Goodlad, 1999). In fact, research relative to teacher education, "emerged as an identifiable field separate from research on teaching only during the last half-century" (Cochran-Smith \& Zeichner, 2005, p.4). Increased 
research in teacher education at the university level is, thus, essential (Holmes Group, 1986) for preparing the teachers our nation needs today.

Perhaps the most critical aspect of teacher education is the student teaching experience (Zeichner, 2002) yet strangely, student teaching practices have remained largely unchanged since the 1920's (Guyton \& McIntyre, 1990) and there is little evidence for what works (Levine, 2010). Recently, teacher educators have begun to explore "co-teaching" as an alternative to the traditional student teaching model (Bacharach et al., 2010; Bacharach, N., Heck, T., \& Dank, M., 2003; Graziano, K. J., \& Navarrete, L. A., 2012; Heck, T.W., Bacharach, N., Dahlberg, K., Ofstedal, K. \& Mann, B, 2010; Roth, W., Tobin, K., Carambo, C., \& Dalland, C., 2004). Co-teaching differs from traditional student teaching in that the co-teaching partners, namely the classroom teacher and the preservice teacher, work "at one another's elbow" with the preservice teachers learning to teach "by participating in collective praxis" (Roth et al., 2004, p. 883). "Although coteaching has been frequently employed in the special education domain, its use during student teaching is a practice in its infancy" (Bacharach et al., 2010, p. 4) and its application in the student teaching experience is a new area of study (Heck et al., 2010).

Advocates of co-teaching as an alternative student teaching method claim there are many benefits "including opportunities to vary content presentation, individualize instruction, scaffold learning experiences, monitor students' understanding (Graziano \& Navarrete , 2012, p. 109), realize increased growth relative to student achievement (Heck et al., 2010), and increase democratization of teaching (Murphy \& Beggs, 2010). Wassell and LaVan (2009) stipulate, however, that all stakeholders have a 
fundamental understanding of the model prior to co-teaching in order to develop successful partnerships. Cook and Friend (1995) concur, adding that while preparation for co-teaching is necessary in clarifying expectations, it is also essential for implementation.

Patton (1986) observed, "that if one had to choose between implementation information and outcomes information...there are many instances in which implementation information would be of greater value" (p. 128). Although much has been written about the necessity of preparation essential to the success of co-teaching partnerships and the potential benefits, very little has been written about how coteaching as a student teaching method is actually executed, or implemented, in real classrooms. An area of consideration is, therefore, implementation (Friend, 1993).

\section{Purpose of the Study}

The purpose of this case study, then, was to understand how co-teaching was implemented in seven elementary and early childhood classrooms in a mid-sized New England city, in an effort to explore alternative models for student teaching in the university setting and add to the limited research available relative to teacher education. The study also sought explanation as to why differences in implementation, if any, existed.

To explore these issues, this case study was guided by the following two questions relative to implementation:

1. How is co-teaching implemented in seven elementary and early childhood classrooms?

2. If differences in implementation are found, why do these differences exist? 
Researchers and readers of case studies alike understand that different types of case studies and their intended purposes abound. For this reason, the previous purpose statement needs further clarification.

Stake (2005), for example, distinguished between three types of case study and their purposes: intrinsic, instrumental, and multiple or collective (p. 445). Merriam (1988) differentiated between case studies that were descriptive, interpretive, or evaluative (p. 22). Yin (2003) described several other purposes for case studies including exploration, explanation, and description (p. 3).

Case researchers also differentiate between case study as "the process of analysis or the product of analysis, or both" (Patton, 2002, p. 447). As a process "the case study approach...constitutes a specific way of collecting, organizing, and analyzing data" (Patton, 2002, p. 447). As a product, case studies can take the form of “structured reporting...narrative reporting...[or] descriptive reporting” (Bassey, 1999, p. 84). Case studies can be told as stories or vignettes (Stake, 1995), can be reported as single-case or multi-case studies, or can be written using a question and answer format (Yin, 2014). In fact, the case study "write-up can be organized [in] any way that contributes to the reader's understanding of the case" (Stake, 1995, p. 122).

Finally, the options for analyzing data as part of case study research also flourish and include content analysis, inductive analysis—as part of grounded theory—(Patton, 2002; Yin, 2014), pattern analysis, explanation building, time-series analysis, logic models, or cross case synthesis (Yin, 2003; Yin, 2014), to name but a few. 
Several choices had to be made to clarify and define the purpose (and limitations) of this case study. First, this case study was instrumental in nature (Stake, 1995; Stake, 2005), undertaken to "advance understanding of...[another] interest,"specifically the implementation of co-teaching as an alternative student teaching method - with the case playing a secondary role (Stake, 2005, p. 445). The case, in instrumental case studies, "facilitates our understanding of something else" (Stake, 2005, p. 445).

Next, I chose to conduct and explanatory (Yin, 2014), single-case, case study. Yin (1989) tells us research relevant to "how" and "why" questions is explanatory and that case studies, as opposed to quantitative methods, are the preferred strategy when such questions are posed. While Stake (2010) observed that there can be many explanations, or causes, related to an event, and that as qualitative researchers we cannot be certain or confident when offering explanations, he also acknowledges, "whether we are quantitative or qualitative researchers, we do need to search for causes, for influences, for preconditions, for correspondences" keeping in mind that our interpretations of the data "stand not as proof but as persuasion of one meaning more than another" (p. 25). Patton (2002) agrees, stating, "when careful study of the data gives rise to ideas about causal linkages, there is no reason to deny those interested in the study's results the benefit of those insights. What is important is that such statements be clearly qualified as what they are: interpretation and hypothesizing" (p. 479). Lofland (1971) calls these interpretations and hypotheses "conjectures" (p. 62) and tells us that it is perfectly appropriate for a qualitative 
researcher, while attempting to explain variations, to make these conjectures as long as the researcher clearly labels them as such.

In attempting to interpret the data and locate hypothetical causes, I stayed grounded in the data, building substantive theories through grounded theory analysis (Glaser, 1992; Glaser \& Strauss, 1967, 2008; Strauss \& Corbin, 1998). The substantive theories generated are not meant as generalizations, but refer to "the limited, local, particular place and time" (Stake, 2010, p. 23) of this particular, single case.

Finally, it is important to differentiate this study from what it is not. The purpose of this case study was not to evaluate co-teaching itself as being preferable or deficient in relation to traditional student teaching practices. It was not meant to measure in quantitative terms the amount or type of co-teaching that occurred or as a way to merely describe co-teaching activities. The learning or expertise of the preservice teachers and cooperating teachers was also not the focus.

The purpose of this explanatory, instrumental, single-case study was to understand, through the use of grounded theory analysis, how co-teaching was implemented in seven elementary and early childhood classrooms in a mid-sized New England city, in an effort to develop substantive theories relative to causal explanations for differences of this particular case.

This case study is both process and product. As a process, data collected was continuously interpreted throughout the period of study (Stake, 2005) using grounded theory analysis. As a product, this case study was written with a specific audience in mind (Merriam, 1988; Patton, 2002; Stake, 1995; Yin, 2014)—my dissertation 
committee. In attempting to communicate directly to my committee (Yin, 2014), I have chosen to compose a case report (a) written from a first-person perspective, (b) that follows graduate school guidelines and the traditional dissertation framework throughout, and (c) which provides vignettes, arranged around sensitizing concepts (Patton, 2002) of selected aspects of the case.

\section{Significance of the Study}

The importance of preparing quality teachers cannot be overemphasized. Standards for learning have never been higher as educators attempt to prepare their students for success and survival, both as citizens and laborers, in an increasingly complex society (Darling-Hammond, 2006). While policymakers call "for increased randomized field trials in all areas of education...it is worth noting...that randomized field trials...are generally appropriate at a point in the maturity of the research where enough theoretical and preliminary empirical work has been completed to permit the design of competing interventions" (Cochran-Smith \& Zeichner, 2005, p. 4).

Due to the systematic and detailed nature of case study methods, case studies in the area of teacher education can provide a detailed look at complex teacher education activities, illuminating what teacher education programs look like from the perspectives of students and faculty (Zeichner, 1999). "By accumulating what might be called cases of understanding, we can have an ever-expanding source of examples from which others can learn" (Sirotnik, 1999, p. 610) and, as a result, construct tentative hypotheses that can help to structure future research and advance the field's knowledge base (Merriam, 2009). This case study serves to add to the limited research available relative to co-teaching as a student teaching method, and will 
attempt to explain how co-teaching is implemented in seven elementary and early childhood classrooms and why variations may exist.

\section{Definition of Key Terms}

"In the world of teacher preparation, student teaching has long been the culmination of a teacher candidate's journey to becoming a licensed teacher...link[ing] the theory of educational preparation with the reality of daily classroom practice" (Bacharach et al., 2010). The student teaching experience is designed to provide the teacher candidate with an opportunity to further develop and refine his or her skills (New England College, 2010). Student teaching, for the purposes of this study, will be operationally defined as the fifteen-week period following completion of required university coursework, during which the preservice teacher teaches in an elementary or early childhood classroom with a cooperating teacher. The cooperating teacher is defined as a certified elementary or early childhood teacher, who hosts the preservice teacher in his or her classroom, and who assists the preservice teacher in becoming a successful professional. To be defined as an elementary classroom, for the purposes of this study, the grade level must fall between grades three through five. To be defined as an early childhood classroom, the grade level must fall between kindergarten through grade two. The preservice teacher will be defined as an student, seeking a degree and certification in elementary or early childhood education, who has completed all required university coursework, and who is eligible to student teach.

Cook \& Friend (1995) define co-teaching as "two or more professionals delivering substantive instruction to a diverse, or blended, group of students in a single 
physical space" ("Ten Questions," para. 1) and identify five co-teaching approaches: one teaching/one assisting, station teaching, parallel teaching, alternative teaching, and team teaching. Heck et al. (2010) further differentiate the co-teaching approaches adding two more categories: one teach/one observe and supplemental teaching (see Appendix A for complete definitions). For the purposes of this study, the operational definition for co-teaching during student teaching will be as follows: A student teaching experience, taking place in one elementary or early childhood classroom, populated by a blended group of elementary or early childhood students with assorted needs, in which one or more of the seven co-teaching approaches is incorporated, where the preservice teacher and cooperating teacher jointly design, teach, manage, assess, and reflect upon lessons taught collaboratively.

\section{Summary and Outline of Study}

\section{Summary.}

Guyton and McIntyre (1990), in their call for increased naturalistic research of clinical practice, described research related to student teaching as a "'black box"; we know what goes in... and what comes out...but not what occurs in the interim" (p. 524). This case study will attempt to explore that "black box;" specifically, this singlecase study will attempt to describe differences in the implementation of co-teaching as an alternative student teaching method, if any, that occur across seven elementary and early childhood classrooms. Interpretations, grounded in the data, will be utilized to generate substantive theories, applicable to this particular case. 


\section{Outline of study.}

In Chapter One, I have provided an introduction to this study and outlined the specific purpose of the research and method of analysis. I have offered a brief statement related to the potential significance of this work and defined key terms.

In Chapter Two, I will review the literature relative to the differences that endure within teacher education programs, flesh out the differences between traditional student teaching and co-teaching methods, and frame the study in relation to implementation and my research questions.

Chapter Three includes my rationale for using case study, the conceptual structure of the study, the case itself, my theoretical framework, contextual factors, my role as the researcher, and my data sources, procedures, and methods of analysis.

Chapter Four contains my findings. Throughout the chapter I use my two research questions as a framework to offer descriptions of the case, position my substantive findings within a formal theoretical framework, and present my own interpretation of the data.

Finally, in Chapter Five, I will offer a summary of the study, discuss the limitations and implications of my findings, and offer suggestions for future research as applied to this particular case. 


\section{Chapter 2: Review of Literature}

\section{Introduction}

"An effective strategy [when utilizing grounded theory as a method of analysis] is, at first, literally to ignore the literature of theory and fact on the area under study, in order to assure that the emergence of categories will not be contaminated by concepts more suited to different areas." (Glaser \& Strauss, 1967, 2008, p. 37). A review of the literature, however, can be helpful in establishing a "backdrop for the problem or issue that has led to the need for the study" (Creswell, 2014, p. 30).

Student teaching has "long been identified by both teacher educators and prospective and experienced teachers as a major, if not the most important, part of preservice teacher preparation" (Hollins \& Guzman, 2005, p. 493). To fully understand the complexity of student teaching, both traditional and co-teaching, it is important to understand three distinct bodies of research as well as how each builds upon the other to frame the present study. I begin with a brief description of the variation that exists in teacher education programs. Then, I outline differences between traditional student teaching methods and co-teaching methods, including ideological distinctions. Finally, I explore theories that suggest co-teaching, when properly implemented, enhances the student teaching experience. It is the intricacies of this last area, the implementation of co-teaching in elementary and early childhood classrooms, in which I am most interested, and, regrettably, it is an area in which little research has been done. 


\section{Variation in Teacher Education Programs}

"There is no more important responsibility for a school, college, department, or faculty of education than to do the best job that it possibly can in preparing teachers to teach in the schools of our nation and to support the learning of teachers throughout their careers" (Zeichner, 1999, p. 13). That said, teacher education programs vary considerably from one institution to another (CCSSO, 2012; Guyton \& McIntyre, 1990) often lacking (1) a clear mission (Goodlad, 1999; Zeichner \& Conklin, 2005), (2) cogently defined clinical preparation practices, (3) clear connections between clinical practice and university work (Darling-Hammond, 2006; Goodlad, 1990; Levine, 2006), and (4) adequate support (National Council for Accreditation of Teacher Education [NCATE], 2010).

In the report of the American Educational Research Association (AERA) on research in teacher education, Cochran-Smith and Fries (2005) emphasized the complexity of teacher preparation that exists within the United States. Programs are affected by (a) local and state policies which include accountability requirements and other controls, (b) the intermingling of various factors between local communities and institutions, (c) "the experiences and abilities prospective teachers bring to their own preparation," and (d) interactions between teacher candidates (p. 48). Zeichner and Conklin (2005) further assert teacher education programs vary in terms of their (a) structure, (b) length, (c) level of degree, (d) admission requirements, (e) curricular requirements, and (f) conceptual orientations.

The National Council for Accreditation of Teacher Education (NCATE, 2010) reports clinical practice remains the most ad hoc part of teacher education in many 
programs. While most states do require student teaching, the majority requiring somewhere between 10 to 14 weeks, most are reticent as to what this critical experience should look like and/or how the programs are to be held accountable. Preservice teachers are often indiscriminately placed with cooperating teachers whose roles have remained undefined and the student teaching experience is frequently unsystematic, with little connection to university work (Darling-Hammond, 2006; Levine, 2006). "This has caused great variation in how and where clinical training is delivered and an endemic unevenness in quality" (NCATE, 2010, p. 4). As a result of the variation in quality that exists within programs, student teaching experiences vary widely across institutions (Bacharach et al., 2010).

\section{Differences Between Traditional Student Teaching and Co-Teaching Traditional student teaching.}

Despite variations across teacher education programs and differences within clinical experiences themselves, a common description of traditional student teaching can be generally agreed upon. Typically, the "established mentoring model runs the candidates through the required courses...[eventually finding] cooperating teachers willing to take them" (Goodlad, 1990). The teacher candidate then spends the initial weeks in the classroom as an observer, slowly assuming the role of the teacher, and eventually accepting full, unassisted, responsibility for the classroom (Bacharach \& Heck, 2012). Alarmingly, "most teacher education programs have no mechanism for making sure mentor teachers are themselves successful or trained in how to coach an adult peer" (Goldstein, 2014, p. 248). Cooperating teachers, often untrained and unsupported, are expected primarily to provide a place for preservice teachers to 
practice teaching (Zeichner, 2010), often leaving the preservice teacher alone in the classroom to 'sink or swim' (Goodlad, 1990). As a result, many sink, leading to negative experiences for the preservice and cooperating teachers (Picanco \& Darragh, 2011) and, more disturbingly, "to the great detriment of children's learning” (Badiali \& Titus, 2010, p. 75).

Traditional student teaching practices typically involve a "triad" model of supervision involving "a cooperating teacher and a university supervisor, who engage in a semester-long series of formal observations and interactions with the student teacher to ensure he or she demonstrates the knowledge and skills necessary to qualify for the licensure of a teacher" (Allen, Perl, Goodson, \& Sprouse, 2014, p. 20). These roles, however, are often poorly defined across institutions (Guyton \& McIntyre, 1990). Additionally, members of the triad frequently report lack of communication as a recurring problem. In their review of the research related to difficulties within field experiences, Guyton and McIntyre (1990) linked problems in communication within the triad to "unclear expectations" and "lack of understanding of each other's problems" (p. 521). These situations inevitably succeed in "creating unstructured and non-supportive environments that generate numerous difficult situations...for the student teacher to navigate during the semester" (Allen et al., 2014, p. 21).

Traditional student teaching practices are generally grounded in a "cultural transmission ideology," which has, at its core, the classical academic tradition of Western education (Kohlberg \& Mayer, 1972, p. 452). "Traditional educators believe that their primary task is the transmission to the present generation of bodies of information and of rules or values collected in the past; they believe that the 
educator's job is the direct instruction of such information and rules" (Kohlberg \& Mayer, 1972, p. 453). Preservice teachers, in fact, often perceive "themselves as observing what teaching requires and then taking on the mantle of the teacher observed" regardless of their own "reflective position on best procedures," most often yielding to the status quo (Goodlad, 1990, p. 219).

Although teacher education has certainly evolved, this custom of observing, practicing, and reflecting with a "critic teacher" is not dissimilar to teacher preparation practices dating back to the $19^{\text {th }}$ century. At that time teaching was considered a relatively simple practice with teachers and parents believing that learning was a passive process made possible through lecture, completed assignments, and group recitation (Forzani, 2014). Teacher educators in the "normal schools" designed programs that allowed preservice teachers the opportunity to "observe and practice key skills of what at the time was viewed as competent instruction" (Forzani, 2014, p. 360). After practicing "key skills," the student teacher met with his or her "critic teacher" to have his or her work "criticized, and the particulars in which he succeeded and those in which he failed...pointed out" (Ogren, as cited in Forzani, 2014, p. 361). "Teaching was viewed as skilled work, and it was assumed that novices could get better at it through ample practice and prescriptive feedback" (Forzani, 2014, p. 361). Traditional student teaching methods stand grounded in "practice-based" and “situated learning" theories (Lave \& Wenger, 1991). "There is an array of entry-level tasks and activities marked out and endorsed by the community of participants, and newcomers are expected to engage in them early on in their career or "trajectory" of participation" (Hodge, 2014, p. 169) with attention focused "on ways in which the 
increasing participation of newcomers in ongoing practice shapes their gradual transformation into oldtimers" (Lave, 1991, p. 72).

\section{Co-Teaching.}

Co-teaching, when used as a student teaching method, is similarly placed in terms of its conceptual foundations. A novice (newcomer) teacher is placed with a cooperating (oldtimer) teacher, with an emphasis on "the relational interdependency of agent and world, activity, meaning, cognition, learning, and knowing, and the inherently socially negotiated quality of meaning" (Lave, 1991, p. 67). Like traditional student teaching practices, co-teaching practices are grounded in "practicebased" and "situated learning" theories.

In contrast to traditional practices, however, co-teaching "is a practice that allows [cooperating and preservice] teachers to have shared experiences... including planning, enacting, and reflecting on curriculum" (Roth \& Tobin, 2002, p. 1). Rather than spending the initial weeks of student teaching as a silent observer, preservice teachers are encouraged to begin to co-teach with their cooperating teachers on the very first day of student teaching or as soon as is practical (Tobin, 2006). The difference between this approach and a traditional model is that (1) "the teacher candidate is integrated from the beginning of the student teaching placement as a teacher versus as a student observer" (Merk, Waggoner, \& Carroll, 2013, p. 83), (2) the knowledge and abilities of both teachers are combined (Heck, Bacharach, Dahlberg, 2008), and (3) the power differential between cooperating teachers and preservice teachers is minimized (Bacharach et al., 2010) allowing for opportunities for preservice and cooperating teachers to learn from and with one another (Merk et 
al., 2013).

Cook and Friend (1995) define co-teaching as "two or more professionals delivering substantive instruction to a diverse or blended group of students in a single physical space" (p. 14). During the co-teaching experience, both the cooperating teacher and the preservice teacher simultaneously share responsibility for teaching all of the learners in a classroom (Merk et al., 2013; Villa, Thousand, \& Nevin, 2013). Co-teaching enables both participants (a) the opportunity to collaborate in the classroom, (b) incorporate different co-teaching approaches (Heck et al., 2010), and (c) learn from each other through collective praxis (Tobin, 2006). In the co-teaching model, the preservice and cooperating teacher "gradually shift the roles as primary teacher and planner" (Picanco \& Darragh, 2011, p. 140) with the preservice teacher ultimately assuming (a) "full responsibility of the classroom by leading the planning, organization, delivery and assessment of instruction" and (b) "effectively manag[ing] human resources by directing other adults, including the cooperating teacher" (Heck et al., 2010, p. 94).

Although co-teaching has long been practiced in the field of special education (Cook \& Friend, 1995) its utilization as a student teaching method is in its infancy. Six strategies related to co-teaching within special education were initially developed by Cook and Friend (1995) and then modified and expanded upon by researchers at the St. Cloud University College of Education in 2010 for student teaching (Picanco \& Darragh, 2011). The seven strategies include (1) one teach, one observe, (2) one teach, one assist, (3) station teaching, (4) parallel teaching, (5) supplemental teaching, (6) alternative or differential teaching, and (7) team teaching (see Appendix A for 
complete definitions).

Advocates of co-teaching as an alternative student teaching method claim there are many benefits including: (a) increased access to quality placements for preservice teachers; (b) improved communication and collaboration between triad members; (c) increased professional development opportunities; (d) positive effects of a smaller teacher to student ratio; and, perhaps most importantly (e) increased growth relative to student achievement. In the following sections, I will briefly outline the relevant literature related to each of these areas.

\section{Placing teacher candidates.}

With many states placing a heightened emphasis on student achievement scores as one indicator of teacher performance, many prospective cooperating teachers are apprehensive about hosting a preservice teacher in their classroom (Darragh, Picanco, Tully, \& Henning, 2011; Diana, 2014; Heck et al., 2010; Picanco \& Darragh, 2011). "The accountability movement prevalent across the country... often [links student] scores to the teacher without noting if he or she had a teacher candidate that year. As such, highly qualified cooperating teachers often opt not to mentor teacher candidates" (Darragh et al., 2011, p. 86) and many field and/or clinical experience directors are finding it increasingly problematic to secure quality placements for candidates (Bacharach \& Heck, 2012).

Cooperating teachers, operating within traditional student teaching practices, are finding it a challenge to leave their classrooms in the hands of preservice teachers who have not yet demonstrated effective teaching strategies (Darragh et al., 2011). Co-teaching, unlike traditional practices, allows cooperating teachers the opportunity 
to share and maintain control of the classroom with the preservice teacher throughout the student teaching experience (Bacharach et al., 2010).

\section{Improved communication and collaboration.}

An additional difficulty associated with the traditional model of student teaching is that it often fails to prepare teacher candidates to effectively collaborate (Darragh et al., 2011). "The model leads to many otherwise well- prepared teachers who, "shut the classroom door to the outside world" and do not view their profession as a collaborative one" as a result of their "apprenticeship and first exposure to the profession was a solo one" (Darragh et al, 2011, p. 86).

Guyton \& McIntyre (1990), in their review of the research related to contextual factors relative to student teaching, found that "preparation of cooperating teachers for their roles is effective in developing a more positive context" (p. 520) with cooperating teachers more likely (a) to be active listeners, (b) to use different instructional strategies, and (c) to communicate more effectively with their student

teachers. Typically, preservice teachers, and the cooperating teachers with whom they are paired, do not have an established teaching relationship prior to the student teaching experience. "Research indicates that planned, purposeful talking with each other about roles and objectives might alleviate contradictions and the frustrations that flow from them" (Guyton \& McIntyre, 1990, p. 524). Co-teaching, when properly implemented, addresses this gap.

Teacher educators at St. Cloud University advocate relationship building prior to the student teaching experience. Through workshops, preservice and cooperating teachers are introduced to one another, and "guided through activities and discussions 
designed to help them build strong relationships, establish and practice effective communication and collaboration strategies, and understand co-teaching and coplanning" (Heck et al., 2010, p. 76). Preliminary results from their work have illuminated that, for the preservice teachers within their programs, this emphasis on relationship building has resulted in: (1) increased ability, and comfort, when collaborating; (2) openness and acceptance related to feedback from their cooperating teachers; and (3) an increased confidence when managing the classroom. Siry (2011) suggests that for preservice teachers entering the field, the tendency is to view the relationship with the cooperating teacher as hierarchal. "However, once [preservice teachers] begin to contribute to decision making and share responsibility in an authentic way, ...their perceptions of the roles of "student" and "teacher" begin to shift" (p. 99).

Data collected over three years from 200 teacher candidates who participated in co-teaching as an alternative to traditional student teaching methods at St. Cloud University (Heck et al., 2008) suggest that teacher candidates believe that co-teaching enriched their collaboration and communication skills. In fact, "in end-of-experience surveys, $92.5 \%$ of teacher candidates $(\mathrm{N}=201)$ and $93.2 \%$ of cooperating teachers $(\mathrm{N}=279)$ responded that increased collaboration and communication skills were a benefit of co-teaching during student teaching" (Heck et al., 2008, p. 4).

\section{Professional development opportunities.}

Federal policymakers, recognizing the importance of continued professional development for in-service teachers, have attempted to improve the use of professional development dollars, but "the variety of programs, lack of coordination amongst them, 
and decentralized nature of education have thwarted efforts to substantially improve professional development" (Rotherdam \& Mitchel, 2014, p. 36). Advocates for coteaching, as an alternative to traditional student teaching methods, suggest that coteaching (and the necessary preparation that must accompany implementation), is an opportunity to offer professional development to in-service teachers.

Researchers at St. Cloud University for example, where the use of co-teaching as an alternative to traditional methods has been pioneered, have stressed that coteaching workshops serve as an excellent opportunity to offer professional development to in-service teachers. Specifically, they state "the co-teaching, communication, collaboration, co-planning, and relationship building skills acquired through...co-teaching workshops not only assist cooperating teachers in their work with teacher candidates, but also support them in their efforts with parents, colleagues, students, and curriculum. This supportive training is professional development" (Heck et al., 2010, p. 22).

Over twenty years ago Berliner and Biddle (1995), reacting to what they termed "The Manufactured Crisis," emphasized the need for increased attention to inservice teacher development. Specifically, they stated "schools will have to provide better, more professional working environments for teachers if those schools are to become better environments for students to learn in" (p. 340). Co-teaching has the potential, if properly implemented, to offer such an environment; an environment where professional development is embedded in the collaboration between professionals. 


\section{Teacher-to-student ratio.}

Darragh et al. (2011), in their survey of 156 teacher candidates involved in coteaching in eastern Washington state, found $65 \%$ of respondents indicated "smaller teacher to student ratios lead to more opportunities for differentiated instruction...individualized instruction, and more opportunities for students to work in small groups" (p. 94).

This increased attention was not unnoticed by students themselves. Data collected via a survey of 1, 686 students in grades 7-12 over four years by researchers at St. Cloud University, indicated students felt they "received more help with questions in co-taught classrooms than they did in settings that did not include coteaching... [and they] also reported they enjoyed and appreciated more individual attention" (Bacharach \& Heck, 2012, p. 55). Additionally, during focus group interviews of 540 students in grades 1-12 over the course of four years, Bacharach \& Heck (2012) found that "students overwhelmingly identified increased engagement and available help when they needed it as the biggest benefits to co-teaching" along with (a) increased opportunities to work in small groups, (b) extra individual attention, (c) quicker response time by teachers to their questions, (d) less time spent waiting while within the classroom, and (e) and increased opportunities to do a "variety of activities that were not possible with just one teacher" (p. 57). In a study of 17 P-12 co-taught classrooms conducted by Merk et al. (2013), students voiced they "felt that their own learning and behavioral needs were met” (p. 91).

Cooperating teachers also agree that a smaller teacher to student ratio, as the result of co-teaching within the student teaching experience, has its benefits. In their 
survey of 47 teaching mentors in eastern Washington state, Picanco and Darragh (2011) found cooperating teachers felt smaller teacher to student ratios offered increased chances for variety within instructional methods as well as improved opportunities for differentiation and small group teaching. Similarly, in their survey of 279 cooperating teachers who participated in co-teaching, Bacharach and Heck (2012) found cooperating teachers felt better able to "reach more students, particularly those with higher needs" (p. 57).

\section{Student achievement.}

That "the novice teacher [is] not as effective as the veteran instructor in positively impacting student achievement during the student teaching internship" (Darragh et al., 2011, p. 86) should come as no surprise. "In a non-co-taught student teaching experience, teacher candidates typically plan lessons in isolation, presenting them to their cooperating teacher in advance of delivering the lesson" (Bacharach et al., 2010, p. 8) before ultimately teaching the lesson alone. In a co-teaching arrangement, however, the preservice and cooperating teachers are involved in all aspects of lesson planning, implementation, and assessment. In their pilot study of seventeen co-taught classrooms, Merk et al. (2013) found "the co-planning process helped [preservice teachers] gain a deeper understanding of how to plan and pace cohesive curriculum, develop an ability to implement constructivist lessons, and create an environment that provided natural opportunities to ask pedagogical and pedagogical content knowledge questions" (p. 87).

Although research on the effects of co-teaching on student achievement is scarce, some work has been completed. In a five-year study conducted by St. Cloud 
State University, researchers compared the standardized math and reading scores of elementary, middle and high school students placed in settings in which the traditional student teaching model was used to those of students in classrooms where the coteaching model had been implemented. The results indicated that students' academic achievement in a co-taught classroom surpassed that of peers placed in classrooms using a traditional student teaching model. Surprisingly, their performance also surpassed that of students placed in a classroom where there was no student teacher (Bacharach et al., 2010).

\section{Preparation and Implementation $=$ Enhanced Student Teaching Experience}

According to Zeichner (2002) to improve the student teaching experience, universities need to "break outside of the traditional structures of student teaching that have been with us for many years" (p. 62). Advocates of co-teaching as an alternative student teaching method claim there are many benefits, including those previously mentioned, as well as increased "opportunities to vary content presentation, individualize instruction, scaffold learning experiences, monitor students' understanding (Graziano \& Navarrete, 2012, p. 109) and increase democratization of teaching (Murphy \& Beggs, 2010).

Although successful co-teaching programs can begin informally without systematic planning, these are unusual; planning is not only valuable in preparing for implementation, but also is important in elucidating, for all stakeholders, the specific expectations that the method demands (Cook \& Friend, 1995). Preparation for coteaching, then, ..."should focus on developing communication and collaboration skills, assessing one's readiness for collaboration and co-teaching, and designing the 
parameters of the co-teaching relationships" (Cook \& Friend, 1995, Professional Preparation, para. 1).

Although much has been written about the necessity of preparation essential to the success of co-teaching partnerships, and the assumed benefits of co-teaching, very little has been written about how co-teaching is actually implemented in real classrooms. An area of consideration is, therefore, implementation (Friend, 1993). Patton tells us (2008) "not knowing enough about implementation limits the usefulness of findings" (p. 310) while Williams (1976) stresses that the failure to study such a fundamental issue as implementation is difficult to comprehend. This study, then, serves to fill the gap in the literature relative to the implementation of coteaching as an alternative student teaching method and will attempt the answer the following two questions relative to implementation:

1. How is co-teaching implemented in seven elementary and early childhood classrooms?

2. If differences in implementation are found, why do these differences exist? 


\section{Chapter 3: Methodology and Procedures}

\section{Rationale for the Use of Case Study as Research Method}

"Three conditions come into play when selecting a research method: (1) The research question(s), (2) the amount of control the researcher has over events, and (3) the degree of focus on contemporary as opposed to entirely historical events" (Yin, 2014, p. 9)

In terms of questions, Yin (1989) tells us research relevant to "how" and "why" questions is explanatory and that case studies, as opposed to quantitative methods, are the preferred strategy when such questions are posed. Specifically, Yin (1989) justifies the use of case study by contrasting its purpose with other methodological choices:

An experiment...deliberately divorces a phenomenon from its context, so that attention can be focused on a few variables... a history, by comparison, does deal with the entangled situation between phenomenon and context, but usually with noncontemporary events...surveys can try to deal with phenomenon and context, but their ability to investigate the context is extremely limited. (p. 23)

Merriam (2009) confirms, "the decision to focus on qualitative case studies stems from the fact that this design is chosen precisely because researchers are interested in insight, discovery, and interpretation rather than hypothesis testing” (p. 42).

Additionally, case studies are selected when the researcher has little control over events and when the focus of the research is on a contemporary phenomenon within some real-life context (Yin, 1989). The case study inquiry "copes with the 
technically distinct situation in which there will be many more variables of interest than data points...[and] relies on multiple sources of evidence, with data needing to converge in a triangulating fashion" (Yin, 2009, p. 18).

\section{Conceptual Structure}

Case studies can be structured in a variety of ways. Stake (1995) prefers to organize case studies around, what he terms "issues" (p. xii). For Stake (1995), "issues are not simple and clean, but intricately wired to political, social, historical, and especially personal contexts" and "draw us toward...teasing out the problems of the case, the conflictual outpourings, [and] the complex backgrounds of human concern" (p. 17). While Stake (1995) identifies the term "issue" in relation to a "problematic situation" (p. 16), the word "issue," may have many meanings including a concern, a problem or difficulty, or a main subject. For the purposes of this research I am choosing, like Stake, to use an issue to form my conceptual structure-with the issue at hand being the implementation of co-teaching as a student teaching method. Unlike Stake, however, I am treating the issue as the main subject versus a problematic situation. This choice is in keeping with grounded theory methods. The researcher enters the area of study with no problem but with a keen interest of "what is going on is an issue and how it is handled" (Glaser, 1992, p. 22).

Grounded theorists, entering the substantive area of study with no problem in mind, "keep an open mind to the emergence of the subjects' problem" (Glaser, 1992, p. 23). Stake (1995) aptly names these emergent problems as emic issues, differentiating them from the interests of the researcher, or, etic issues. Etic issues are "brought in by the researcher from the outside...emic issues emerge. These are the 
issues of the actors, the people who belong to the case. These are issues from the inside" (p. 20). In attending to the emic issues, the researcher gains a deeper understanding of the initial etic issue, through the perspective of the actors in the setting being studied.

Patton (2002) distinguishes between etic and emic perspectives in terms of the researcher's analytical approach. Researchers who maintain an etic perspective analyze data deductively, "according to an existing framework" (p. 453). In contrast, researchers who analyze data inductively, or from an emic perspective, are "immersed in the data...-grounded - so that embedded meanings and relationships can emerge" (p. 454).

Yin (2014), in detailing four general analytic strategies available to case researchers, suggests, as one option, that the data be worked from the "ground up," and affirms that "an inductive strategy [when analyzing case data] can yield appreciable benefits" (p. 138). Yin, thus, references grounded theory and its discoverers, Barry Glaser and Anselm Strauss (1967), as an analytical option for case researchers. It is to grounded theory that I now turn, to provide the theoretical framework for this study.

\section{Theoretical Framework}

\section{Grounded theory.}

In the opening paragraph of their groundbreaking book, The Discovery of Grounded Theory, Glaser and Strauss (1967) emphasized the need to develop theory from data that is "systematically obtained and analyzed" in an effort to provide "relevant predictions, explanations, interpretations, and applications" (p. 1). They 
proclaimed, "such a theory fits empirical situations, and is understandable by sociologists and layman alike" (p. 1).

At the time of their discovery, qualitative research, often criticized as unsystematic, was losing its attractiveness while quantitative, positivist methods were gaining in popularity. These quantitative methods sought to objectively verify quantitative knowledge and, when connected to theory at all, emphasized the testing of existing theory versus theory development (Charmaz, 2006). Glaser and Strauss (1967) refuted these positivist assumptions and offered qualitative researchers "systematic strategies for qualitative research practice...with guidelines for action" (p. 5) which "legitimized qualitative research as a credible methodological approach" (p. 6) aimed at the advancement, versus verification, of theory.

Grounded theory offered researchers a method of analysis that achieved both parsimony and scope accounting for "as much variation in behavior in the action scene with as few categories and properties as possible" (Glaser, 1992, p, 18). Through creativity, openness to new categories, coding, memo writing, constant comparison, and validation, the researcher is able to generate and label categories and properties that are understandable to others.

In the remainder of this section I will detail the major components of grounded theory, utilizing the same framework presented by Glaser and Strauss (1967) when they unveiled their discovery.

\section{Generating theory.}

In their discussion of theory, Glaser and Strauss (1967) delineate between theory that is generated and, thus, "fits" the data —and theory that is based on a priori 
suppositions, namely logico-deductive theory. They argue that in attempting to substantiate logico-deductive theories, researchers run the risk of forcing the data to fit with their prior assumptions. In contrast, theories that are generated are derived directly from the data.

Two basic types of theory, grounded in the data, may be generated: substantive or formal. Substantive theories are "developed for a substantive, or empirical area of...inquiry" while "formal theories are "developed for a formal, or conceptual area of inquiry" (Glaser \& Strauss, 1967, p. 32). Substantive theories appear first, with the researcher determining if any formal theories exist that might support the substantive theories. "Substantive theory in turn helps to generate new grounded formal theories and to reformulate previously established ones" (Glaser \& Strauss, 1967, p. 34).

In endeavoring to generate theory, substantive or formal, Glaser and Strauss (1967) identified two key analytical elements: "conceptual categories and their conceptual properties; and...hypotheses or generalized relations among the categories and their properties" (p. 35). I will briefly describe these elements in the following sections.

\section{Categories and properties.}

Categories and properties arise from the data and generally progress from lower level conceptions early in analysis to higher levels of conception much later in the process. A category "stands by itself as a conceptual element of the theory. A property, in turn, is a conceptual aspect or element of a category" (Glaser \& Strauss, 1967, p. 36). Both are conceived while comparing likenesses and disparities in the data and, while they can be derived from existing theory, this may inhibit the 
emergence of new categories and/or not fit with the data at hand. Instead, the "aim is at achieving much diversity in emergent categories, synthesized at as many levels of conceptual and hypothetical generalization as possible....[which] provides...apparent connections between data and lower and higher level conceptual abstractions of categories and properties" (Glaser \& Strauss, 1967, p. 37). Categories and properties should be both analytic — or "sufficiently generalized to designate characteristics of concrete elements" — and sensitizing — “yield[ing] a "meaningful" picture, abetted by apt illustrations that enable one to grasp the reference in terms of one's own experience" (Glaser \& Strauss, 1967, p. 38).

\section{Hypotheses.}

Quite rapidly, while generating categories and properties, tentative relationships surface, leading to suggested hypotheses. When the researcher uses his or her hypotheses to generate theory, the subsequent task of generating and validating multiple hypotheses, simultaneously, ensues. The researcher, while continuously making comparisons, is also watchful for new hypotheses that may develop (Glaser \& Strauss, 1967).

Glaser and Strauss (1967) tell us that, initially, our hypotheses may appear disconnected but as they continue to evolve "and become related, their accumulating interrelations form an integrated central theoretical framework - the core of emerging theory" (p. 40). This core, thus, guides the researcher as data is continually collected and analyzed, through theoretical sampling, with the researcher ever mindful of "emergent perspectives that will change and help develop his [or her] theory" (p. 40). 


\section{Theoretical sampling.}

Glaser (1992) defines theoretical sampling as "the process of data collection for generating theory whereby the analyst jointly collects, codes, and analyzes his [or her] data and decides what data to collect next and where to find them, in order to develop his [or her] theory as it emerges" (p. 101). More simply, theoretical sampling drives and determines data collection.

Categories and properties are developed from the very beginning of raw data collection. These categories are not yet complete, thus leading the researcher to gather additional data. Theoretical categories and properties are then connected with other emergent theoretical categories and continue until each category is saturated. (Glaser, 1992). Saturation is reached when continued data collection (a) ceases to produce different categories, (b) categories are fully developed, and (c) the connections between categories are well-founded (Strauss \& Corbin, 1998). Grounded theory researchers engage in theoretical sampling to: (a) identify emergent codes, which become categories; (b) more fully develop "thin areas;" and (c) cultivate substantive theory (Glaser, 1992, p. 101).

Theoretical sampling is not predetermined but is based on the simultaneous collection and analysis of data. Sampling is determined by the presence or absence of concepts that noticeably occur across "incidents, events, or happenings" (Strauss \& Corbin, 1998, p. 202). It is collective, built on the early, emergent categories "aimed at developing, densifying, and saturating those categories" (Strauss \& Corbin, 1998, p. 203). 
While theoretical sampling is not defined in advance, the researcher does, however, establish a point of departure for data collection. Initial decisions related to (a) the location or group to be studied, (b) the types of data to be collected (i.e., interviews, observations, documents), and (c) the length of the study are, thus, made at the outset of the study. These decisions may later be modified as categories emerge. The degree of modification is based on the relationship between the initial decisions and the data collected (Stauss \& Corbin, 1998).

\section{Substantive and formal theory.}

In the opening lines of their chapter entitled, "From Substantive to Formal Theory," Glaser and Strauss (1967) remarked, "Since substantive theory is grounded in research on one particular substantive area...it might be taken to apply only to that specific area...[however] a theory at such a conceptual level...may have important

general implications and relevance...[leading to] to development of a grounded formal theory" (p. 79). Formal theory, then, can be built from theory that is substantive (Glaser \& Strauss, 1967).

Substantive theories are derived from one substantive area while formal theories are "less specific to a group and place, and as such, apply to a wider range of disciplinary concerns and problems" (Strauss \& Corbin, 1998, p. 23). It is possible to arrive at formal theory directly from a substantive area if the researcher, through his or her own learnedness, is able to conceptualize categories that cut across substantive areas, although this requires a great amount of discipline and experience on the part of the researcher (Glaser \& Strauss, 1967). 
In arriving at theory that is formal from that which is substantive, Glaser and Strauss (1967) also caution the researcher against simply re-writing substantive theory as formal by omitting substantive words. Instead, formal theories should be generated in the same ways in which substantive theories are generated-through the development of categories and properties related to multiple substantive areas through comparative analysis.

Most researchers lean towards the generation of theory that is substantive versus that which is formal, for a variety of additional reasons. For example, many researchers tend to focus on their own areas of specialization while others tend to view formal theory as too abstract and impersonal, preferring to generate substantive theories only (Glaser \& Strauss, 1967). Other researchers prefer to use formal theory within their own substantive areas, versus generate it, as a way to (a) verify an aspect of the formal theory, (b) explain distinctions in recognized theories through comparative analysis, or (c) give meaning to the substantive area during or after the collection of data.

In sum, most grounded theories are substantive because the focus is on issues in a specific substantive area. These substantive theories, when analyzed comparatively, may have a role in the development of grounded formal theories, when the substantive theories cut across a variety of substantive areas.

\section{Constant comparative method.}

In developing the constant comparative method for analysis, Glaser and Strauss (1967) drew inspiration from two differing qualitative analytic practices, namely (1) coding qualitative data to adapt it to a quantifiable form and (2) generating 
theory through the identification of properties. The discoverers of grounded theory proposed a method of analysis which "combine[d], by an analytic procedure of constant comparison, the explicit coding procedure of the first approach and the style of theory development of the second" (Glaser \& Strauss, 1967, p. 102). The purpose of this method was to simultaneously utilize explicit coding and analytic procedures to more systematically generate theory that was "integrated, consistent, plausible, close to the data — and at the same time in a form clear enough to be readily, if only partially, operationalized for testing in quantitative research" (p. 103). The constant comparative method is comprised of four, overlapping stages, discussed in the following sections.

\section{Comparing incidents.}

As data is collected, the researcher begins coding incidents and happenings into as many categories and properties as possible. As additional data is collected, data that fits is applied to an existing category; data that does not fit requires new categories be created. Coding, in this stage, is flexible and can be both formal and informal. As incidents are coded, the researcher reviews previous incidents and data that fell within the same category. This comparison, again, can be informal with the researcher making these comparisons based on recall.

This constant comparison of incidents and happenings begins to lead the researcher toward the formation of properties of categories. Categories and properties that develop will find their roots in either the researcher's own constructions or from “the language of the research situation" (Glaser \& Strauss, 1967, p. 107).

Interestingly, as the analysis proceeds, the categories that arise from the language of 
the research situation tend to be the issues of the participants while the researcher's constructed categories tend to explain the issues.

As analysts continue to code their categories, memoing ensues. During memo writing the analyst records his or her thoughts while attempting to use the data to draw conclusions. Memo writing occurs throughout the research process to keep the analyst deep in the analysis and to "increase the level of abstraction of...ideas" (Charmaz, 2006, p. 72). Like coding and analysis, the writing of memos is done instinctively, not according to a preconditioned schedule (Charmaz, 2006; Glaser \& Strauss, 1967).

Glaser and Strauss (1967) recommend that researchers code field notes and compose memos related to illustrations of instances drawn from the substantive area of study. Each illustration can be applied to only one category resulting in multiple illustrations rather than the reliance on just one. The resulting memos and field notes allow the researcher to reposition, or break down, the substantive area of study "for clear integration of the theory" (Glaser \& Strauss, 1967, p 108).

\section{Integrating categories.}

As further incidents occur, the researcher moves from comparing incidents to comparing a new incident to categories initially constructed as the result of prior comparisons of incidents. "Constant comparison causes the accumulated knowledge pertaining to a property of the category to readily start to become integrated; that is, related in many different ways, resulting in a unified whole" (Glaser \& Strauss, 1967, p. 109). As categories and properties become integrated, theory begins to develop.

Glaser and Strauss (1967) state ease of integration is more likely to occur when data is collected through theoretical sampling as part of ongoing analysis. "Emergence 
of integration,,,[however, may] also occur in analyses that are separate from data collection, but contrivance may be necessary when data run thin and no more can be collected" (Glaser \& Strauss, 1967, p. 109).

\section{Delimiting the theory.}

To delimit means to define, delineate, or bound. Glaser and Strauss (1967) describe the process of delimiting the theory as the demarcation of both the theory and the categories.

To begin, the theory, which until this point has been continuously revised and reformed, begins to take a more solid form. It may still be modified, however, as the analyst: (a) makes clarifications; (b) eliminates properties that are deemed nonapplicable; (c) integrates particularizing details of other properties into existing, interconnected categories; and (d) reduces the theory to a smaller group of central hypotheses by uncovering consistencies found in initial categories and properties. Glaser and Strauss (1967) refer to the latter as "reduction" (p. 110).

Reduction involves the "reduction of terminology and consequent generalizing, forced by constant comparisons" (Glaser \& Strauss, 1967, p. 110). The goal of reduction is for the analyst to begin to "achieve two major requirements of theory: (1) parsimony of variables and formulation, and (2) scope in the applicability of the theory to a wide range of situations while keeping a close correspondence of theory and data" (Glaser \& Strauss, 1967, p. 111).

The next step for the analyst, once his or her theory solidifies, is to decrease the initial list of categories to fit within the theory. This allows the analyst to become 
more concerned with incidents that relate to the theory. Constant comparison becomes more focused (Glaser \& Strauss, 1967).

Categories will continually be delimited as "they become theoretically saturated" (Glaser \& Strauss, 1967, p. 111). Analysts quickly begin to see if new incidents relate to previously established categories. If they do, the incidents are not coded; the category has already been established and needs no further justification. If new incidents do not fit a previously established category, then the incident is compared and coded with other incidents using constant comparison (Glaser \& Strauss, 1967).

Two occasions may arise related to theoretical saturation. Occasionally, the analyst will uncover new categories while well into the process of coding and is advised, at that point, to code for the latest category and search for theoretical saturation either in the remaining data or through the collection of additional data. Additionally, the analyst may recall incidents heard or seen in the field that were not recorded at the time. If the incident is related to a category that is theoretically saturated, the incident can be ignored. If the incident relates to a new property within an existing category, the incident can be recorded within the analyst's memos and added to his or her theory. If the incident indicates a new category, the analyst records the incident and category in his or her memos and links it with the developing theory. If the incident is minimal that is enough. If the remembered incident is major in developing theory, however, the analyst should return to coding of field notes for comparison to other incidents or return to the field for additional data (Glaser \& Strauss, 1967). 
Delimiting the theory allows the analyst to deal with data in three ways. First, data is bound, based on "the reduction of theory and the delimitation and saturation of categories" (Glaser \& Strauss, 1967, p. 112). Second, data is extended, through theoretical sampling. And, third, data is contained in that the analyst, by clearly defining categories, searches for data related to those categories, thus imposing limits on "the possible universe of data" (Glaser \& Strauss, 1967, p. 112).

\section{Writing the theory.}

Analysts who have coded data, written memos related to specific categories, and developed theories as a result of theoretical sampling, constant comparison, and theoretical saturation, should feel confident that their analysis was systematic and that the research is nearing its end. At this point, Glaser and Strauss (1967) recommend analysts organize their memos by category and then use those categories as major sections when writing. The analyst can review and include previously coded data as necessary, to "validate a suggested point, pinpoint data behind a hypotheses or gap in the theory, and provide illustrations" (p. 113). The resulting substantive theory is, thus, presented as "a reasonably accurate statement of the matters studied, and...couched in a form that others going into the same field could use" (p. 113).

\section{Credibility of grounded theory.}

Through the systematic use of grounded theory, analysts develop substantive theories based on "perceptions...personal experiences, and...hard-won analyses" (Glaser \& Strauss, 1967, p. 225). The analyst is aware that his or her explanations are not the only plausible explanations, but that, based on his or her work in the field and the ongoing relationship between the data and the analysis, the substantive theories 
developed can be reported with conviction. The challenge, for the researcher, is to report his or her convictions while conveying credibility. The researcher is advised to solve this problem in two ways.

First, the researcher is advised to specifically outline his or her theoretical framework when writing his or her report. This framework may come at the beginning or at the end of the writing and may be referred to throughout, offering the reader "an abstract presentation of the overall framework and its principal associated theoretical statements" (Glaser \& Strauss, 1967, p. 238). I have elected to present the theoretical framework prior to the presentation of my methods, procedures, analysis, and findings. Also in keeping with the recommendations set forth by Glaser and Strauss, I have, and will continue, to frequently refer to my theoretical framework throughout my writing.

Second, it is recommended that the researcher produce a report that richly describes the data relative to the substantive area studied, and the emergent theory, in such a way as to almost place the reader at the site. To do this, the researcher might offer the reader illuminative snapshots, such as vignettes. If the theory is based on a variety of concepts, the analyst may also choose to (a) utilize direct quotes obtained through interviews, (b) incorporate written portions from his or her field notes, (c) cite information obtained from insiders, (d) utilize case studies to encapsulate happenings, (e) and/or include more personal incidents related to the researcher and the area of study (Glaser \& Strauss, 1967).

Additionally, analysts that include their "codified procedure for analyzing data" increase the conveyance of credibility (Glaser \& Strauss, 1967, p. 229). 
Qualitative analyses which include coding procedures allow the reader to appreciate the data to theory connections, and, thus, to be more open to the theory presented. The inclusion of coding procedures does not, however, fully address researcher bias, particularly in relation to negative cases or alternative hypotheses. Regrettably, there are few guidelines for qualitative researchers in terms of the depth of search for nonconfirmatory evidence and/or other theories. The constant comparative method does reduce these threats to credibility, however, due to its systematic nature (Glaser \& Strauss, 1967).

\section{Summary.}

Since 1967 grounded theory has had several developments. In particular, Glaser and Strauss took their work in different directions resulting in a condemnation of Strauss by Glaser (1992) for "misconceiv[ing]... conceptions on grounded theory to an extreme, even destructive degree" (p. 1). Despite their differences, however, the work of Glaser and Strauss continues to endure because it underscores explicit procedures for generating theory. As a result, grounded theory has served as the basis for inquiry across many disciplines, and lends itself particularly well in forming the theoretical framework in doctoral dissertations (Patton, 2002).

"Glaser and Strauss aimed to move qualitative inquiry beyond descriptive studies into the realm of explanatory theoretical frameworks, thereby providing abstract, conceptual understandings of the studied phenomena" (Charmaz, 2006, p. 6). For the case study researcher, the aim of grounded theory is to develop theory from the data (Merriam, 1988), through "the views of the participants" (Creswell, 2014, p. 14) with the resulting theory being substantive, meant to be applied "to a specific 
aspect of educational practice" (Merriam, 1988, p. 141). "Besides parsimony and scope, the emergent theory can be evaluated in terms of its overall explanatory power, by how well the generalizations are supported, by how well integrated the elements are, and by whether there is a logical consistency to every dimension of the theory" (Merriam, 1988, p. 144).

Researchers and readers alike share the responsibility in judging the credibility of any theory presented. For researchers, the task is to fully describe how he or she reached the reported conclusions - where did the study take place, who was involved, what data was collected, how was it analyzed, how did the researcher arrive at the theory - to intimately involve the reader in the site, the collection of data, and the analysis. The reader, then, will assess credibility based on his or her own experiences, familiarity with the research setting or topic of study, and overall confidence in the researcher's assertions (Glaser \& Strauss, 1967). In the following sections, in an attempt to fully describe how I reached my reported conclusions, I will familiarize the committee with my methodological and analytical procedures. I will begin by identifying the most central aspect of this study - the case. Then, I will outline the context of this research and will place myself, as the researcher, within the outlined context. I will then address issues relative to validity, reliability, and ethics, and will expand on my role as a grounded researcher. Next, I will detail my data sources and collection procedures. And, finally, I will conclude this chapter with a discussion of my analysis. 


\section{The Case}

Patton (2002), in discussing theory developed inductively, emphasized, "grounded theory depends on methods that take the researcher into and close to the real world so that the results and findings are grounded in the empirical world" (p. 125). In case study, the empirical world is located within the selected case.

In fact, "the single most defining characteristic of case study research lies is delimiting the object of study, the case" (Merriam, 2009, p. 40). Yin (2014) recommends a two-step approach. First, case researchers should define the case. In defining the case, the researcher has several options. For example, a case could be a person, a group, an event, or a thing. Stake (1995) advises that in selecting the case, particularly when conducting instrumental case studies such as this one, the researcher use the issues to guide the choice.

As previously stated, the issue, or main subject of this study, is the implementation of co-teaching as a student teaching method. To learn more about implementation, a typical group of seven preservice teachers, entering the student teaching component of their respective teacher education programs in a college setting during the Spring 2016 semester, was identified through the probing of knowledgeable people within the college's Office of Partnerships and Placements. Each preservice teacher was subsequently, randomly paired with a cooperating teacher, who was employed at the college's elementary, laboratory school, with the intention of implementing co-teaching as a student teaching method, within the cooperating teacher's assigned classroom. Once the co-teaching pairs were established, all pairs 
were informed about the study and the researcher's guiding questions relative to implementation:

1. How is co-teaching implemented in seven elementary and early childhood classrooms?

2. If differences in implementation are found, why do these differences exist?

Yin (2014) states, "as a general guide, the...definition of your case (or the unit of analysis) is related to the way you define your initial research question(s)" (p. 31) while Stake (2005) also recommends cases be selected based on what can be learned. Because my research questions sought to uncover how co-teaching was implemented across seven classrooms and explain why variations, if any, were present, and, because I was very open with both the preservice teachers and cooperating teachers about these questions, I included, in a somewhat minimal sense, the preservice and cooperating teachers as co-researchers. Essentially, through an open dialogue, I paired what Stake (2005) called a "functioning body" (p. 444) with what Patton (2002) called a "learning-oriented" process aimed at achieving understanding about processes (in this case implementation) through reflection (p. 179). The case, the "functioning body" is singular, but it has what Stake (2005) calls subsections. Patton (2002) refers to these subsections as layers. The layers, or subsections, in this particular study are the seven preservice teachers, the seven cooperating teachers, and the classrooms in which they worked. The singular case, the "functioning body," however, is the group.

To further define this particular case, let us return to the ideological underpinnings of co-teaching as a student teaching method. Co-teaching "is a practice that allows [preservice and cooperating] teachers to have shared experiences... 
including planning, enacting, and reflecting on curriculum" (Roth \& Tobin, 2002, p. 1), allowing both teachers the opportunity to learn from and with one another through collective praxis (Tobin, 2006). For the purposes of this research, because the preservice teachers and cooperating teachers were endeavoring to learn with and from one another through shared practice, and, because they all were intimately involved in learning about the implementation of co-teaching and answering the research questions, I have elected to define this specific case, this functioning group, as a “community of practice."

Communities of practice are groups of people who "share information, insight, ...discuss their situations...[and] become informally bound by the value that they find in learning together" (Wenger, McDermott, \& Snyder, 2002, p. 4). They are comprised of "learners who have different levels of knowledge and mastery of the knowledge, behaviors, attitudes, and norms of the group" (Merriam \& Bierema, 2014, p. 121). This specific "community of practice," comprised of beginning and experienced teachers, found value in working together to explore the implementation of co-teaching.

Communities of practice, whether created formally or informally, typically share a similar structure, comprised of three key elements, including: (a) a domain of knowledge; (b) a group, or community, of people who share a common interest in the domain; and (c) a shared practice relative to the domain. A domain is an issue, and its presence unites the community in terms of their own value and their value to other stakeholders (Wenger et al., 2002). In this case, implementation of co-teaching is the issue; the domain both legitimizes the group while defining, or delimiting, the case. 
Layered, or nested, case studies begin with one case $(\mathrm{N}=1)$. The community of practice identified for this case study had, as its layers or subsections, seven preservice teachers, seven cooperating teachers with whom they were paired, and the seven classroom spaces in which they taught. Within the case, the researcher collects data from multiple participants with the intention of "doing justice to [the] individual case" (Patton, 2002, p. 449).

Before moving on to Yin's (2014) second recommendation for delimiting the case, it is necessary to at least give a small degree of description relative to the participants and the classrooms in which they co-taught. Case researchers are prohibited, however, from disclosing confidential information relative to their participants when describing their research. For this reason, I am altering some description relative to the case to conceal participant identities (American Psychological Association [APA], 2010).

Ranging in age from twenty-one to thirty-two years, all seven preservice teachers who participated in this work were female. Of the seven, six self-identified as white; the seventh participant self-identified as black. At the time of this study, two of the preservice teachers were earning their undergraduate degrees in early childhood, two were earning dual, undergraduate degrees in elementary and special education, and three were enrolled in masters programs in elementary education. Of the three graduate students, two were part of a "fast-track" program in which requirements could be completed in one-year. The third graduate student was enrolled in a full, two-year graduate program. All seven had previously taught, as practicum students, at 
the elementary, laboratory school. None, however, had had practicums with the cooperating teachers to whom they were assigned.

The seven cooperating teachers ranged in age from their middle thirties to middle sixties and between them, had over one hundred years of teaching experience, ranging from seven to forty years. All seven were white. Six were female; one male. The classrooms in which they taught were both early childhood and elementary. One cooperating teacher was in kindergarten, two in first grade, one in third grade, two in fourth grade, and one in fifth grade. All seven stated they had previously hosted student teachers. Several remarked that they had previously co-taught, but only two had ever attended any type of co-teaching preparatory workshop.

As previously stated, the preservice teachers were randomly assigned to the cooperating teachers - with one exception. A preservice teacher who had been placed in my second grade classroom during the Fall 2015 semester as an observer, as the result of an unsuccessful student teaching experience in another district, was also placed in a fourth grade classroom, as an observer. Because she and the cooperating teacher developed a good working relationship, and because she was already familiar with the classroom and its routines, the cooperating teacher requested she stay on as her co-teacher during the Spring 2016 semester.

Finally, the second recommendation Yin (2014) offers in terms of delimiting or defining the case is the "bounding" of the case, both in terms of time and the unit of analysis. By bounding the case by time, the researcher establishes the estimated beginning and end of the case study. For this research, the required fifteen weeks of student teaching, undertaken during the Spring 2016 semester, served as the delimited 
period of time. Yin (2014) also recommends cases be bound by the unit of analysis and states "if the unit of analysis is a small group," as it is in this case, "the persons to be included in the group (the immediate topic of the case study) must be distinguished from those who are outside of it (the context of the case study)" (p. 33). I have already identified the "immediate topic" of this case study, identifying and describing the participants within the group. I have also bound the case in relation to time. To make clear, the singular $(\mathrm{N}=1)$ case for this case study is:

A community of practice, endeavoring to implement co-teaching as a student teaching method during the Spring 2016 semester at an elementary, laboratory school located on a college campus. The community of practice, or unit of analysis - the caseincludes, as its subsections, seven preservice teachers, the seven cooperating teachers with whom they are paired, and the seven early childhood and elementary classroom spaces in which they taught.

In keeping with Yin's (2014) recommendations, I turn now to the outside context of the case.

\section{Context for this Research}

"The case to be studied is a complex entity located in a milieu or situation embedded in a number of contexts or backgrounds" (Stake, 2005, p. 449). To fully understand the circumstances in which this case study took place, it is necessary to describe the outside environmental contexts in which the case was located. In the following sections I will review two, relevant environmental contexts. In keeping with ethical considerations, pseudonyms are used to maintain confidentiality and the description of some characteristics has been limited (APA, 2010). 


\section{New England College.}

New England College was chosen as the site for this research due to its rich history in teacher education dating back to the middle of the nineteenth century. Now nestled on a 180-acre suburban campus with five academic schools—including management, nursing, social work, education, and arts and sciences - the school was originally established in the state's capital city as the state's "Normal School," dedicated to the preparation of teachers. The Normal School quickly became one of the largest and highly regarded of its kind, and, in the late nineteenth century, expanded to include an attached laboratory school, which would allow preservice teachers to practice with real students. By the 1920s the Normal School had educated over 4000 , predominantly female, teachers, and regularly drew notable visitors such as John Dewey, Maria Montessori, and Julia Ward Howe for observations and discussions (Christiansen, 2016).

As legislation continued to be passed among states requiring teachers have earned bachelor's degrees (Goldstein, 2014), the school reformed into a state college, renaming itself New England College. The newly established college, along with the newly named Harold Shipyard Laboratory School, moved to its present location, on the edge of the state's capital, in 1959. Through the end of the 1960s, even as New England College began to offer programs in other academic areas, the majority of students enrolled were education majors choosing from six courses of study: early childhood and elementary education; junior high school education; secondary education; industrial arts education; special education; and, liberal arts (Christiansen, 2016). 
New England College's School of Education has continued to grow. Today, it is accredited by the NCATE and offers a dozen undergraduate programs and over twenty graduate programs in education, including a joint $\mathrm{PhD}$ in Education offered in conjunction with an affiliated state university, making New England College an ideal context in which to study teacher education practices.

\section{Harold Shipyard School.}

One of the few remaining laboratory schools in the country, Harold Shipyard began as a ten-room observation and training school, located in the state capital, in 1898 as part of New England College. Its initial functions, among others, were to (a) provide preservice teachers a place for observation and practice, (b) serve as a model school for the state's public school system, and (c) provide opportunity for the study and evaluation of new ideas.

Today, the mid-century school is located at the heart of the New England College campus, and boasts the original stone entablature from its humble beginnings. A black, wrought iron fence, surrounds the school's play yard, which includes several play structures and expansive grassy areas. College faculty and students frequently crisscross the grounds on their way to and from classes as the school's youngest students run, hang from the jungle gym, and dig in the sandboxes.

The hallways and classrooms at Harold Shipyard, although dated, are colorful, alive with sound, and always bustling with children and adults. Twenty-five faculty members educate over 220 learners grades prekindergarten through five. The school is tuition-based, with families paying approximately $\$ 10,000-\$ 13,000$ per year, per child. Children in grades prekindergarten and kindergarten are selected via lottery, 
while children in grades one through five are admitted on a rolling basis, vacancies permitting.

The legacy of Harold Shipyard continues, serving as a place for preservice teachers to practice their craft within real classroom settings. Enrolled in both undergraduate and graduate programs, these preservice teachers work alongside faculty who have "published books, articles, and plays...have been keynote speakers at teacher conferences, and have presented papers and workshops at international, national, and local conferences" (Fennessey, 2004, p. 13). Shipyard faculty work with over a dozen practicum courses encompassing a multitude of areas including, but not limited to, early childhood and elementary education, special education, health education, and technology education. Shipyard faculty also regularly open their classrooms to work with student teachers making Harold Shipyard, like New England College, an ideal context in which to study teacher education practices.

\section{Relationship of Researcher to Context}

Stake (1995) tells case researchers, "we need to pick cases which are easy to get to and hospitable to our inquiry" (p. 4). In the case of this research, I was fortunate to have professional and scholarly relationships with key gatekeepers at both New England College and Harold Shipyard School. Specifically, I am employed as an associate professor and second grade teacher at Harold Shipyard, which falls under the umbrella of New England College. Further, I am a doctoral candidate enrolled in the joint program offered by New England College and its affiliated state university.

Creswell (2014) advises researchers discuss their experiences with (a) the research setting, (b) the research problem, and (c) the participants in an effort to 
familiarize readers with prior connections, and the potential problems, or benefits, which may result due to those connections. Let me begin by describing my relationship to the research problem and setting, and, explain why I chose to conduct research at that setting.

I became familiar with Harold Shipyard School sixteen years ago, as a preservice teacher myself. Enrolled in a Masters of Teaching program at New England College, I was required to teach a small group of fourth graders at Harold Shipyard as part of my science practicum course. I graduated from New England College that same year and, after substitute teaching at local public schools for several years, was hired to teach second grade at Harold Shipyard. I am now in my twelfth year in the same second grade classroom.

Two factors, related to New England College and Harold Shipyard, are significant in terms of this research. First, because Harold Shipyard is located on the New England College campus, many of my colleagues hold terminal degrees. Their professionalism and scholarship served as a catalyst in my decision to pursue my doctorate. Had that decision not been made, this research, as such, would not exist. Second, because part of my responsibilities at Harold Shipyard involve mentoring preservice teachers, either through practicum experiences or student teaching experiences, my research interests have tended to revolve around teacher education.

I specifically became interested in co-teaching when I was asked to participate in a pilot study exploring co-teaching as an alternative student teaching method at Harold Shipyard. I served as the cooperating teacher during the study and, since then, 
have hosted three other student teachers using the model. I also have begun to use the model within the practicum.

While engaged in co-teaching, I was concurrently taking doctoral courses and became drawn to the literature on co-teaching. While I agreed with many of the benefits of co-teaching that advocates claimed, I became curious about implementation. Specifically, I sought to know more about how implementation occurred, and, how it might vary from one classroom to the next and what might cause those variations. The lack of literature related to these interests led me to this study.

As previously stated, co-teaching has been used within the special education domain for many years. Its use as a student teaching method, however, is still quite new, and, therefore, finding a setting in which to study implementation was potentially problematic. Fortunately, due to Harold Shipyard and New England College's rich history as related to innovation in teacher education, as well as my professional relationship with key gatekeepers, I was able to secure permission to conduct my study at Harold Shipyard (see Appendix B).

The seven preservice teachers who participated in this study, prior to knowing about the study, asked to be placed in classrooms at Harold Shipyard as a result of previous experiences at the school, while taking practicum courses. I had no prior relationships with six of these preservice teachers. I did have a professional relationship with one participant who was placed in my second grade classroom as an observer, during the Fall 2015 semester, after her placement as a student teacher in another school district was unsuccessful. While placed in my classroom neither she nor I knew she would be placed as a preservice/co-teacher at Harold Shipyard during 
the Spring 2016 semester. I contacted all seven preservice teachers, once New England College's Office of Partnerships and Placements placed them at Harold Shipyard, via email, to inform them of the study, and ask for their consent to participate (see Appendix C). All seven chose to participate.

As stated, I have been a teacher at Harold Shipyard for twelve years, and, thus, my relationships with the seven cooperating teachers involved in this study are both personal and professional. That said, these relationships have been formed outside of their classrooms, in the larger context. In other words, prior to this study, I had not seen any of them teach or interact with preservice teachers nor had I discussed coteaching with any of the cooperating teachers at length. Nevertheless, my previous relationships may have an impact on my work.

For example, Creswell (2014) warns researchers against collecting data at the workplace on the grounds that: (a) it may compromise the researcher in reporting information; (b) power inequities, between the researcher and the participants, may become problematic; and (c) the roles of the researchers and participants may be threatened. Stake (2005), however, asserts that when the researcher "is given enough time and access [and] can become personally knowledgeable about the activities and spaces, [and] the relationships and contexts, of the case...[he or] she can become experientially acquainted with the case [making] the case...embraceable" (p. 455).

All research, including case studies, is susceptible to concerns related to validity, reliability, and ethics (Merriam, 1988). In the following sections, because of my prior connections to the research setting and participants, I will briefly address these concerns. 


\section{Internal validity.}

According to Creswell (2014), "qualitative validity means the researcher checks for the accuracy of findings by employing certain procedures" (p. 201). Validity is based upon determining if the researcher's findings are judged valid by (a) the participants (b) the researcher, and (c) the reader. In other words, do the "findings match reality[?] Do the findings capture what is really there? Are investigators observing or measuring what they think they are measuring?" (Merriam, 1988, p.166).

Researchers are advised to use several strategies to enhance the validity of their studies (Creswell, 2014). For the purposes of this study, I utilized two strategies to check the accuracy of my findings. First, I employed triangulation, collecting "multiple sources of data and [utilizing] multiple methods to confirm the emerging findings" (Merriam, 1988, p. 169). And, second, I utilized member-checks throughout the study - through the asking of follow-up questions during interviews and while engaged in analysis - to offer participants the opportunity to comment on my findings and validate my own emergent thinking (Creswell, 2014).

\section{External validity.}

External validity is concerned with the generalizability of research results. Grounded theorists who study cases, however, attempt to build theory, with specific attention paid to providing explanations relative to the substantive area of study versus provide generalizations. When reporting their findings, grounded theorists report on the particulars of the phenomenon studied. Their intention is not to suggest that a generated theory, from one substantive area, can be applied to a broader situation. 
When reading my findings and concluding comments in chapters four and five, the reader is reminded "that the reader judges the applicability of the findings and determines whether they fit his or her own situation, understanding that the findings in case study are "less definitive, less certain...intended to be heard, discussed, and further investigated" (Fraenkel, Wallen, \& Hyun, 2012, p. 437).

\section{Reliability.}

Qualitative reliability indicates "the extent to which one's findings can be replicated" (Merriam, 1988, p. 170). In other words, "if a later investigator followed the same procedures as described by an earlier investigator and conducted the same case study all over again, the later investigator should arrive at the same findings and conclusions" (Yin, 2009, p. 45). While keeping in mind that qualitative researchers, in general, do not view human behavior as fixed, nor do they operate on the notion that there is but one reality which can be repeated, it is still advisable for qualitative researchers to take steps toward increasing the reliability of their work (Merriam, 1988). Yin (2009) recommends case researchers document their procedures "to make as many steps as operational as possible and to conduct research as if someone were always looking over your shoulder" (p. 45). In an attempt to operationalize my steps, I followed the guidance provided by Yin (2009) in two ways.

First, I created a case study protocol (see Appendix D) to (a) provide an overview of the study, (b) detail field procedures, and (c) outline the case study report. The protocol served as a guide in defining data collection procedures, helped me to maintain focus, and allowed me to be reflective about potential concerns, including the preparation of this dissertation. Second, I maintained a case study database that 
included transcribed interviews, field notes, assorted relevant documents, artifacts, and the case study protocol itself. The case study database serves as an evidentiary source for persons wishing to review my evidence directly, or, replicate this study.

\section{Ethics.}

As Stake (2005) puts it, "qualitative researchers are guests in the private spaces of the world. Their manners should be good and their code of ethics strict" (p. 459). Because case study methods seek to examine contemporary events in real-life contexts, researchers are obligated to conduct their study with special care and sensitivity to protect human subjects (Yin, 2009). In the case of this research, Institutional Review Board approval was granted (see Appendix E), and informed consent was gained from all participants that took part in this study, prior to the collection of any data. Participant names, as well as the names of the research setting, have been changed to maintain confidentiality. Participants were informed as to the questions under investigation and were encouraged, throughout the study, to ask questions and offer feedback. Similarly, participants were regularly reminded that their participation was optional, and that they could withdraw from the study at any time. Additionally, all participants took part in co-teaching preparatory workshops to learn (a) about the model, (b) common language, (c) strategies for co-teaching, and (d) about roles and expectations. In the next section I will provide a short description of the preparatory workshops.

\section{Preparatory Workshops.}

In order to implement co-teaching as a student teaching method, the participants in this study needed to have a basic understanding of the model. Because, 
as the researcher, I did not want to influence participants, the principal at Harold Shipyard arranged the logistics for several workshops to take place, securing a location, the time for the workshops, and a knowledgeable facilitator.

The facilitator chosen, like myself, was a classroom teacher, who had taken part in the previous pilot study of co-teaching as an alternative student teaching method. The facilitator was not assigned a student teacher for the Spring 2016 semester, nor did she have any other relationship to this research. To guide the workshops, the facilitator utilized resources provided by the Teacher Quality Enhancement Center (TQE) at St. Cloud University, including both video and print resources (Heck, et al., 2010).

Two sets of workshops were arranged. The first workshop involved all faculty members and administrators from Harold Shipyard and took place prior to the implementation of co-teaching. The workshop was held on a Friday afternoon, in early January 2016, as part of a scheduled Professional Development, and was meant to offer attendees (a) the history and theory behind co-teaching, (b) a chance to compare co-teaching to traditional practices, (c) current research related to co-teaching, (d) common language, (e) an introduction to the various co-teaching strategies, and (f) a description of roles and responsibilities. The workshop took place in Harold Shipyard's main library and lasted approximately one hour. I did not attend the workshop.

The second workshop took place on the fourth day of student teaching, after preservice teachers and cooperating teachers had already begun working together. This decision was made due to (a) the availability of the preservice teachers (we could 
not require them to come to a workshop outside of their required student teaching timeline) and (b) the flexibility of the school schedule (a substitute teacher was available to cover the facilitator's classroom). Additionally, although it would have perhaps been preferable to arrange the workshop at a set time and duration, like the first workshop, it was decided that mini-workshops would instead be conducted based on the school schedule. The facilitator positioned herself in a small room, adjacent to the main library, for the duration of the school day. Only cooperating teachers and preservice teachers who were co-teaching were invited. As cooperating teachers and the preservice teachers with whom they were working were available, they would attend a thirty-minute mini-workshop with the facilitator. This workshop was intended to (a) provide an opportunity for co-teachers to develop their relationship, (b) practice communication strategies, and (c) plan for effective co-planning/co-teaching. All seven co-teaching pairs attended; I did not attend any of the workshops.

\section{Summary.}

The activities and functioning of a case "are expected to be influenced by contexts, so contexts need to be described, even if evidence of influence is not found" (Stake, 2005, p. 452). In the previous sections I have attempted to adequately describe the contexts in which this case study research took place and, have placed myself within that context. I turn now to my role as researcher, or, more specifically, as a grounded theory researcher.

\section{Statement on Role of Researcher}

"Science has traditionally emphasized objectivity, so qualitative inquiry within this tradition emphasizes procedures for minimizing investigator bias...[through] 
rigorous and systematic data collection procedures" (Patton, 2002, p. 545). Grounded theory, with its emphasis on attaining objectivity through systematic rigor and thoroughness, attempts to minimize researcher bias, explore issues from an emic perspective, and provide explanatory theories relative to the issues related to the substantive area of study.

\section{Characteristics of grounded theorists.}

Researchers using grounded theory are advised to be flexible, creative, and open to regular ambiguity — about the data, the procedures, the analyses, and their own transformation as a result of the process. Through the constant collection, analysis, and shaping of the data, the grounded theorist can soon become so engrossed in the data that he or she may become shaped by the data itself (Strauss \& Corbin, 1998).

According to Strauss and Corbin (1998), "the problem that arises during this mutual shaping process [of the data and the researcher] is how one can immerse oneself in the data and still maintain a balance between objectivity and sensitivity" (p. 42). In the following sections I will briefly describe how I attempted to (a) attain (a realistically achievable) objectivity, (b) remain sensitive, and (c) understand how the data shaped me.

\section{Striving for objectivity.}

Patton (2002) states the "popularity of [grounded theory] may owe much to the fact that it unabashedly admonishes the researcher to strive for "objectivity"' (p. 127) however, he admits, that "to claim the mantle of "objectivity" in the postmodern age is to expose oneself as embarrassingly naïve" (p. 50). He recommends, instead, that 
researchers avoid the term altogether as the word (like subjectivity) has become loaded with damaging implications.

"Researchers have learned that a state of complete objectivity is impossible and that in every piece of research — quantitative or qualitative - there is an element of subjectivity. What is important is to recognize that subjectivity is an issue and that researchers should take appropriate measures to minimize its intrusion into their analyses" (Strauss \& Corbin, 1998, p. 43). In an effort to address my own subjectivity, and remain more objective in my analyses, I steadily undertook techniques recommended by Strauss and Corbin (1998) while conducting this research. Specifically, I attempted to think comparatively by constantly comparing data with data and by examining my developing thoughts against existent literature and my own biases. Next, I struggled to see and capture events through the eyes of the participants while collecting multiple sources of data-interviews, observations, and documents-systematically. As my thinking developed and categories emerged, I remained unquestionably uncertain, and sought validation through the collection of additional data, and, through the participants themselves, asking them to review and judge my emerging hypotheses from the very first day of data collection through the last days of preparing this dissertation.

As Strauss and Corbin (1998) portray it, the level of objectivity I was striving to achieve meant taking on the characteristics of a grounded researcher, maintaining an "openness, a willingness to listen and to "give voice" to respondents... hearing what others [had] to say, seeing what others do, and representing these as accurately as possible" (p. 43) thus enabling me to present my findings here, confident that those 
findings are, mostly, "a reasonable, impartial representation of [the] problem under investigation" (p. 53).

\section{Sensitivity.}

Sensitivity arises from both knowledge and experience on the part of the researcher and "enables creativity and the discovery of new theory from data" (Strauss \& Corbin, 1998, p. 53). In terms of knowledge, the researcher approaches the research topic with accumulated theories, amassed as a result of prior experiences and studies. These accumulated theories can support the researcher in "recogniz[ing] incidents as being conceptually similar or dissimilar and to give them conceptual names" (Strauss, \& Corbin, 1998, p. 47). In terms of experience, the researcher may have professional experience, related to the topic of study. These experiences can give rise to deeper understanding, if tempered by: (a) a comparison between what is actually seen and heard versus what the analyst thinks he or she sees or hears, an aspect of theoretical comparison; and (b) the persistence on the part of the analyst to attempt to view incidents through the eyes of the participants (Strauss \& Corbin, 1998).

As a doctoral candidate, I bring to this research a limited (if slowly expanding) knowledge of existing theories and a fair degree of professional experience. Both situations can be viewed as both advantageous and disadvantageous. Advantageously, my limited knowledge of existing theory enabled me to remain more open and creative in developing theory, and less apt to try to fit data into existing theoretical codes. Also, my professional experience allowed me to enter the site more quickly, with a strong degree of familiarity. Disadvantageously, my limited knowledge may have impeded my ability to generate grounded theory. It is for this reason that I studied, as 
recommended by Glaser (1992) the theoretical codes offered in Theoretical Sensitivity (Glaser, 1978) to increase my "knowledge, understanding and skill” (Glaser, 1992, p. 27). Also disadvantageously, my professional experience may have interfered with my ability to view situations sensitively, or through the eyes of the participants. It is for this reason that I steadfastly compared the raw data from actual events with my own interpretations - asking What is this? What is really happening here?-in an effort to more strategically use my experience for interpretation (Strauss \& Corbin, 1998). In this sense, my "subjectivity is not seen as a failing needing to be eliminated but as an essential element of understanding" (Stake, 1995, p. 45).

\section{Mutual shaping.}

As previously stated, "the problem that arises during [the] mutual shaping process [of the data and the researcher] is how one can immerse oneself in the data and still maintain a balance between objectivity and sensitivity" (Strauss \& Corbin, 1998, p. 42). Interestingly, I believe being a novice analyst enhanced my ability to remain mostly objective and sensitive while engaging in analysis. I entered the field with a keen interest, not a problem. I was genuinely interested in exploring the implementation of co-teaching as a student teaching method across classrooms and in looking at variations, if any, that existed.

Glaser (1978) says the researcher should "trust in discovery" and "learn not to know" (p. 24). In my case, as a beginning researcher, that was all I could do as there is so much that I do not know. My objectivity and sensitivity arose as the result of my inexperience, and my determination to systematically utilize the grounded theory 
methods outlined by Glaser and Strauss (1967; 2008), Strauss and Corbin (1998), and Glaser (1978; 1992), while I was immersed in my data.

In the following sections I will outline my data sources and procedures, as well my systematic analysis.

\section{Data Collection: Sources and Procedures}

\section{Overview.}

"Grounded theories...[are] built with diverse kinds of data—fieldwork, interviews, and information in records or reports. The kind of data the researcher pursues depends on the topic and the access" (Charmaz, 2006, p. 14). Researchers can "add new pieces to the research puzzle or conjure entire new puzzles — while [they] gather data - and that can even occur late in the analysis" (Charmaz, 2006, p. 14). Glaser and Strauss $(1967,2008)$ defined this process as "theoretical sampling." "The analyst jointly collects, codes, and analyzes his data and decides what data to collect next" (p. 45). Charmaz (2006) distinguishes between initial and theoretical sampling. Simply put, "initial sampling...is where you start, whereas theoretical sampling directs you where to go" (p. 100).

My case study protocol served as a form of initial sampling, directing me as to the type of data I would collect and analyze first. "In initial sampling, the researcher is interested in generating as many categories as possible; hence, he or she gathers data in a wide range of pertinent areas" (Glaser \& Strauss, 1998, p. 203). All participants were informed as to the three main types of data to be collected during the study including (1) interviews, (2) observations, and (3) documents. 
Throughout data collection and analysis, I continuously composed "memos"

(Charmaz, 2006; Glaser, 1992; Glaser \& Strauss, 1967, 2008; Strauss \& Corbin, 1998) to record my thoughts, questions, connections, and next steps (Charmaz, 2006). "Memo-writing constitutes a crucial method in grounded theory because it prompts [the researcher] to analyze [the] data early in the research process" (Charmaz, 2006, p. 72) and "provide direction for theoretical sampling" (Strauss \& Corbin, 1998, p. 241). Through memo-writing, I determined my initial, anticipated sources of datainterviews, observations, and documents - although rich, were insufficient. As a result, I decided to expand the range of documents beyond what I had initially intended. I searched out additional documents, both elicited and extant (Charmaz, 2006), that were not part of the original case study protocol. I also interviewed key people at New England College to gain a broader knowledge related to (a) student teaching requirements and (b) accreditation requirements.

Yin (2014) advises case study researchers maintain a case study database, distinguishing the database from the case study report. The database serves as a way of "organizing and documenting the data collected for case studies" (Yin, 2014, p. 123). The case study database deliberately divorces raw data from the researcher's final report, leaving it open to separate analysis, while supporting the validity and reliability of the evidence (Yin, 2014). As previously mentioned, I maintained a case study database throughout this research study which included: (a) the approved research proposal; (b) Institutional Review Board approval and related, signed consent forms; (c) participant contact information; (d) the case study protocol; (e) transcribed interviews; (f) observational field notes; (g) assorted documents; and (h) my memos. 
Additionally, I maintained a computerized database, which included all of the above, as well as audio recordings of each interview.

\section{Interviews.}

Interviewing is the most common form of data collection in qualitative studies and the best technique to use when conducting intensive case studies (Merriam, 2009). "Intensive qualitative interviewing fits grounded theory methods particularly well. Both grounded theory methods and intensive interviewing are open-ended yet directed, shaped yet emergent, and paced yet unrestricted" (Charmaz, 2006, p. 28).

I chose to utilize Seidman's $(2006,2013)$ in-depth, phenomenological interview structure to design my interview schedule and questions. Seidman asserts this structure is useful when researching a wide variety of contemporary issues and is particularly well suited to researchers interested in understanding the meaning people make of their lived experiences. According to Seidman, four phenomenological themes provide the foundation for the structure and include: (a) "the temporal and transitory nature of human experience;" (b) "subjective understanding," or understanding the experience through the participant's subjective lens; (c) "lived experience," or getting the "'was" [to] come as close as possible to what was the "is";" and (d) "the emphasis on meaning and meaning in context" through reflection (p. 16).

Seidman $(2006,2013)$ recommends researchers conduct a series of three interviews and outlines the focus of each. During the first interview, the researcher is interested in the participant's life history or temporal/transitory experience. During the second interview, the questions help the participants to talk about the meaning they 
are making of their experiences, within the context of that experience, with an emphasis on the details of the experience. During the third interview the participants reflect on their experience. As part of my application for Institutional Review Board approval, and as part of my case study protocol, I created interview guides detailing the questions for each interview, in advance, based on this structure (see Appendices F, G, H). However, as a grounded theorist I revised the interview guides as needed, while keeping within the overall structure, based upon my ongoing data collection and analysis.

Strauss and Corbin (1998), in their discussion of guiding questions, support the evolution of questions based on the evolution of theory. The researcher begins with open-ended questions, "tend[ing] to become more specific and refined as the research moves along" with the researcher "want[ing] to ask questions that give further information about specific concepts and their properties and dimensions (p. 78). For example, during the first set of interviews a participant, when discussing practicum experiences versus student teaching experiences, mentioned differences in planning. I began to ask myself questions related to the participant's statement. How was planning happening during the implementation of co-teaching? Who was planning? When did planning take place? Where? Asking these types of specific questions during data collection and analysis allows the analyst to recognize his or her biases and increase his or her sensitivity toward the emic issues of participants (Strauss and Corbin, 1998). As a result of the participant's comment I added another question to my interview guide for interview two, related to planning, to discover and compare how planning was occurring across classrooms. 
In addition to making changes to my interview guides, I also made changes to my line of questioning during the interviews themselves. This is in keeping with Seidman's (2013) recommendations allowing the responses of the participants to guide the interview, and, also in keeping with grounded theory methods, which advise the researcher against stiff adherence to initial guidelines (Strauss \& Corbin, 1998).

Seidman (2013) makes several suggestions when detailing the three-interview structure but recognizes that "researchers will have reasons for exploring alternatives to the structure and procedures" (p. 25). As part of the structure, for example Seidman $(2006,2013)$ recommends the three interviews take place over the course of a two- to three-week period. I, however, chose to spread the interviews over the required length of student teaching — fifteen weeks - to more fully capture the meaning participants were making of their lived experiences over the full course of that experience.

Each participant was individually interviewed three times—once during the second week of student teaching, once during week seven, and once during the final week of student teaching. All interviews were conducted within private spaces at Harold Shipyard based upon the availability of the spaces. At the beginning of each interview I (a) reminded participants about my research questions, (b) reiterated that all interview information was confidential, (c) described the nature of the interview, and (d) asked permission to audiotape our conversation. All participants agreed to being audiotaped. In keeping with Glaser's (1992) recommendations, I transcribed the first set of interviews, verbatim, in their entirety, for analysis and coding. Later interviews, either in their totality or selected sections, were selectively transcribed, 
based on theoretical sampling to prevent the redundant accumulation of data relative to the emerging theory (Glaser, 1992).

All interviews were scheduled according to the availability of the interviewees (Yin, 2014). Seidman $(2006,2013)$ recommends each interview last approximately one to one and one-half hours. Each interview I conducted, however, lasted approximately thirty minutes. Although I would have preferred to stay within Seidman's recommendations for the length of the interviews, I was unable based upon the availability of the participants.

"To say that one samples theoretically means that sampling, rather than being predetermined before beginning the research, evolves during the process. It is based on concepts that emerged from analysis and that appear to have relevance to the evolving theory" (Strauss \& Corbin, 1998, p. 202). Although my case study protocol identified preservice and cooperating teachers as my interviewees, during my data collection and analysis I also recognized the need to informally interview persons from the larger context in which this case was positioned. Specifically, I conducted interviews with colleagues from New England College, to obtain information relevant to program and accreditation requirements. During these informal interviews I took notes, which became part of my case study database. I did not audio record these conversations.

\section{Observation.}

Observation is an invaluable research tool when a phenomenon can be seen directly (Merriam, 2009; Stake, 2010). Personal contact with the natural setting enables the researcher to (a) gain an enhanced understanding of context, (b) maintain 
an inductive stance, (c) observe intricacies within the setting that might go unnoticed by participants, (d) observe things that participants may be reluctant to share during interviews, (e) move beyond the perceptions of participants, and (f) reflect upon the researcher's own perceptions (Patton, 2002). Ultimately, the responsibility of the researcher is "to know what is happening, to see it, to hear it, [and] to try to make sense of it" (Stake, 2010, p. 94). "Grounded theorists select the scenes they [want to] observe and direct their gaze within them" (Charmaz, 2006, p. 23).

In an effort to select scenes of interest, a clear schedule for observations was devised (Yin, 2014) to capture co-teaching activities across the seven classrooms at specific points within the student teaching experience. Observations were conducted in each classroom three times during the course of the spring semester - once within week two, once within week seven, and once within the last week - with each observation lasting roughly one hour, resulting in approximately twenty-one hours of observation. Highly descriptive field notes were recorded during each observation "to provide a relatively incontestable description for further analysis and ultimate reporting" (Stake, 1995, p. 62).

Stake (1995) reminds case researchers that "we can only look at a few aspects [of a case] and that "we choose opportunities" (p. 60). Yet Yin (2014) reminds us that we are "intruding into the world of the case and the participants being studied...[and that] special arrangements to become an observer" have to be made (p.88). Although the frequency of observations and the weeks during which they were to occur was predefined, ultimately, the cooperating teacher in each individual classroom decided upon the specific times, within those weeks, that the observations took place. 
Finally, in addition to planning where and when observations will occur, and after gaining access, another fundamental decision researchers make when entering into observations relates to the researcher's desired extent of participation. The preferred degree of participation may evolve, however, during the course of the research, or differ from setting to setting, regardless of the researcher's resolve (Patton, 2002). It was my overall intent while conducting observations to act as complete observer within each classroom. However, circumstances occasionally arose (e.g. students asking for help; teachers engaging me in classroom discussions) which required I act as a participant within the setting.

\section{Documents.}

\section{Extant texts.}

"Extant texts consist of varied documents that the researcher had no hand in shaping. Researchers treat extant texts as data to address their research questions although these texts were produced for other-often very different—purposes" (Charmaz, 2006, p. 35). For the purposes of this research, two types of extant texts were utilized.

First, all preservice teachers were required to submit a "Teacher Candidate Work Sample" (TCWS) as part of their student teaching requirements. Part six of the TCWS asks preservice teachers to reflect on and learn from their practice. Specifically, the preservice teacher "reflects on key findings about student growth, formulates conclusions, makes instructional decisions to improve teaching practice, and self-assesses" (New England College, 2014, p. 14). All preservice teachers were told at the outset of the study that I would be requesting part six of the TCWS. I asked 
all preservice teachers to provide me with this written work either via email or in the form of a hard copy. Of the seven preservice teachers, six submitted their TCWS to me via email. The seventh did not submit.

"Guiding data collection during theoretical sampling are analytic questions and comparisons" (Strauss \& Glaser, 1998, p. 203). After receiving part six of the TCWS, and conducting interviews and observations, it became clear that I needed to know more about the various requirements expected of the preservice teacher. For this reason I sought out texts relative to both, the TCWS, and student teaching requirements overall. I also sought out elicited texts, which I will describe in the next section.

\section{Elicited texts.}

"Elicited texts involve research participants in producing written data in response to a researcher's request and thus offer a means of generating data" (Charmaz, 2006, p. 35). Although my case study protocol outlined the specific documents I would be utilizing as part of my study, namely part six of the TCWS, upon my initial perusal of these documents I felt I needed additional data relative to the implementation of co-teaching. For this reason, during the third interview, I asked all preservice teachers to compose a one-page summary of their thinking about implementation. I emphasized that this writing was optional. All agreed during the interview to complete the task, but of the seven preservice teachers only three actually submitted this elicited text. 


\section{Data Analysis}

\section{Overview.}

Since their discovery of grounded theory in 1967, Glaser and Strauss took their analytical method in different directions. Specifically, "Strauss (1987) moved the method toward verification" and, along with Juliet Corbin, introduced new technical procedures for analysis, relying less on the constant comparative methods introduced by Glaser and Strauss in 1967 (Charmaz, 2006, p. 8). Outraged that their work was "a whole different method," Glaser (1992) criticized the authors, arguing that their procedures functioned under "a logic that thwarts and frustrates the discovery of what is really going on in the substantive area under study" (p. 3).

Despite Glaser's opposition, Strauss and Corbin's work remains an influential resource for researchers and has served as a valuable guide for graduate students utilizing the method (Charmaz, 2006). Their straightforward writing style and basic descriptions of flexible analytical tools renders their work accessible to even the most inexperienced researcher. In fact, Strauss and Corbin (1998) state their work is intended "to provide the basic knowledge and procedures needed by persons who are about to embark on their first qualitative research projects and who want to build theory at the substantive level" (p. x). In the following sections, I will detail how I used the analytical methods offered by Strauss and Corbin, in combination with those recommended by Glaser $(1978 ; 1992)$ as I embarked on my first qualitative research endeavor. 


\section{Labeling to establish initial concepts.}

“To uncover, name, and develop concepts, we must open up the text and expose the thoughts, ideas, and meanings contained therein" (Strauss \& Corbin, 1998, p. 102). The analyst, in his or her interactions with the data, breaks the data into discrete fragments, and assigns representative names, or labels, to these fragments. The labels assigned are generally based on the researcher's experience and are grounded in the context being studied. Labeling is not a form of analysis, but a first essential step toward developing concepts that can be analyzed.

In transcribing my initial interviews and field notes, I began to write short memos related to my initial naming, or labeling, as a way of keeping track of my thinking for future analysis, and as a record of my analytical process (Strauss \& Corbin, 1998). Some of my initial labels, for example, were "time of year," “confidence," "preconceived notions," and "mental models." I labeled spontaneously and liberally, as my thinking developed, without a fixed reference to previous labels. After labeling several initial interviews and pages of field notes, and amassing a multitude of names, I stopped labeling, and turned to a form of analysis that "uses the procedures of comparative analysis, the asking of questions, and...analytical tools to break the data apart and dig beneath the surface" namely, "microanalysis" (Strauss \& Corbin, 1998, p. 109).

\section{Microanalysis.}

Also known as line-by-line analysis, microanalysis is an analytical technique used to generate initial categories (Strauss \& Corbin, 1998). A category is "a phenomenon, that is, a problem, an issue, an event, or a happening that is defined as 
being significant to respondents" (Strauss \& Corbin, 1998, p. 124). The technique is flexible, allowing researchers to use both open and axial coding to analyze all types of data collected - transcribed interviews, observational field notes, documents, etc.microscopically ((Strauss \& Corbin, 1998).

\section{Open coding.}

Strauss and Corbin (1998) define open coding as "the analytic process through which concepts are identified and their properties and dimensions are discovered in data" (p. 101). There are several options available to the analyst for open coding including: (a) line-by-line analysis; (b) coding whole sentences or paragraphs; or (c) scanning transcriptions, field notes, or other documents in their entirety. Open coding, like labeling, involves breaking the data apart, but in more attentive, discriminate ways.

During open coding the analyst continues to write memos with the memos growing "in complexity, density, clarity, and accuracy as the research progresses" (Strauss \& Corbin, 1998, p. 218). The goal, ultimately, is for the researcher to "discern the range of potential meanings...and develop them more fully in terms of their properties and dimensions" (p. 109).

After transcribing the initial interviews, I stopped labeling and developed a list of my initial labels. I wanted to gain a deeper understanding of the data and begin to group some of my initial labels into categories. "Categories are concepts, derived from the data, that stand for phenomena...[they are] abstract, explanatory terms...[replete with] subcategories...[that explain] the when, where, why, how, and so on of a category that are likely to exist" (Strauss and Corbin, 1998, p. 114). For 
example, my initial list of labels included the labels "time of year," "fall versus spring," and "lack of time." I began, in a very tentative, preliminary way, to group these initial concepts under the category "time" and to record my thinking, in terms of the properties and dimensions of "time," through the writing of memos.

I also returned to the transcribed interviews and, through a combination of lineby-line analysis and the scanning of sentences, paragraphs, and the entire document, attempted to identify major ideas while simultaneously engaging in constant comparison. For example, after re-reading a transcription, I noticed the interviewee used the word "view" when discussing the way preservice teachers are to be viewed while co-teaching - as teachers. I started thinking about the word "view" and its meanings as both noun and verb, and how we, as observers, "view" different things. In utilizing what Strauss and Corbin (1998) refer to as systematic or theoretical comparison, I began to think about how a teacher is "viewed" compared to how a doctor is "viewed" with the intention of sensitizing myself to properties and dimensions in the data. I also started to think about how the larger context either enables, or inhibits, the "viewing" of preservice teachers as teachers versus students. I noted that "viewing" could be a potential category with subcategories such as "view of self," "view by others," and "view within the larger context."

\section{Summary of microanalysis.}

Microanalysis is undertaken throughout the analytical process, occurring mainly in the early stages of analysis to identify categories and properties, and, revisited as necessary when new data is obtained or when it is necessary to reexamine old data. Although microanalysis is also termed line-by-line analysis, the technique 
does not require analysts to code the entirety of the data. Instead, the analyst scans the data with the purpose of identifying segments of potential relevance (Strauss \& Corbin, 1998).

Analysts engaged in microanalysis are required to step outside of their own way of thinking and, through a deep concentration on the data, consider all plausible meanings. Sensitivity on the part of the researcher is essential; the researcher needs to approach the data without any preconceived ideas, and, with a familiarity of his or her own field. Rather than looking at the data generally, the analyst looks at the details, considering not just what was said or done, but how it was said or done, and asks questions along the way — both specific and theoretical—-to locate relationships and variations. The data is what is important, leading the analyst to identify categories and interactions, through constant comparison, that eventually lead to theory development (Strauss \& Corbin, 1998).

\section{Axial coding.}

Whereas open coding requires the analyst to break apart or fracture the data, axial coding allows for its reassembling. Specifically, during axial coding, "categories are related to their subcategories to form more precise and complete explanations about phenomena" with the categories "[standing] for a phenomenon, that is, a problem, an issue, an event, or a happening that is defined as being significant to respondents" (Strauss \& Corbin, 1998, p. 124). Axial coding is not necessarily a separate step; it can occur simultaneously with, or as the result of, open coding.

Strauss and Corbin (1998), in their discussion of axial coding, recommend analysts relate structure with process. The structure "[sets] the stage...in which 
problems, issues, happenings, or events pertaining to a phenomenon are situated or arise" (p. 127) while process "denotes the action/interaction over time of persons, organizations, and communities in response to certain problems and issues" (p. 127). To integrate both structure and process, analysts are advised to utilize what Strauss and Corbin (1998) refer to as "the paradigm" during axial coding. The paradigm, essentially, serves as a plan for the ordering of data into three parts including (a) conditions, (b) actions/interactions, and (c) consequences.

As a beginning analyst who was noticing a connection between the process of the implementation of co-teaching as a student teaching method, and the structure of the multiple contexts in which implementation was occurring, I attempted to utilize Strauss and Corbin's paradigm to order my data but found the process to be both challenging and restraining. Charmaz (2006) helped to define my frustration by explaining that "the frame may...limit your vision...[and that researchers] who prefer simple, flexible guidelines — and can tolerate ambiguity — do not need axial coding" (p. 61).

Like Charmaz (2006), I did not utilize the formal procedures of axial coding as recommended by Strauss and Corbin, but instead adhered more closely to Glaser's (1992) process of analysis "continually coding, comparing, analyzing and memoing...to generate categories" (p. 19). While engaged in this process I continually searched for and was alert to what Glaser (1978) terms the "core variable" or "the main concern or problem for the people in the setting, for what sums up in a pattern of behavior the substance of the what is going on in the data, for what is the 
essence of relevance reflected in the data, [and] for gerunds which bring out process and change" (p. 94).

\section{Selective coding.}

According to Strauss and Corbin (1998), selective coding "is the process of integrating and refining categories" (p. 143) while Glaser (1992) states that "to selectively code means to delimit coding to only those variables that relate to the core variable, in sufficiently significant ways to be used in a parsimonious theory" (p. 75). In Glaser's (1978) opinion, selective coding cannot begin until the core variable has been identified and states that this is in direct contrast to Strauss and Corbin's usage of selective coding as a vehicle for identifying it.

Again, I elected to adhere more closely to Glaser's (1978) analytical recommendations, entering into selective coding only after identifying my core variable. Through my analyses of my field notes and transcribed interviews I began to get a sense that, for the participants, the main concern relative to all stakeholders was moving the preservice teacher from student to teacher while co-teaching. I also noticed a distinction between being $a$ teacher versus being the teacher. I returned to Glaser's (1978) discussion of core variables as basic social processes in an effort to name my core variable. According to Glaser, "a process is something which occurs over time and involves change over time" and, for many analysts, the tendency is to label a process with a gerund (p. 95). I determined that this transition from student to teacher was indeed processual and, therefore, named my core variable Transitioning from Student to Teacher Alongside the Teacher. 
For Glaser (1978) the goal of grounded theory is to generate a theory around a core variable that "accounts for most of the variation in a pattern of behavior" (p. 93). The core variable is (a) relevant, (b) works, (c) is central to most of the categories generated from the data, (d) and "has the prime function of integrating the theory and rendering the theory dense and saturated as the relationships increase" (p. 93). To selectively code "means that the analyst delimits his coding to only those variables that relate to the core variable in sufficiently significant ways to be used in a parsimonious theory" (Glaser, 1978, p. 61).

\section{Sorting memos.}

As a beginning analyst, I used the sorting of memos while engaged in selective coding. According to Glaser (1978) "the theoretical sorting of memos is the key to formulating the theory for presentation to others" (p. 116) and is a necessary step for integration. Glaser (1978) recommends memos be sorted around the core variable and that the analyst utilize both theoretical and substantive codes to establish the relationship of categories to the core variable. The theoretical codes "conceptualize how the substantive codes may relate to each other as hypotheses to be integrated into a theory. They, like substantive codes are emergent; they weave the fractured story back together again. Without substantive codes, they are empty abstractions" (p. 72).

Glaser (1978) states that it is essential for a grounded theorist to have an understanding of theoretical codes and offers beginning analysts eighteen coding families for study. In my initial stages of sorting, I attempted to sort my memos around what Glaser calls “The Six C's: Causes, Contexts, Contingencies, Consequences, Covariances, and Conditions" (p. 74). My preliminary thinking led me 
to believe that I would be able to use this coding family to explain any variation found during the implementation of co-teaching as a student teaching method. In particular, I was drawn to thinking about causes, contexts, contingencies, and conditions. I attempted to systematically sort my memos, using my initial substantive codes, into this theoretical coding family but found the exercise to be frustrating and challenging, much like my attempt at using Strauss and Corbin's (1998) paradigm for axial coding. I returned to a study of the theoretical coding families provided by Glaser (1978) and, in doing so, attempted to identify a theoretical coding family that better fit with my data and my core variable. For me, in keeping with Glaser's thinking "the theoretical code [had to] earn its way like a substantive code" (p. 72). In my review I centered upon what Glaser calls "The Mainline Family" of theoretical codes. According to Glaser (1978), "these codes...represent mainline, traditional established sociology...concerned with...people in process [adding that] every study, including a grounded theory study, is "of" one of these codes, and to know which one clearly infuses the study theoretically while broadening its perspective" (p. 77).

Of particular interest to me was the code "status passage" which Glaser describes as "moving people along and getting them through" (Glaser, 1978, p. 77). Status passages "may entail movement into a different part of a social structure; or a loss or gain of privilege, influence or power, and a changed identity and sense of self, as well as changed behavior" and are, generally, openly discussed by participants (Glaser \& Strauss, 2010, p. 2). To me, the idea of status passage fit with my core variable. 
Glaser (1978) states that theoretical codes can be used flexibly and adds that that any number of theoretical codes can fit a given study. He does remind the analyst, however, that although choices relative to codes may be somewhat subjective, once selected "the choice starts determining integrative patterns which limits the freedom of further choices" (p. 72). Thus, I returned to memo sorting, re-sorting my substantive codes theoretically, alongside my theoretical coding choice, status passage. After the sorting was complete I used the sort to guide my writing in the following sections. As Glaser (1992) states, "the write-up of sorts (sorted memos) is a theory of a core variable which freezes the ongoing for a moment" (p. 111). For this particular grounded theory study, it is a theory of the emic, or the main issue(s) of the people who belong to this specific case. 


\section{Chapter 4: Findings}

\section{Introduction}

The purpose of this explanatory, instrumental, single-case study was to understand, through the use of grounded theory analysis, how co-teaching was implemented in seven elementary and early childhood classrooms in a mid-sized New England city, in an effort to develop substantive theories relative to causal explanations for differences of this particular case.

The case study was guided by the following two questions relative to implementation:

1. How is co-teaching implemented in seven elementary and early childhood classrooms?

2. If differences in implementation are found, why do these differences exist?

In an attempt to answer these questions, I systematically used grounded theory analysis to identify the main, or emic, issues of the participants involved in this work. I also sought to identify a core variable, which closely related to the concerns of the participants while they were implementing co-teaching as a student teaching method. As previously stated, I named the core variable: Transitioning from Student to Teacher Alongside the Teacher.

Through the sorting of memos under my identified core variable, and the use of my selected theoretical coding family, "Status Passage," I began to notice two distinct, intersecting passages. Figure 1 is a representation of these separate, but interlocking passages. 
Figure 1

Two Intersecting Passages

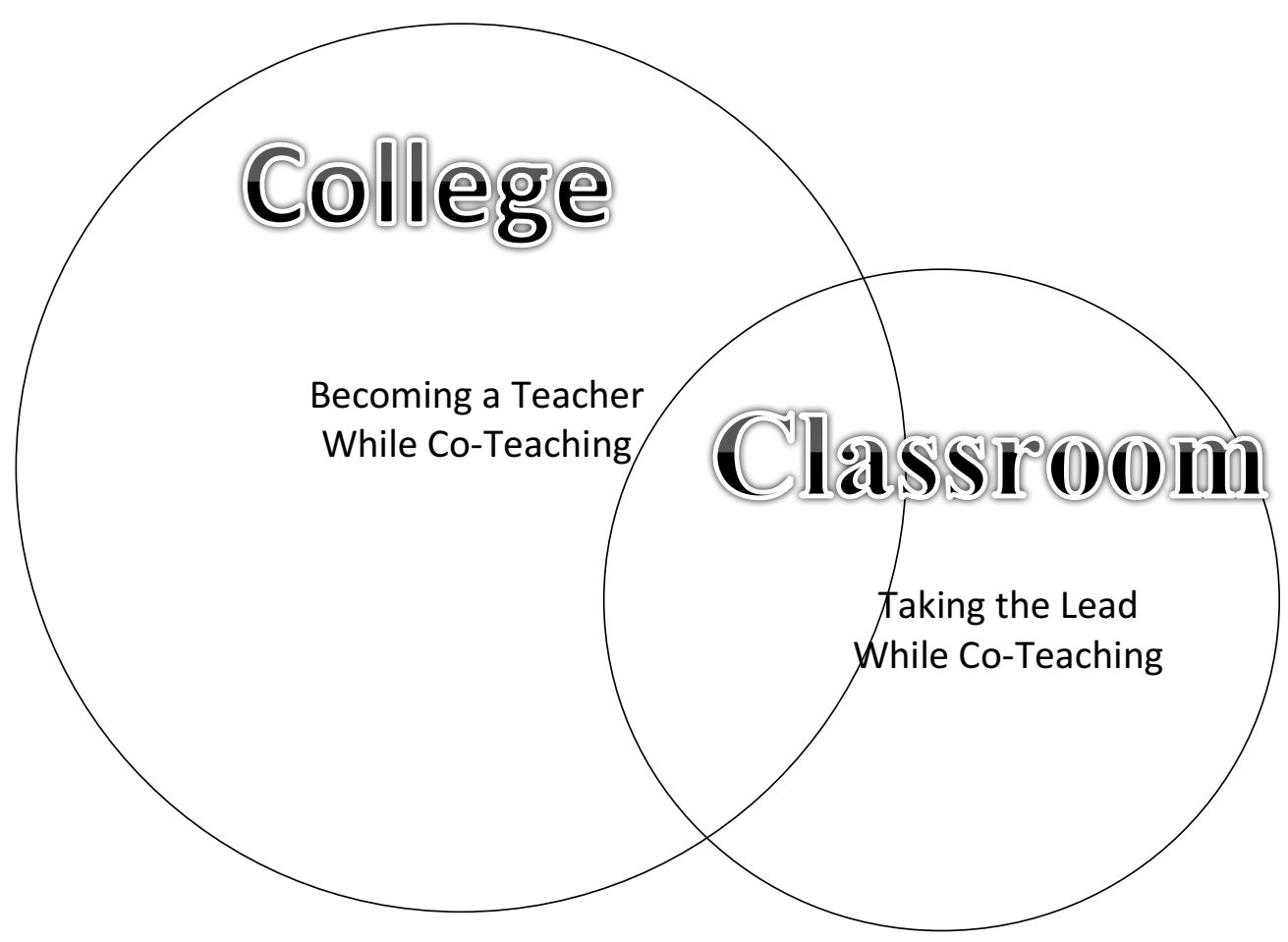

The first passage, Becoming a Teacher While Co-Teaching, was situated

within the larger context of this study, namely, the college setting. The second passage, Taking the Lead While Co-Teaching, was more closely situated to the classroom context. Interestingly, it was through the identification of these two separate but intersecting passages, as well as through the comparison of their properties using my theoretical coding family, that I began to understand how co-teaching was implemented and what caused variation.

\section{Becoming a teacher versus taking the lead.}

The first passage I identified, Becoming a Teacher While Co-Teaching, is somewhat obvious in light of the purposes of teacher preparation programs and their components. Student teaching is the culminating experience for preservice teachers 
on their passage to licensure. All stakeholders, including college personnel, cooperating teachers, and the preservice teachers themselves, operate under specific guidelines, provided by the college, to ensure this passage is efficient and successful. According to New England College's (2010) Student Teaching Handbook, during student teaching "the teacher candidate accomplishes the final transition from preparation to practice" (p. 7).

The second passage, Taking the Lead While Co-Teaching, was taken directly from the words of the participants. The language was used early in the study and became, what Glaser (1978) terms an "in vivo code" (p. 70). Throughout data collection and analysis, variations on the wording of this passage were used by participants during interviews, and by myself while coding and analyzing observational field notes and transcribed interviews. Table 1 offers a sample of statements related to this identified passage.

Table 1

Sample of Statements Related to the Identification of "Taking the Lead "as a Passage

AC: "Um, I think this class, it was, it was hard for her to kind of take the lead with this group."

CL: "I think she wants to feel like she's really the lead at that time."

KD: "I feel like going in at first, it was like, I wasn't, I was the, they called me the student teacher. The students had a higher respect for Heather. She was, like, the lead and that's how it was and I was less than her...When... I started to take over it started to even out...They treat us the same. Like we're equal. Like we're both 
teachers."

AC: "I'm trying to give her more independence. She needs that before she leaves and goes and gets a job. I feel like she needs to have control of the class and be the lead, experience being the lead teacher"

\section{Properties of Status Passage}

I initially utilized the properties of passage offered by Glaser and Strauss (2010) to establish similarities and differences, and to visually compare Becoming a Teacher While Co-Teaching with Taking the Lead While Co-Teaching. Table 2 offers a side-by-side comparison of the two passages and their properties.

Table 2

Becoming a Teacher and Taking the Lead: A Side-by-Side Comparison

\begin{tabular}{c|c|c}
\hline $\begin{array}{c}\text { Properties of Status } \\
\text { Passage }\end{array}$ & $\begin{array}{c}\text { Becoming a Teacher } \\
\text { While Co-Teaching }\end{array}$ & $\begin{array}{c}\text { Taking the Lead } \\
\text { While Co-Teaching }\end{array}$ \\
voluntary? & $\begin{array}{c}\text { The choice to become a } \\
\text { teacher is voluntary; the } \\
\text { passagee has no choice } \\
\text { regarding student teaching. }\end{array}$ & $\begin{array}{c}\text { The person making the } \\
\text { passage may do so } \\
\text { voluntarily or have no } \\
\text { choice or perhaps have } \\
\text { degrees of choice either } \\
\text { the }\end{array}$ \\
$\begin{array}{c}\text { Is the passage } \\
\text { inevitable? }\end{array}$ & $\begin{array}{c}\text { The passage is mostly } \\
\text { inevitable; holding back a }\end{array}$ & $\begin{array}{c}\text { The passage is } \\
\text { aspects of the passage. }\end{array}$ \\
\hline
\end{tabular}




\begin{tabular}{|c|c|c|}
\hline $\begin{array}{c}\text { Is the passage } \\
\text { desirable or } \\
\text { undesirable to } \\
\text { passagee or other } \\
\text { stakeholders? }\end{array}$ & $\begin{array}{l}\text { The passage is desirable by } \\
\text { both agents and passagees. }\end{array}$ & $\begin{array}{l}\text { The passage may be } \\
\text { desirable or undesirable by } \\
\text { the passagee or other } \\
\text { stakeholders. }\end{array}$ \\
\hline $\begin{array}{l}\text { Is the passage } \\
\text { reversible? }\end{array}$ & $\begin{array}{l}\text { The passage is reversible in } \\
\text { accordance with structural } \\
\text { or personal conditions but } \\
\text { is not likely. }\end{array}$ & $\begin{array}{l}\text { The passage is reversible in } \\
\text { accordance with structural or } \\
\text { personal conditions and is } \\
\text { unpredictable. }\end{array}$ \\
\hline $\begin{array}{l}\text { Do the passagee or } \\
\text { other stakeholders } \\
\text { have control over the } \\
\text { passage? }\end{array}$ & $\begin{array}{l}\text { The passagee and other } \\
\text { stakeholders have minimal } \\
\text { control. }\end{array}$ & $\begin{array}{c}\text { The passagee and other } \\
\text { stakeholders have varying } \\
\text { degrees of control. }\end{array}$ \\
\hline $\begin{array}{l}\text { Does the passage } \\
\text { require legitimation } \\
\text { by authorized } \\
\text { stakeholders? }\end{array}$ & $\begin{array}{l}\text { The passage does require } \\
\text { legitimation by authorized } \\
\text { stakeholders. }\end{array}$ & $\begin{array}{l}\text { The passage requires } \\
\text { minimal, if any, legitimation } \\
\text { by authorized stakeholders. }\end{array}$ \\
\hline $\begin{array}{l}\text { Are the signs of } \\
\text { passage clear to the } \\
\text { passagee and other } \\
\text { stakeholders? }\end{array}$ & $\begin{array}{l}\text { The signs of passage are } \\
\text { clear to the passagee and } \\
\text { other stakeholders. }\end{array}$ & $\begin{array}{l}\text { The signs of passage are not } \\
\text { clear to the passagee or other } \\
\text { stakeholders. }\end{array}$ \\
\hline $\begin{array}{l}\text { Are temporal aspects } \\
\text { of the passage known? }\end{array}$ & $\begin{array}{c}\text { Temporal aspects are } \\
\text { known. }\end{array}$ & $\begin{array}{l}\text { Temporal aspects are } \\
\text { generally unknown. }\end{array}$ \\
\hline
\end{tabular}

A preliminary analysis of the table brought to mind the urging by Glaser and Strauss (2010) for researchers to more closely examine passages that are not "regularly scheduled [in] character" (p. 3). They state, "sociologists have tended to assume in their analyses that status passages are fairly regularized, scheduled, and prescribed. But those three properties of passage can be absent or present only in 
some degree in some types of status passage" (p. 3). Their words made me revisit an earlier sort of my memos where I was attempting to sort based on what was the same throughout the implementation of co-teaching, what was different, and what might cause that sameness or variation. A re-read of my memo, which included only substantive codes, juxtaposed with my new thinking related to status passages, helped me to understand that what was the same, was fairly regularized, scheduled, and prescribed. Not being regularized, scheduled, or prescribed led to variation.

Thus, I was able to separate out my interpretations as related to my two research questions. How co-teaching was implemented as a student teaching method with the purpose of helping the preservice teachers to Become a Teacher While CoTeaching, was regularly scheduled in character and, therefore, not especially subject to variation. How co-teaching was implemented as a student teaching method with the purpose of helping the preservice teachers to Take the Lead While Co-Teaching was not regularly scheduled and, therefore, led to variation. In the following sections I will attempt to more sufficiently discuss my interpretations using my two research questions and the properties of status passage as a framework. Throughout, I will include the substantive codes and categories developed during my analysis (in bold italics) and will provide excerpts of transcribed interviews. I will also include illustrative vignettes, within my analysis of question two, to more fully capture and describe the implementation of co-teaching as a student teaching method within this particular case. 


\section{Question 1: How is Co-teaching Implemented in Seven Elementary and Early Childhood Classrooms?}

\section{Overview.}

Student teachers are not uncommon at Harold Shipyard School. From year to year, the school regularly hosts a multitude of preservice teachers making the passage from student to teacher. The administration, classroom teachers, specialists, teacher assistants, staff, parents, and Harold Shipyard's youngest students welcome their presence and are generally hospitable.

The welcoming of the preservice teachers, who were to engage in this study as co-teachers with their cooperating teachers, was not very different than the welcoming that traditional student teachers would normally experience. Prior to their arrival they all attended, along with preservice teachers assigned to other schools, a Preparing to Student Teach Meeting, hosted by New England College's school of education, with the purpose of learning about "the application process for student teaching, requirements and deadlines, and the policies and expectations as they relate to student teaching” (New England College, 2016). The student teachers were then assigned to their cooperating teachers and were given details as to where and when to report for the first day of student teaching.

Once the preservice teachers arrived at Harold Shipyard for their first day, they were escorted to their assigned classrooms where they met their cooperating teachers and the students. They were given a teacher desk and shown where to store their personal belongings. The cooperating teachers also offered information relative to the layout and procedures in the school and in the classrooms. Additionally, all of the 
preservice teachers were warmly greeted by the administration within the first two days of their arrival.

The preservice teachers also became aware of their ability, or inability, to access the school, the classrooms, and information. For example, the preservice teachers had restricted access to the school. While Harold Shipyard faculty had electronic key-cards and classroom keys that allowed them to access the school and/or classrooms twenty-four hours a day, the preservice teachers had to be "buzzed in" to gain entry to the school and, then, either wait for their cooperating teacher to arrive or locate someone else with a key to access their classrooms. Similarly, access was restricted relative to information. The administration at Harold Shipyard utilizes a secure, online, organizational system, which requires a password, to store and disseminate information. Preservice teachers did not have, nor were they provided with, passwords. Again, this is not unlike traditional student teaching practices at Harold Shipyard.

Despite these restrictions, the preservice teachers all reported feeling welcome. Said one preservice teacher: “Here, I don't feel like an outsider. I'm invited to the meetings, and, like with parents... and I was invited to the Pasta Dinner. I was, um, invited to take part in being more of, in the school community." Said another: "So, um, I just love it here, like how everything works and, um, how, I really like how the teachers collaborate. So, like, even when we're at lunch we're talking about, like, different, like, lessons and how we can collaborate. So it's very much like a team effort here." 
Due to my study, a preparatory workshop was held during the first week of student teaching to establish expectations relative to the implementation of coteaching. This workshop would not have taken place if traditional student teachers had been placed at Harold Shipyard. During the workshop the facilitator outlined key aspects of co-teaching, including co-planning and communication, and provided the preservice and cooperating teachers with a copy of co-teaching strategies. The facilitator also situated the expectations of co-teaching, within the larger context — or expectations, of student teaching. Figure 2 is a representation of my thinking relative to the subservient role of the implementation of co-teaching to the larger context of student teaching.

Figure 2

Co-teaching Within the Larger Context of Student Teaching

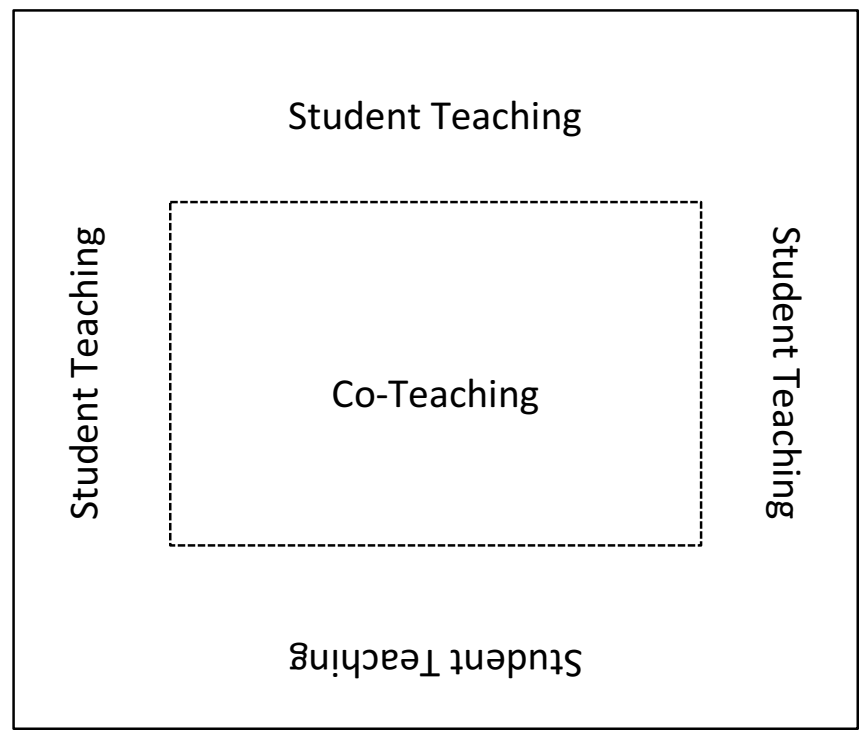




\section{A status passage analysis: Becoming a teacher while co-teaching.}

As previously stated, my core variable in this study, or the main issue relative to participants, was Transitioning from Student to Teacher Alongside the Teacher. By remaining grounded in the data, and through the use of theoretical codes, I identified two distinct passages. In the following sections, I will utilize the properties of status passage to analyze the first of these identified passages, Becoming a Teacher While Co-Teaching. I will begin by discussing temporal expectations relative to student teaching and co-teaching. Then, I will discuss the desirability or undesirability of this passage for all stakeholders. Next, I will consider the passage in terms of reversibility and inevitability. I will then conclude with a summary of my analysis.

\section{Temporal expectations.}

“Temporal expectations refer to any temporal aspects of status passage such as rate, transitional statuses, scheduling, or coordination" (Glaser \& Strauss, 2010, p. 34). Some of the main considerations relative to temporal expectations are (a) the degree to which they are known, and (b) who legitimizes the expectations.

In the case of this research there are two temporal layers to this experience. The first temporal layer is related to the overall student teaching expectations. The second layer is related to co-teaching. Figure 3 depicts how co-teaching, and its temporal expectations, was layered within the larger context of student teaching and its temporal expectations. 
Figure 3

Temporal Expectations: Co-Teaching Within Student Teaching

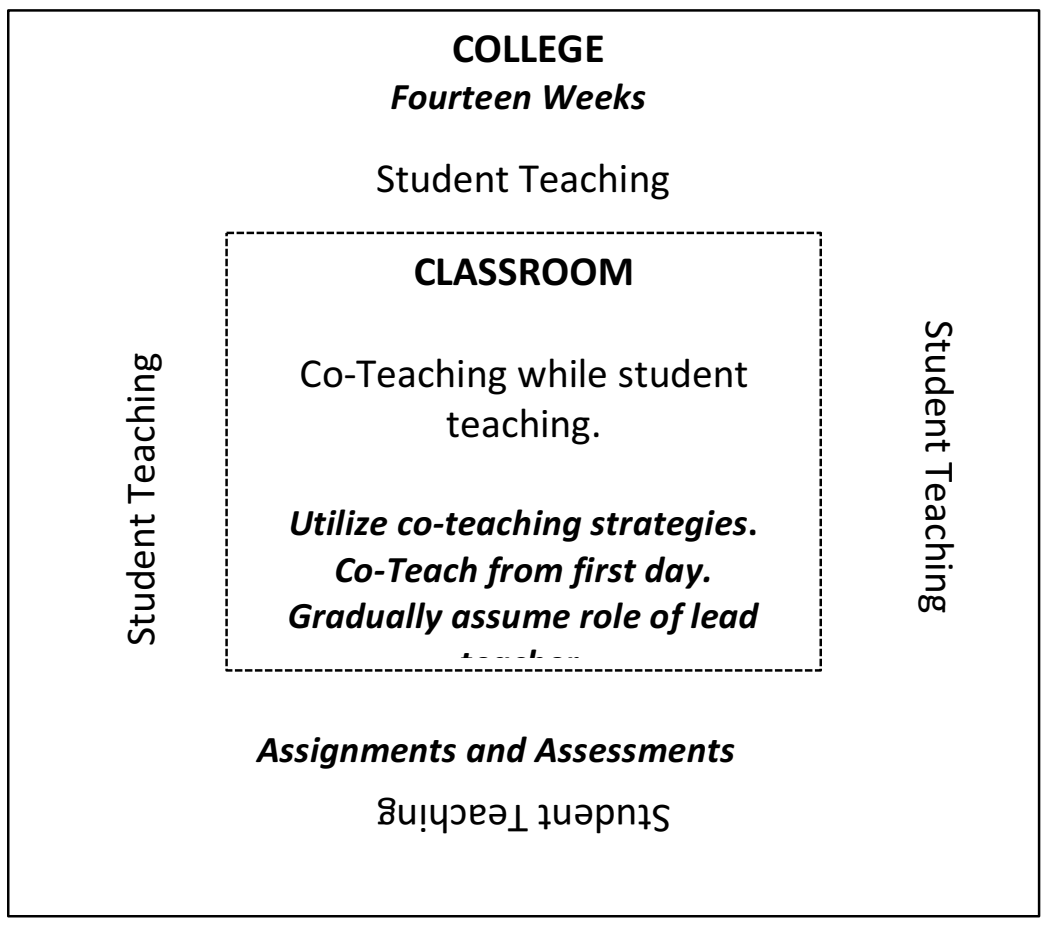

I will first address the temporal expectations as related to student teaching and will follow with a discussion of the temporal aspects relative to the implementation of co-teaching — as related to Becoming a Teacher While Co-Teaching.

\section{Student teaching.}

New England College's (2011) Student Teaching Handbook clearly articulates the temporal expectations for the student teaching experience. The handbook begins by defining (a) the overall objectives of the student teaching component, (b) key terms, and (c) the roles, requirements, and responsibilities of various stakeholders, including the cooperating teacher, the college supervisor, and the seminar instructor.

The cooperating teacher, as previously defined, is a certified elementary or early childhood teacher, who hosts the preservice teacher in his or her classroom, and who assists the preservice teacher in becoming a successful professional. The college 
supervisor is a New England College faculty member, full-time or adjunct, who is responsible for the supervision and evaluation of the student teacher in consultation with the cooperating teacher. Different college supervisors were assigned to the preservice teachers involved in this study. Seminar course instructors met weekly with the preservice teacher, and, like the college supervisors, varied. Glaser and Strauss (2010) would refer to the cooperating teachers, college supervisors, and seminar instructors as agents. These agents "legitimately determine temporal expectations and [have the] discretionary power to...announce them to others with some degree of clarity" (Glaser and Strauss, 2010, p. 24).

Also included in the handbook are the temporal expectations relative to time. Student teaching, for preservice teachers enrolled in early childhood and elementary programs, is to occur for a period of at least fourteen weeks. A "student teaching calendar" is also offered to provide guidance in terms of pacing. Specifically, the calendar is divided into three separate phases: (1) induction; (2) immersion; and (3) culmination. These three phases represent the traditional student teaching trajectory, which includes a period of observation (induction), a gradual takeover of the teaching responsibilities (immersion), and the release of teaching responsibilities back to the cooperating teacher (culmination).

The handbook also addresses (a) legal matters, (b) placement policies, and (c) the grading system, which clearly outlines two assessments that the preservice teachers must successfully complete while student teaching - the Teacher Candidate Work Sample (TCWS) and the Observation and Progress Reports (OPR). Briefly, the TCWS is a written unit plan, designed by the preservice teacher, which must be 
implemented in the classroom in which the preservice teacher is placed. The completion of the TCWS is guided by the seminar instructor and is comprised of six parts: (1) contextual factors; (2) goals; (3) assessment system; (4) deign for instruction - the unit; (5) assessment results; and (6) learning from practice- the reflection. The OPRs are rubrics used to guide the evaluation of the preservice teachers while they are engaged in teaching an approximately one-hour lesson. Six OPRs are completed during the course of the semester. The cooperating teacher completes three and three are completed by the college supervisor.

Remarkably, during our initial interviews, many of the preservice teachers reported that they had minimal expectations of the student teaching experience and, when they did have them at all, their expectations arose from conversations with peers. Table 3 contains excerpts from transcribed interviews relative to expectations of student teaching.

Table 3

Preservice Teachers' Expectations of Student Teaching

CV: “Um, I don't think I came in with any expectations cuz (sic) I, um, didn't know what I was going to be getting into...Like I didn't know if I'd be thrown into it the first day or if I'd be sitting back even with the, um, knowing that I was coming to HSS I just figured I'd go in the first day and see wha-what it was all about, what was going to happen." Expectations of student teaching 
I: What did you think student teaching was all about or what you, what you would be doing?

SM: Well, thinking about it, it, I felt like it was very vaguely described to us. Like I knew we were going to have to do like a work sample which is like has a unit plan and like contextual factors about the school and stuff like that, but, until like that semester came, I feel like I didn't know exactly what I was going to have to do...I don't wanna (sic) like blame anyone because...I could've asked more questions, I suppose I probably should have.” Expectations of student teaching

I: Did you have any, if you hadn't known that you were coming to Harold Shipyard, um, and you were just knowing student teaching is off in the future, did you have any expectations about it?

DB: I was extremely intimidated.

I: How come?

DB: I just, from what other people have said, who are older than me I know that it's a grueling experience and you learn a lot and you put a lot of work into it, um, also just not knowing where you would be or who your teacher would be or who the kids would be or where they come from. It's just a lot of the unknown is intimidating." Expectations of student teaching

I: Did you have any expectations about the student teaching experience? Did you have a vision of what student teaching would look like?

YO: Not really. And it's funny cuz (sic) one of my practicum courses had a student teacher in it, and she was very involved, um, but I was very anxious because I had no 
idea what to expect. Up until the meeting, the big meeting we had with all the supervisors and cooperating teachers and teacher candidates, I had no idea. Um, so, I felt anxious. And I think part of it was that you hear other people's stories and experiences and they're so different. They vary so much from school to school. And then the expectations, aside from the Teacher Candidate Work Sample that they tell us about, they don't really give us much information until that meeting. So, um, we were told, "Oh yeah, you'll have a supervisor," but their role wasn't really clear to me necessarily. And I didn't necessarily seek out the information either. I'm sure I could have found it if I did. Um, but I, I did not have many expectations at all, whatsoever, about student teaching, cuz (sic) I just felt very in the dark.

\section{Co-teaching.}

As previously stated, in order to implement co-teaching as a student teaching method, the participants in this study needed to have a basic understanding of the model. Because, as the researcher, I did not want to influence participants, the principal at Harold Shipyard arranged the logistics for several workshops to take place, securing a location, the time for the workshops, and a knowledgeable facilitator.

The facilitator chosen was a classroom teacher, who had taken part in a previous pilot study of co-teaching as an alternative student teaching method. To guide the workshops, the facilitator utilized resources provided by the Teacher Quality Enhancement Center (TQE) at St. Cloud University, including both video and print resources (Heck et al., 2010). 
Two sets of workshops were arranged. The first workshop involved all faculty members and administrators from Harold Shipyard and took place prior to the implementation of co-teaching. The workshop was held on a Friday afternoon, in early January 2016, as part of a scheduled Professional Development, and was meant to offer attendees (a) the history and theory behind co-teaching, (b) a chance to compare co-teaching to traditional practices, (c) current research related to co-teaching, (d) common language, (e) an introduction to the various co-teaching strategies, and (f) a description of roles and responsibilities.

The second workshop took place on the fourth day of student teaching, after preservice teachers and cooperating teachers had already begun working together. The facilitator positioned herself in a small room, adjacent to Harold Shipyard's main library, for the duration of the school day. Only cooperating teachers and preservice teachers who were co-teaching were invited. As cooperating teachers and the preservice teachers with whom they were working were available, they would attend a thirty-minute mini-workshop with the facilitator. This workshop was intended to (a) provide an opportunity for co-teachers to develop their relationship, (b) practice communication strategies, and (c) plan for effective co-planning/co-teaching. Because co-teaching took place within the larger context of student teaching, the temporal expectations outlined within the Student Teaching Handbook (New England College, 2010) applied to the co-teaching experience as well. These expectations included the duration of the experience, the key agents, and assessments, and the phasing into "immersion" or takeover. The only expectations that differed were (a) in terms of the "inclusion" phase, instead of acting as an observer, the 
preservice teachers were expected to co-teach alongside their cooperating teachers from the very first day of the experience, or as soon as was practical, and (b) instead of using the terms immersion, inclusion, and culmination, the facilitator informed participants that the preservice teachers, ultimately, "were expected to assume full responsibility for the classroom” (M. Nonis, personal communication, May 5, 2016).

\section{Desirability.}

When considering desirability in relation to status passage, several questions must be considered. For example, is the passage voluntary? Is the passage desirable to the passagee only, the agents only, or is it desirable to both? What are the stakes for the people involved and how do those stakes affect actions?

For the purposes of this study, the passagees, or preservice teachers, entered into the passage of Becoming a Teacher While Co-Teaching voluntarily. First, all of the preservice teachers voluntarily enrolled in their respective education programs with the understanding that they would eventually student teach. Second, all of the preservice teachers voluntarily took part in this study, knowing that they would be coteaching with their cooperating teachers.

Similarly, the cooperating teachers, as agents, entered into this passage voluntarily. They were not required to host a student teacher by the administration at Harold Shipyard nor were they required to co-teach and/or take part in this study.

Finally, other key agents such as the college supervisors or seminar instructors entered into the passage voluntarily, as part of their professional careers. Their involvement, however, was more closely related to the temporal requirements related to the student teaching experience versus the implementation of co-teaching. 
All stakeholders in the passage both desired the passage and had a vested interest in the successful completion of the passage for each preservice teacher. This high degree of desirability coupled with vested interests, according to Glaser and Strauss (2010), makes cooperation a dominant characteristic. In terms of cooperation as related to this study, the college supervisors and seminar instructors were accepting of the co-teaching model.

For cooperating teachers, their cooperation was related both to the program requirements and the college supervisors and seminar instructors who oversaw these requirements, and to the preservice teachers themselves. Figure 4 illustrates the relationship the cooperating teachers had to both the agents and passagees.

Figure 4

Cooperating Teachers: Cooperation With Agents and Passagees

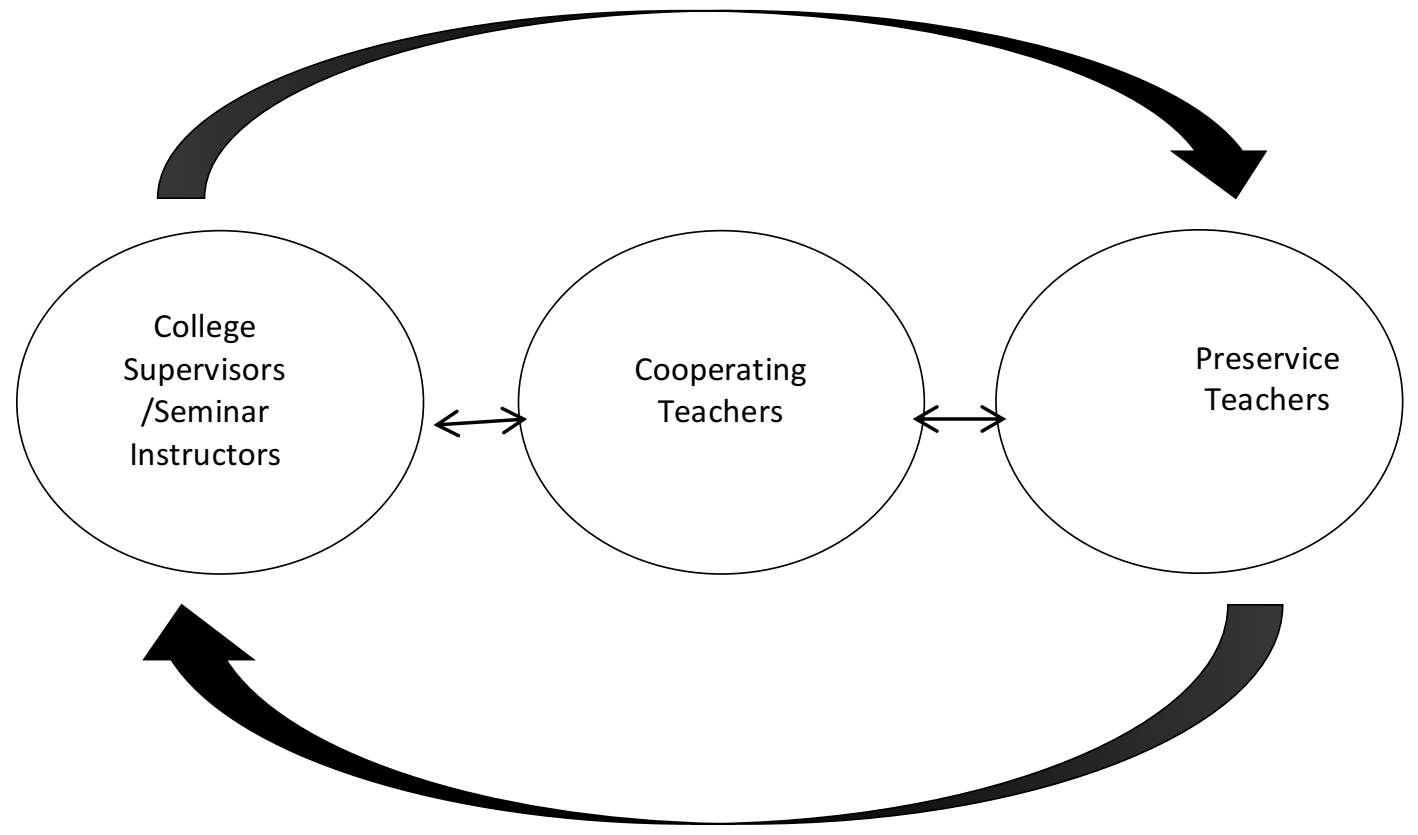


In terms of cooperation relative to temporal expectations, namely the OPR, the cooperating teachers generally interrupted co-teaching when college supervisors observed the preservice teachers, or used co-teaching strategies such as station teaching or parallel teaching, which would allow the college supervisors to see the preservice teachers teaching alone. They also allowed for changes within their classroom curriculum to accommodate the TCWS.

Additionally, the cooperating teachers helped their preservice teachers navigate program requirements, as related to the temporal expectations of student teaching, and requirements within the classroom. They also often reflected on their own personalities in terms of making the co-teaching relationship work. Table 4 includes excerpts from transcribed interviews as evidence of the cooperating teachers' roles related to cooperation.

Table 4

Cooperating Teachers: Evidence of Cooperation

CL: "I'm not really good with assessment. That's not a good thing to say as a teacher. But I'm not. Um, and she cam- - her Teacher Candidate Sample, that, that one thing that we've talked about was something I never thought of doing with the kids."

\section{TCWS}

BN: “And I think that we've transitioned more, we had a meeting with, um...her supervisor...um, and he asked, you know, what the, I think he's, he's used to more traditional student teaching that has a trajectory. And he, he asked, you know, what our plan was. "Have you put it on paper for, for when she really, um, takes more 
ownership?" Because we were, we were planning together...and he, I think his feeling was that she really needed the opportunity to, to manage more of it...Um, so we sat down with a calendar and we $\mathrm{pl}$ —we planned the planning." Supervisor

HR: “Um, I think there were, I'm not going to say problems. I think, um, there were maybe some misunderstandings in the beginning. And I think we ironed them out. I started, um, giving her more work to do...she thought I was asking for plans, full plans, like written plans. I go, "No, I'm not asking for full written plans.” I go, “really, only when you do your o-you know, when you have your observations." So I think that gave her a lot of like, it gave her, like I could just see the stress leaving her body." Planning; TCWS

ES: "I think that I'm trying really hard on being, not, I think when I first started taking on student teachers...it was really hard for me because I like things done in a certain way...and I've been working on that...my role is also to be here for these candidates." Letting go; relinquishing control

In terms of the preservice teachers and cooperation, evidence of cooperation with the college supervisors and seminar instructors was not present and perhaps not surprising due to the coordinated temporal nature of this passage. The preservice teachers knew the temporal expectations for successful completion of student teaching, namely the duration of the experience and the assignments and assessments, and fulfilled the expectations.

Cooperation by preservice teachers was directed, instead, toward the cooperating teachers. Not surprisingly, the preservice teachers were aware of the 
power differential between the cooperating teachers and themselves, and attempted to acclimate to the cooperating teacher's way of doing things. Table 5 offers evidence related to the preservice teachers and cooperation.

Table 5

Preservice Teachers: Evidence of Cooperation

DB: “I never want to step on anybody's toes...I think everyone holds you to a very high standard here." Go with the flow

LP: “And I'm not gonna (sic) tell her how to, if she, if that's how she wants the kids, that's fine. It's her classroom" View of Power Differential

VR: "I can't change the expectations in the class, nor do I want to because she runs her class this way. This is her classroom, it's not mine." The teacher; hierarchy

SM: "She's a veteran teacher so she definitely knows, like how to, definitely knows how to do things that I'm still learning. So I'm like, kind of like, uh, piggybacking off what she's doing to find my own way right now." The teacher; hierarchy

VR: "So, yeah. I'm trying to make it easier for myself. I tried my best to fit exactly what, into what she was doing." Go with the flow

\section{Reversible or Nonreversible.}

According to Glaser and Strauss (2010), reversibility refers to a change in direction of the passage arising from structural and/or personal conditions. In this case, the passage to Becoming a Teacher While Co-Teaching would be reversed. The 
likelihood of the passage being reversed is closely connected with the person making the passage and with other agents.

An agent is someone who causes something to happen or exerts power (Merriam-Webster, 2016). When considering the passage to Becoming a Teacher While Co-Teaching, there are several key agents including the preservice teacher's college supervisor, her seminar course instructor, and the cooperating teacher with whom the preservice teacher is paired. These agents have the power to prevent reversibility, to "ensure that no changes occur in the direction of the passage" (Glaser \& Strauss, 2010, p. 14).

The college supervisors visited the classrooms in which the preservice teachers were assigned three times over the course of the semester with the purpose of completing three separate OPRs. Following their observations, the college supervisors conferred with the preservice teachers and cooperating teachers to "[inform] the cooperating teacher and teacher candidate of specific strengths and weaknesses of the teacher candidate and solicit information from the cooperating teacher in order to address the professional development of the teacher candidate" (New England College, 2016.). Additionally, the college supervisor was expected to "[serve] as a resource person by providing counseling for individual teacher candidates concerning professional problems and/or personal problems" if necessary (New England College, 2016).

Seminar course instructors met weekly with the preservice teachers. The main responsibilities of the seminar instructors was to "engage teacher candidates in reflective discussions, guide their planning, and assist candidates with the 
development of their TCWS. They [also] confer with college supervisors assuring that candidates have a productive learning experience" (New England College, 2016).

In terms of Becoming a Teacher While Co-Teaching and this particular case, all of these agents facilitated the process. The college supervisors and seminar instructors fulfilled their responsibilities in ensuring assessments and assignments, the OPRs and the TCWS, were successfully completed on time, thus, preventing reversals in the passage. Interestingly, all of the cooperating teachers also took steps while coteaching with their preservice teachers, to ensure that their preservice teachers would successfully complete those requirements. Table 6 provides excerpts from transcribed interviews indicating the cooperating teachers' role in preventing reversibility.

Table 6

Excerpts from Transcribed Interviews: Preventing Reversibility

HR: "If she needs to do something, okay, like I know something is due for her tomorrow and I said, "Listen, if you need to take some time, I can take over.'”' Program requirements; TCWS

BN: "She was putting a lot of time into [the TCWS] and it was, like I think she was doing less planning in the beginning because she was getting those pieces done. She's not anymore." TCWS

ES: “A lot, the student teachers, the co-teachers, they're really stressed with all the stuff they have to do with their seminar classes, so that impacts what they do here, too. You know? They're, they know that this, this is a full-time job, and this is so much work and then, but they're also worried about what they have to do for Chalk \& Wire, 
what they have to do for their courses, those extensive lesson plans, all those contextual factors, the asses - all the different pieces to the Candidate Work Sample, and, that they have to have done for their class. That impacts a lot, you know, cuz (sic) then I feel like, “Oh, I feel bad. I don't want to tell her that she's gotta (sic) plan these two lessons for tomorrow and she's gotta (sic) correct all these papers for tomorrow because she has to write that paper for her seminar!"” $\mathbf{T C W S}$

HR: "There was one thing, like, um, we had a difference of opinion on, um, something in the lesson plan. And I know it's not, it's not major, but it bothered me because I really felt like, um, it wasn't correct. But, you know what, it was her supervisor so that's the way she did it.

I: Okay, so you differed from what he wanted in that lesson plan?

HR: Mm hmm.

I: And she followed his way?

HR: Yes. In all the lesson plans. College Supervisor

Perhaps more interestingly, all of the cooperating teachers also reported holding back aspects of teaching. In general, the cooperating teachers shielded the preservice teachers from a variety of responsibilities including, but not limited to, correcting papers, communicating with families, assembling homework, and completing progress reports. Said one teacher: "They have no idea what's behind the curtain."

According to Glaser and Strauss (2010), "because agents are often in control of many of the processes of a given passage, they can for personal reasons make phasing 
tough or easy for the passagee" (p. 28). For example, agents may be fearful of making the passage, even if it is a voluntary one, too difficult in the beginning for fear of disillusioning the passagee. The disillusionment may, in the agent's eyes, lead to a reversal in the passage.

Agents may or may not disclose their personal reasons for concealing aspects of the passage (Glaser \& Strauss, 2010). In the case of this work, the cooperating teachers were mostly open about their personal reasons for holding back some aspects of teaching. Table 7 includes excerpts from transcribed interviews which detail what was held back and/or why.

Table 7

Holding Back Aspects of Teaching: Personal Reasons Why

HR: "There were a couple of times where, um, I had her looking at emails if, if I wanted her to see something, just so, you know, it was maybe something that I'm like, "I feel like you need to be aware that things like this happen." But for the most part I still had the administrative type duties where I feel like she really couldn't take over those parts...I don't feel like it had to do with control it just had to do with, I, I just feel unable." Holding back.

BN: "I always have this feeling at the end of student teaching where I think everything got so busy that, you know, she didn't look at a report card, um, or really understand, like, the bigger picture when it came to assessments or, um, ever even read a newsletter that I wrote. Or, you know, I go through this list of things, um, that always happens. Like there's just never enough time and they're always just overwhelmed 
enough that, um, throwing one more thing on, but I think that might be the job. It makes me wonder if the job is a little bit, um, it just feels like a lot. Um, so I don't know, I don't know that she didn't, I mean she took over implementing plans for a couple weeks. She took o- and, and most of that, um, you know she did some of the planning. I just did most of the planning." Time; Holding back.

ZP: "I did the correcting for fear that it wasn't going to get done...I would be concerned if there wasn't feedback on their paper for them to learn why their mistake was what it was...Like never would I allow her to correct some papers and then just put it in their...folder and send it home." Holding back; relinquishing control.

ES: "It's still not the whole picture. She, well, answering the emails no, but I always cc'd her on every major correspondence, you know, so she was in the loop, but, but...I was the one who was constructing the emails, but I always cc'd her so she could see the kinds of stuff we have to deal with. Um, but, um, she, I made su-I made her do the homework but, but then I was like, oh but, you know what, she was coming up with the math homework, taking care of all that, but, um, and then when there were tests, like if the tests were already made, it was just easier, like, you know, like it wasn't like she was making tests up. Or I might have had her come up with the challenge questions, so she would have a part in it. Um, the spelling homework, I was still pretty much, you know like that was, it's pretty basic, our spelling, so, and would just, "You know, okay.”...She's correcting papers. You know, she was doing that. But, but we planed a lot together." Taking over. 
I: Are you holding back on some things?

ZP: Yeah, yeah. I, I feel bad for her...I can't, I can't, I don't think I can let her do all, ask her to do all that. I don't think she can do it.

I: Right. So give me an example of something you're holding back on.

ZP: Um, (sigh) everything.

\section{Inevitability.}

Although the passage to Becoming a Teacher While Co-Teaching is reversible, in this research, key agents prevented it and the passage was not reversed for any of the participants. As a result, the passage became almost inevitable.

When one thinks of the word inevitable, one may tend to think in terms of certainty. Inevitable, however, has as its synonyms unavoidable, predictable, or expected. As previously stated, student teaching is the culminating experience for preservice teachers on their journey to licensure, or, to Becoming a Teacher. Is that passage inevitable? Does co-teaching affect the probability of a successful passage?

My initial thinking led me to believe that the passage was not certain. After all, it is quite easy to think of circumstances that may impede the inevitability of becoming a teacher as part of the student teaching experience. A preservice teacher may not be adequately prepared or may become suddenly disabled. These events would surely impede the passage.

In my re-reading of Glaser and Strauss (2010), however, I came to realize the role that institutions have in managing, directing, and controlling passages, and, that 
the likelihood of a preservice teacher not making the passage during student teaching to Becoming a Teacher While Co-Teaching, is, in fact, unlikely.

A return to my data, namely extant texts outlining the various degree requirements relative to the participants in my study, underscores the organizational features relative to this passage. Preservice teachers, before being eligible to student teach must successfully complete a predetermined course of study, earn a determined number of credits, pass qualifying examinations, undergo background checks, complete community service requirements, and maintain a minimum grade point average. They also must attend meetings prior to beginning to student teach and attend weekly seminars.

As Glaser and Strauss (2010) state, "to the degree that the phasing and rate of passage is clearly determinate...organizations...can be delineated for handling specific transitional statuses within the total passage....schools graduate...students on schedule; holding people back is infrequent" (p. 15). In terms of this particular case, agents, operating under the expectations for student teaching at New England College, managed, directed, and controlled the passages, making the passage to Becoming a Teacher While Co-Teaching, generally inevitable for all of the preservice teachers involved in this study.

\section{Summary of question 1 .}

The Harold Shipyard School (2016) webpage maintains that one of the school's roles is to "provide for observation in a setting of quality educational practice." Similarly, under its "Guiding Principles" it states, that "as an exemplary laboratory school...we provide a vibrant, educational environment for our future 
educators in training to be cultivated, polished and enhanced for any career opportunity because of the HSS experience.” As such, the faculty, staff, and administration at Harold Shipyard regularly welcome and host scores of practicum students and student teachers.

Perhaps due to the constant presence of New England College students, the cooperating teachers at Harold Shipyard are generally hospitable. In fact, remarkably, all of the preservice teachers in this study reported positive working relationships with their cooperating teachers. Table 8 provides evidence of these positive working relationships.

Table 8

Evidence of Positive Working Relationships

DB: "Since the start we've been really natural in the classroom and it's just continued." Getting along

CV: I was surprised at how good of a match it was...it was just interesting to see how that happened." Relationship

YO: "We have a good relationship. I have a lot of respect for her and I've learned a

lot from her." Relationship

CB: "I think things are going really well. Um, we, I think we both have kind of the same teaching style...I think Amy is a great teacher...and I'm learning a lot.”

The positive remarks provided by the preservice teachers may relate to the willingness of the cooperating teachers to (a) cooperate with the preservice teachers in 
terms of their college requirements and (b) hold back aspects of the profession in an effort to make the passage easier. Additionally, for their part, all of the preservice teachers were very accepting of the hierarchy and worked in accordance with the cooperating teachers' expectations. Table 9 provides statements related to the acceptance of the hierarchy drawn from transcribed interviews.

Table 9

Evidence of Acceptance of Hierarchy

VR: “But I still think there's gonna (sic) be that hierarchy and it's not a, it's not a bad thing but I think that's natural in ou-in our particular setting...if you remove a hierarchy there's a lot more opportunity for conflict, you know...I would never argue about her decision because I think most of her decisions are right.” Hierarchy

I: Is the hierarchy still present?

SM: "I think in some ways it, it is, only because, um, I am a student teacher so I'm still, I'm not like a professional teacher where I'm at, like, like the same level almost. I'm still, um, learning and it's not my profession yet. She is higher than me because she's, like, the, my cooperating teacher, the lead teacher in the room." Hierarchy

DB: "I knew from day one that the standards that you're held to here are so high...I'm being compared to all these teachers with at least a master's degree, who have been teaching for so long." View of experience

I: Do you feel, even though you and Terry are very similar...

CV: $\mathrm{Mm}$ hmm... 
I: ...do you feel that a hierarchy still exists?

CV: Of course, of course a hierarchy exists. I'm a student teacher...it's also there not just because, um, of our roles and position, but also because she's been teaching for so long. There's so much more that she's seen and done and understands that, um, I'm also really grateful that I have her for my teacher because she has so much experience for me to learn from." Hierarchy

Co-teaching, perhaps due to the preparatory workshop and its position within the larger context of student teaching, unfolded in much the same way across the seven classrooms. All of the preservice teachers reported being involved in classroom activities from the very first day. All participants also reported that they (a) sat down together weekly to plan for the following week, (b) reflected daily, on an informal basis, regarding lessons and student progress, and (c) used all of the various coteaching strategies in flexible ways. Both the cooperating teachers and the preservice teachers also reported that, while co-teaching, all of the college requirements, as related to student teaching expectations, were successfully completed.

The temporal expectations of student teaching, clearly articulated in terms of duration, phases, and key checkpoints (i.e., the completion of six OPRs and TCWS) establish a shape to the passage, Becoming a Teacher While Co-Teaching. "One basic way of controlling the shape of a status passage is to prescribe its direction and schedule...agents and passagees can expect what the shape of the passage will be with a strong degree of certainty before entering it and while they are in it" (Glaser \& 
Strauss, 2010, p. 58). Figure 5 is my interpretation of the shape of the passage, from the view of the agents, for this particular case.

Figure 5

Shape of Becoming a Teacher While Co-Teaching: View of Agents

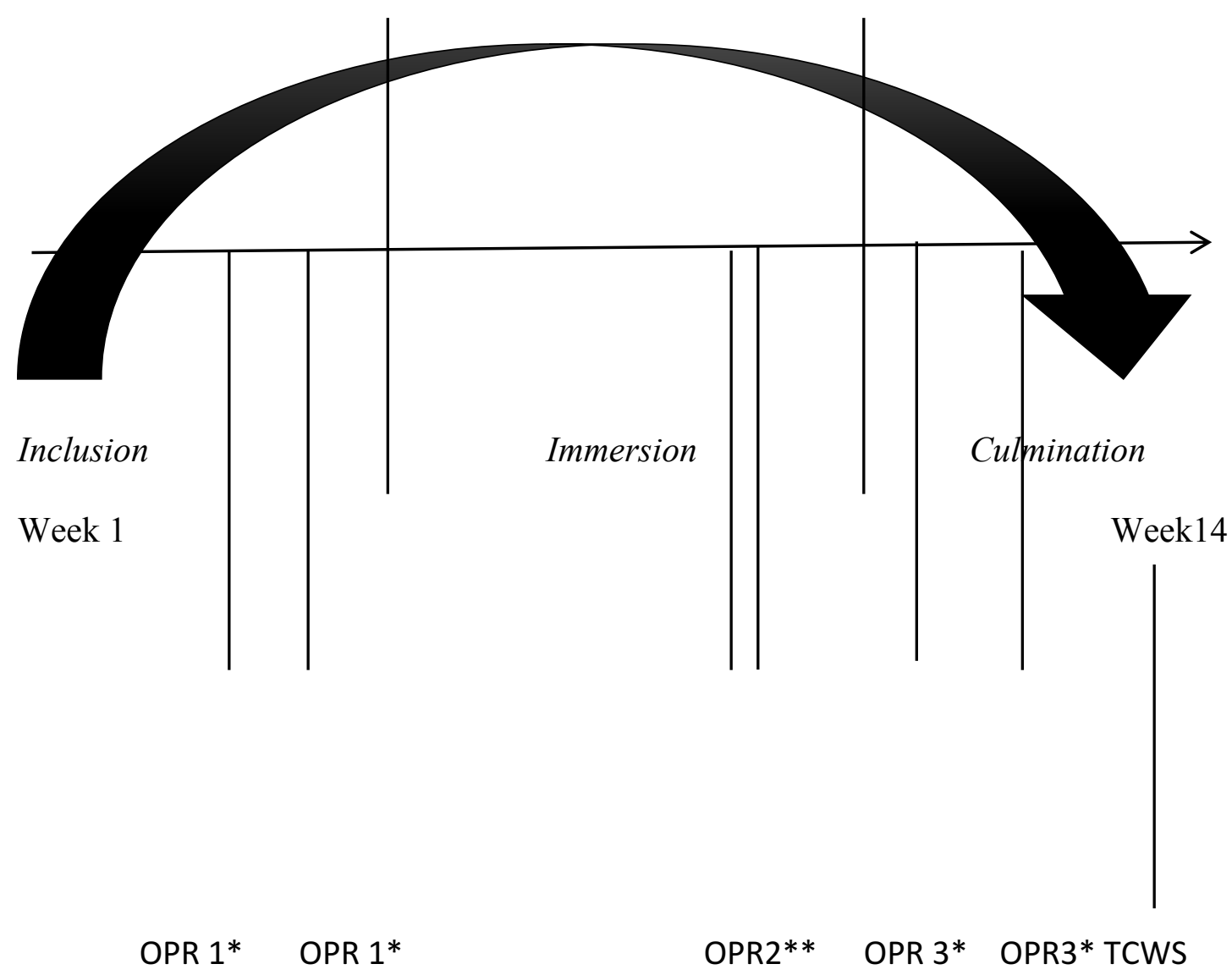

*Done by cooperating teacher or college supervisor

**Done by both cooperating teacher and college supervisor, simultaneously

Despite claiming that they had no expectations for student teaching, the preservice teachers did have an understanding of the duration of the student teaching 
experience and expectations relative to assignments and assessments. Figure 6 is my interpretation of the passage through the eyes of the preservice teachers.

Figure 6

Shape Becoming a Teacher While Co-Teaching; The Preservice Teacher's View

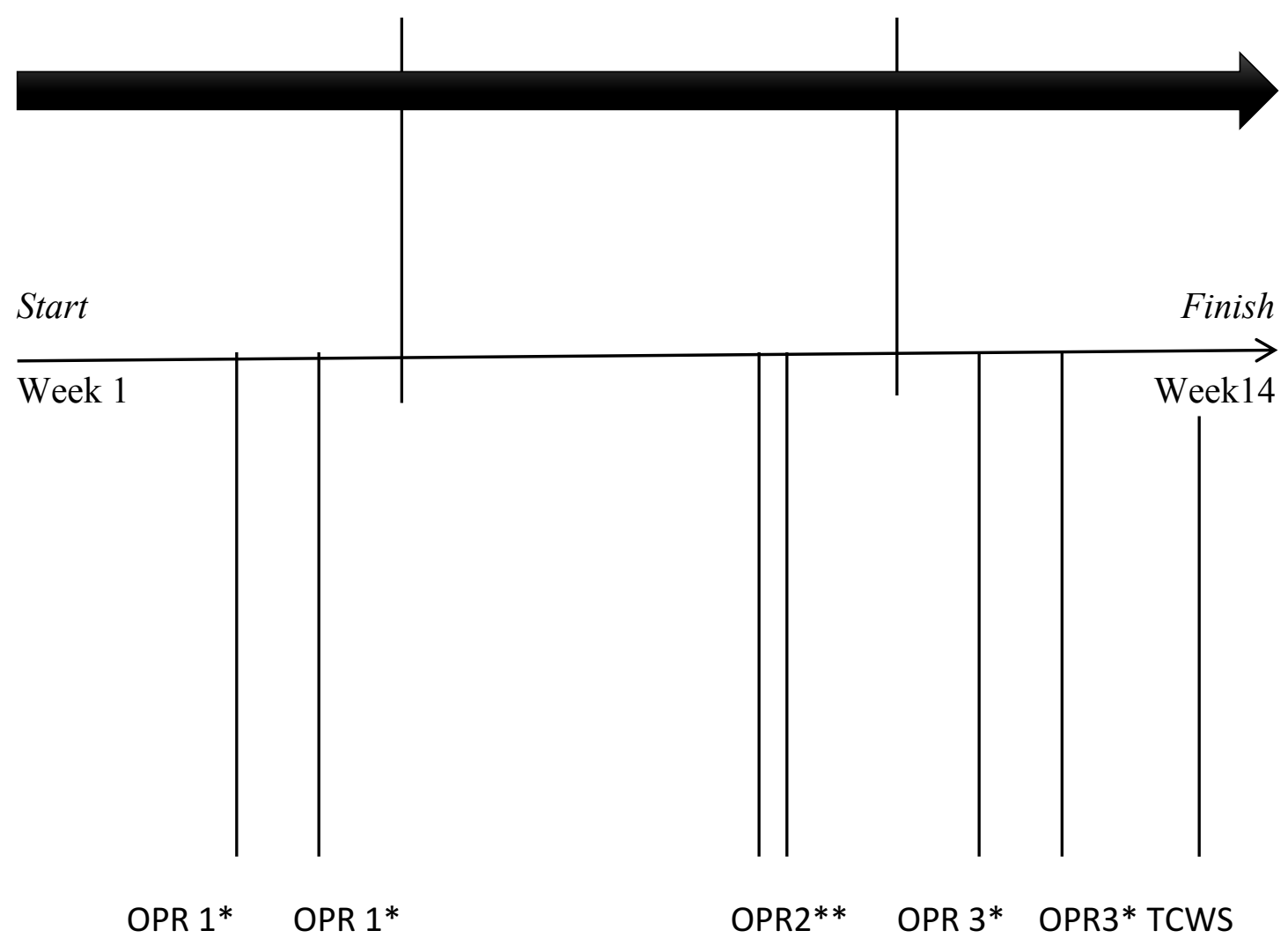

*Done by cooperating teacher or college supervisor

**Done by both cooperating teacher and college supervisor, simultaneously

"The certainty of such prescribed passages (which typically occur in large institutions, organizations, or services) enables everyone to recognize both when a passage is out of shape and the manifest reasons for that misshapenness" (Glaser \& Strauss, 2010, p. 59). In the case of this research, the shape and directionality of the 
passage remained stable due to both the actions of the passagees and the agents. The passagees accepted the hierarchy and acclimated themselves to the classrooms to which they were assigned; they also successfully completed the required assessments and assignments. The cooperating teachers both shielded the preservice teachers from certain aspects of the profession and prevented reversibility through cooperation with the preservice teachers, college supervisors, and seminar instructors. Finally, the college supervisors and seminar instructors were cooperative in terms of their acceptance of the co-teaching model. Additionally, they helped to ensure that the shape of the passage remained intact by guiding the preservice teachers through the temporal aspects of student teaching.

In sum, the implementation of co-teaching did not affect the status passage. How co-teaching was implemented, in terms of Becoming a Teacher While CoTeaching, occurred in much the same way as the more traditional model would have been implemented - embedded in the larger context of student teaching. As such, the temporal expectations of New England College, and the key agents involved, clearly articulated the shape of the passage and ensured its nonreversibility, and, inevitability for this particular case.

\section{Question 2: If differences in implementation are found, why do these differences} exist?

\section{Overview.}

In the introduction to this current chapter, I identified the core variable of this study, or main issue of the participants, as Transitioning from Student to Teacher 
Alongside the Teacher. I then separated the core variable into two distinct passages, Becoming a Teacher While Co-Teaching and Taking the Lead While Co-Teaching.

In all of the classrooms, both the cooperating and preservice teachers reported using all of the co-teaching strategies in flexible ways. They also stated that sometimes they specifically planned to use these strategies and sometimes they just occurred naturally. During our second interview I asked participants to review a list of the strategies and comment on which ones they were utilizing. Table 10 contains excerpts from selected interviews detailing the use of co-teaching strategies.

Table 10

Use of Co-Teaching Strategies Across Classrooms

CL: "We use all of them, um, we use one teac — I would say all day long we use a lot of it. Um, I mean one teach/one obs-like I mean this morning we both taught. One would teach, the other would kind of jump in. Kind of that sort of thing. One teach/ one assist, we do that. Um, teaching stations are our centers. I take charge of one or two centers. She takes charge of one or two centers. So that's kind of that kind of teaching....I don't know which one. I think we use them all." Strategy use

AC: "We use one teach/one assist. And I think we've been doing a lot of the team teaching too...we just haven't done any parallel...we have so many things going on we just haven't got to it." Strategy use

ZP: "We use almost all, almost all of them except we haven't done parallel." Strategy use 
TH: "We're following...the different possibilities that co-teaching offers...we do a lot of these [strategies]. I would say towards the beginning it was more one teach/one observe. I'd say one teach/one assist happened a bunch and happens still. Station teaching happens a bunch. Parallel teaching, that's what we're starting now. Um, supplemental, she's done a little of that. Alternative teaching, we've done a little of that...team teaching a bit." Strategy use

While all participants indicated that they used a variety of co-teaching strategies within their classrooms, Taking the Lead While Co-Teaching, emerged, from the data, as a key concern for both the preservice and cooperating teachers implementing co-teaching as a student teaching method. As one participant said, "I think what's relevant to the research, maybe is, about this coexistence of having the co-teaching model but still working, but, how important is still that time where they take over, which is more of a traditional. So, I think that's pretty relevant to this research. Do we still need, do we need to get rid of that altogether? Or, do we still need, is that still a valuable piece of this?"

In their discussion of the myths and realities of co-teaching, Heck et al. (2010) state:

Teacher candidates who co-teach are expected to take full responsibility of the classroom by leading the planning, organization, delivery and assessment of instruction. Candidates learn skills necessary to effectively manage human resources by directing other adults, including the cooperating teacher (p. 94). 
During the preparatory co-teaching workshop, held for the purposes of this study on day four of the student teaching experience, the facilitator established this expectation for both the preservice and cooperating teachers. This status passage, howeverTaking the Lead While Co-Teaching-varied from classroom to classroom with some preservice teachers mostly taking the lead, some never taking the lead, and some falling somewhere in between these two extremes. In figure 7, I have attempted to illustrate my interpretation of each preservice teacher's place along this continuum.

Figure 7

Taking the Lead: Preservice Teachers Placed on the Continuum

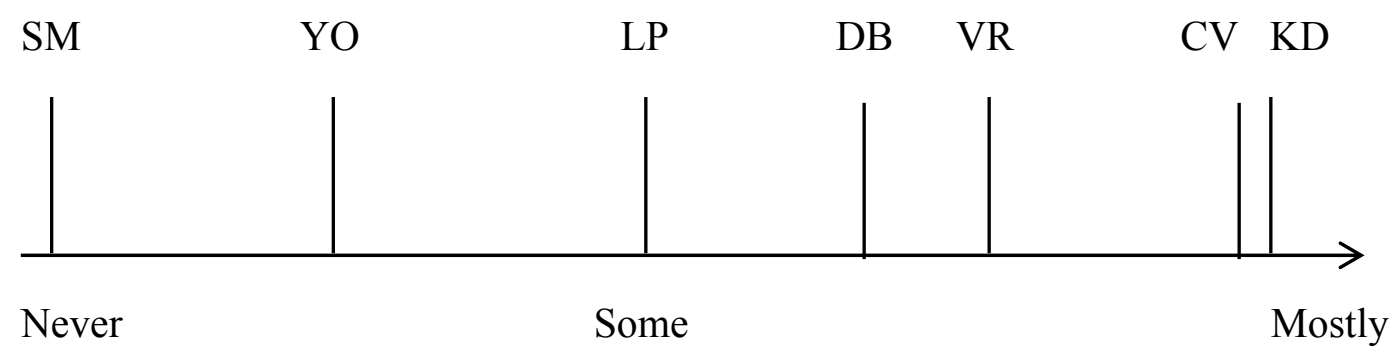

\section{A status passage analysis: Taking the Lead While Co-Teaching.}

I have elected to use the properties of status passage as a way to analyze this concern, and, to answer question two, or why differences in implementation exist. As I did while answering question one, I will begin by discussing temporal expectations, in this case, related to Taking the Lead While Co-Teaching. Next, I will offer my interpretations relative to the desirability or undesirability by the preservice and cooperating teachers in terms of making this passage. Then, I will discuss factors that emerged related to reversibility. Finally, I will conclude with a summary of my analysis. 


\section{Temporality.}

As previously stated, "temporal expectations refer to any temporal aspects of status passage such as rate, transitional statuses, scheduling, or coordination" (Glaser \& Strauss, 2010, p. 34). In contrast to the fairly regularized temporal expectations for Becoming a Teacher as established by the college, temporal expectations relative to Taking the Lead While Co-Teaching were only loosely scheduled and/or defined, which caused great variation when comparing the passages of participants.

Temporal expectations can vary from known to completely unknown (Glaser \& Strauss, 2010). In the case of this research, both the preservice and cooperating teachers were informed during the preparatory workshop that the preservice teachers were expected to eventually assume full responsibility for the classroom, or, to Take the Lead. The rate, transitional statuses, scheduling, and coordination were left, however, up to the preservice and cooperating teachers.

In New England College's (2011) Student Teaching Handbook, guidelines are offered for traditional student teaching placements relative to rates and transitional statuses. Preservice teachers are expected to complete phase one, induction, during the first two weeks of their placement. During this phase preservice teachers are expected to observe and become acclimated to the classroom and the school. Phase two, which spans weeks three through twelve, is labeled immersion. During this phase preservice teachers are expected to gradually assume full responsibility for the classroom, and to maintain full responsibility for a minimum of four weeks. Phase three, labeled culmination, occurs during the last two weeks of student teaching, and 
involves the preservice teacher transitioning the classroom back to the cooperating teacher.

While all the participants in this study were at least somewhat aware of the traditional model of student teaching, its pacing, and its associated transitional statuses - immersion, inclusion, and culmination — only some of the cooperating teachers transferred the pacing relative to these phases to Taking the Lead While CoTeaching, while also keeping within a co-teaching framework. In other words, while co-teaching, four of the cooperating teachers maintained the general pacing relative to the traditional guidelines. These teachers, in general, believed it was necessary for the preservice teachers to take over. Table 11 provides excerpts of transcribed interviews related to preservice teachers taking the lead.

Table 11

Cooperating Teachers on Preservice Teachers Taking the Lead

HR: "I feel it's important to have the teacher or, um, the student teacher at one point take over the class...I feel like, for her to be truly prepared, she's going to have to be able to do it on her own." Taking Over.

TH: "So, um, and then I also think, at some point it's really valuable to have to run the class yourself and be in the room by yourself to learn to manage a class without the cooperating teacher there...I try to get out of the classroom as much as I can cuz (sic) I think that's a really valuable experience for them. "Taking Over; Pushing Forward

ES: "Which, you know, we're here for our co-teachers but I feel like, um, yeah, the 
only way to really learn and get used to it is by immediately dealing with the issues with the kids. Figuring out like how to, how would I run morning meeting? How am I going to transition them from the rug to the lining them up, like all that stuff's important. And I keep telling myself...like she's been with me six days, seven days, and I'm like, all right, I need to stop being the one to do, to direct, I, I need to now let her, you know, line them up and, cause all that stuff's important, too. Pushing forward; Taking the lead

AC: "I think, I think sometimes they think it's a ton of work. And they get really overwhelmed by the work sample and all the things that they have to do. But I think that they need to know it's a lot of work. That it's not coming and going and, it gets stressful." Viewing the Profession; Student to teacher

TH: "Um, my general tendency though is in general for the, me to start off with most of the responsibility and gradually, um, give up that responsibility to the co-teacher in increments. But by the end, as I said, they should have total responsibility, for at least, for a short amount of time." Taking over; Pushing forward

These cooperating teachers also reported feeling that their preservice teachers were ready to take on this responsibility. Table 12 offers statements, transcribed from interviews with the cooperating teachers, which relate viewing the preservice teachers as capable. 
Table 12

Cooperating Teachers on Viewing Preservice Teachers as Capable

ES: "So I feel that the co-teaching model is really, really beneficial. However, I think another, though, factor is the competency of the student, of the teacher candidate.

I: All right. So say more about that.

ES: Okay, so I think that this model is, is, it's great and wonderful, I mean it's great, but I think it's gonna (sic) be harder if you have a weaker candidate...but when you have someone great and someone strong, like Veronica, um...it's like a dream. It's so effective. Holding back; Pushing forward

TH: "She's a very bright woman and she picks up on how things work without having to be ex-explained at great length. And she takes a lot of initiative. So I don't have to ask her to do every little thing, she kind of sees what needs to happen and steps up to the plate. She puts a lot of thought and effort into any lessons that I ask her to prepare...I trust her to teach a good lesson and manage the class." View as capable.

AC: "I think, overall, she's worked with young kids. She had a job in a daycare before, um, student teaching. So I think she has that, you know, experience with kids." View as capable

I: "Do you feel like she was prepared to student teach?

HR: I do. I do. View as capable; preparation 
These four cooperating teachers, along with the preservice teachers with whom they were paired, established timelines for Taking the Lead. Glaser and Strauss (2010) refer to such timelines as "mini-schedules." These mini-schedules are often created when temporal expectations are generally unscheduled, and, are usually negotiated by the agent(s) and passagee. The mini-schedules, thus, inform the actions of the agent(s) and the passagee with the intention of moving the passagee forward and minimizing delays (Glaser \& Strauss, 2010). The rate and schedule of the passage is, thus, established.

"When temporal aspects are generally unknown or must be created arbitrarily anew, legitimators and their announcements are of great theoretical significance" (Glaser \& Strauss, 2010, p. 36). The above four cooperating teachers acted as the legitimators within their classrooms, negotiating mini-schedules with their preservice teachers, setting the rate and pacing of the passage. In a separate classroom, however, the acting legitimator was not the cooperating teacher, but the college supervisor.

In this particular classroom the cooperating teacher also felt as if the preservice teacher with whom she was paired was capable. During her first interview the cooperating teacher stated, "I really do think Yvonne showed up like ten steps ahead of any of my other co-teachers. So she didn't have big gaps in content...she was more ready...more like she was a partner than a practicum student." This idea of treating the preservice teacher as a "partner" versus a passagee transitioning from student to teacher, may have been due to several factors unique to this classroom.

First, the cooperating teacher in this classroom, although in her seventh year of teaching overall, was in her first year teaching at this particular grade level. As such, 
she was learning to teach at this grade level alongside her preservice teacher. Second, both the cooperating teacher and preservice teacher were relatively close in age. This similarity was unlike any other co-teaching pair. Third, the classroom in which these co-teaching partners worked was also unusual in that at least half the class, based on assessments, needed daily one-on-one interventions. An illustrative vignette, taken from my field notes, is included here to provide a snapshot of this particular classroom:

When I arrive, Yvonne is in hallway doing a running record. Beth is in teaching chair next to easel...Kids are giggly over an orange peel on rug. Beth talks about the work they are going to do...Kids go back to desks...Beth calls over four students for a conference...Yvonne returns...She gets a highlighter and shows Beth results of running record. "Her self correct rate was one-to-two," says Yvonne. "That's amazing," says Beth...Yvonne takes another student out into hallway to do a running record. There are lots of things in this room to accommodate special needs-special stools that swivel. Little cushions to put atop stools. Privacy shields. Headphones. A timer...Yvonne walks back in. Yvonne raises a shade...Yvonne says, "My goodness, you've gotten so much work done" to a child... "So here's what I'm thinking, " says Beth to Yvonne. She proceeds to tell Yvonne what she's thinking but I can't hear. I do see her hold her palm up and say, “for five minutes. ”...Beth rings a chime...says, ”If you can hear me wiggle your fingers. I want you to leave your pencils...Come on over to the rug. You need a break. "...Kids move to rug loudly. Yvonne runs the GoNoodle video...Beth goes to get her coffee at her desk and checks her phone. 
A review of my field notes led me to think that in this room, it was difficult to distinguish who was the cooperating teacher and who was the preservice teacher. In a follow up interview I asked the cooperating teacher, Beth, a question about the hierarchy:

I: There is a hierarchy...

BN: Right.

I: ...um, do you feel that affects anything?

BN: Yes, absolutely. Um, (pause) mmm, I feel like that has so much to do with the person too, um, it, it's actually really easy to think of, of Yvonne as a peer"

As previously discussed, the implementation of co-teaching occurred within the larger temporal expectations of student teaching. College supervisors, as agents, were instrumental in ensuring that the shape of the passage remained intact. In this particular classroom, the college supervisor, more familiar with the pacing and transitional statuses relative to the traditional student teaching model, had concerns that Yvonne was not assuming full responsibility for the classroom. Yvonne described his concerns during our second interview. An excerpt of that interview, along with my notes made during microanalysis (in bold italics), is included below:

"It's been kind of, the reason, what sparked the conversation was that, um, my supervisor is really adamant that I have that time...um, so he was like, "Well when are you gonna (sic) do it all?" ...(she tells him they are co-teaching, she continues quoting him)..."Yeah, but, like, you know, maybe you could co-plan" and he's like, "I 
just want to make sure you're getting," you know, I think he's so concerned about the college's requirement." She goes on to say that she will do all the planning and they will implement lessons together. She continues to reiterate that the student needs are driving things and they don't have a date for her to take over and she doesn't anticipate that happening.

In a follow-up interview, I asked Beth if she ever planned for Yvonne to take over. She replied: "We actually scripted on a calendar because when [her supervisor] came he was like, "What is she doing?" and I wasn't able to say she owns this, this, and this. Um, so when we planned it out we talked more about what she would plan, um, rather implement. And I did feel like I was stepping out and, and I went out of my way to, um, like sit down one day and clean my desk while she was, like do a lot to take myself out of...so I don't know."

In the case of this particular classroom, the college supervisor stepped in as legitimator. Beth and Yvonne responded to his concerns by negotiating their own mini-schedule for Taking the Lead.

Unlike in Beth and Yvonne's classroom, in all of the other classrooms the cooperating teachers acted as the legitimators or agents. Glaser and Strauss (2010) tell us that when a passage is unscheduled, or temporally unknown, "the legitimator... has more discretion in setting the timing" (p. 39). In the two remaining classrooms the cooperating teachers, acting as legitimators, exercised their discretion relative to the pacing and scheduling of the passage of Taking the Lead. 
In the first of these two classrooms, the cooperating teacher, like all of the other cooperating teachers already mentioned, clearly felt that the preservice teacher with whom she was paired was capable. During my first observation, early in the semester, the cooperating teacher said to me, "I could walk out and she could run this room." This teacher's view of Taking the Lead While Co-Teaching, however, varied in terms of her continued level of involvement. In her first interview she described what, for her, Taking the Lead the lead looked like: "I was always open. "Are you ready to take over? Go for it. You want to do morning meeting? It's all yours." You know, if they feel comfortable doing it with me on the side, I was fine with it."

This classroom was similar to Beth and Yvonne's in that the co-teaching pair acted more as partners. This partnership, however, was based on the cooperating teacher's desire to stay determinedly involved. Unlike Beth and Yvonne's classroom, the legitimator was the cooperating teacher and the college supervisor did not influence the actions of the co-teaching pair. The following vignette, drawn from my observational field notes, offers a glimpse into this particular classroom. Denise is the preservice teacher:

Denise leading a child in reading morning message. Denise is in main chair, up front. Celeste at side on stool. Celeste interjects quite a bit. "Can you hear him boys and girls? You have a very low voice!" says Celeste. Denise actually speaks softly, too. Celeste is loudest in group...Denise continues to lead child in reading morning message. Celeste instructs a child to throw something in the trash. Both teachers ask questions...Denise leads majority of discussion. Celeste interjects here and there but also does more re-direction of children who aren't paying attention...Celeste intros 
and activity of cubes in a box-red or blue...Denise moves over to stool near Celeste's desk. Celeste moves to larger chair...Celeste firmly in charge at this point...Denise does not interject as often as Celeste does.

While Celeste, as the cooperating teacher, was the legitimator of the passage, Denise did later negotiate a mini-schedule in terms of her view of Taking the Lead. Celeste, in our second interview, stated: "She has asked me several times, "When you had students before did they take over" and I said, "They did" and she says, "I, I really feel like I'm going to miss something if I don't get a chance to actually be in charge" and I said, "But you are. We're both, we're co-teaching. We're both in charge"...she says, "I know but, I don't, not sure that piece, that overall piece where you have the final say pretty much on what" and, and I do, I do...pretty much on whether it's going to work or not, she said, "I'd really like to try that..." I told her after report cards. We're gonna (sic) try it for a week or two." In this case, Celeste exercised her discretion relative to the pacing and scheduling of the passage of Taking the Lead.

In the last classroom, unlike the other six, the cooperating teacher did not feel as if her preservice teacher was capable. In our third interview I asked this cooperating teacher about letting go, and letting her preservice teacher Take the Lead. An excerpt of our interview follows:

I: You said it's hard to let...

ZP: Yeah..

I: ...go.

ZP: Um, honestly it depends on the student teacher. 
I: Okay.

ZP: Sometimes I appreciate and respect them so much so, that I am able to let that go. But some — uh, le - you know, it depends. Sometimes I'm very cautious and I'm very much afraid to give them the freedom.

I: If you feel like they're not...

ZP: If I feel like they're not going to [sighs] what's the, what's the word I'm looking for? Maybe if I feel like they're not ready. And sometimes it takes such a long time for me to believe that they're ready. I'll hesitate.

Interestingly, the preservice teacher in this classroom was the one preservice teacher who had a prior relationship with the cooperating teacher. This preservice teacher was initially placed, as a traditional student teacher, in another school during the fall 2015 semester. During our first interview she explained why she left her initial placement: "I left because it, it was, the classroom was not a good fit for me...I was not, like, meshing well with the classroom teacher, that, I wasn't ready, uh, as like, as a, like as a teacher right then." After leaving her placement she was assigned as an observer to my classroom, and the classroom in which she co-taught, as an observer/assistant for the remainder of the fall semester.

In our second interview I asked the cooperating teacher if she and her preservice teacher had established any type of timeline for Taking the Lead.

I: Have you sat with her and worked out any kind of a timeline? Does she know that in your mind you're thinking at some point she has to... 
ZP: Nah...

I: ...take over?

ZP: No. But...we've had a general conversation at recess with Veronica and Ellen so I think, you know, the seed was planted...

I: $\mathrm{Mm} \mathrm{hmm.}$

ZP: ...but I think she's just taking care of what's right in front of her...'Okay, no problem. No problem. Okay, I'll do that, okay, no problem.” But, I think it's a problem, I think she's just making believe it's not a problem.

I: You're very child centered...if she's not ready, would you let her take over, even if you thought that the children would...

VP: I won't. No. I won't. Not completely. Not completely.

In this classroom the preservice teacher did not ever take over, nor did she negotiate a mini-schedule to do so because, in her view, she was the lead. When I asked her, during interview two, what percentage of time she felt she was taking the lead, she responded, "Well, today it was like a hundred percent!"

\section{Summary.}

The temporal expectations for Taking the Lead While Co-Teaching were not regularly scheduled, and, as a result, temporal expectations across the seven classrooms varied. For the most part, the cooperating teachers legitimized the pacing and scheduling of Taking the Lead.

In four of the classrooms the cooperating teachers believed that it was necessary for their preservice teachers to take the lead. They also viewed their 
preservice teachers as capable. In these rooms the cooperating teachers negotiated mini-schedules with the preservice teachers related to Taking the Lead While CoTeaching, and oversaw, as agents, their passagees.

In the fifth classroom the cooperating teacher also viewed her preservice teacher as capable and a mini-schedule for taking the lead was also negotiated. This negotiation, however, resulted due to the temporal expectations of the college supervisor and his adherence to the regularly scheduled temporal expectations of traditional student teaching.

In the sixth classroom the cooperating teacher had an alternative view of Taking the Lead While Co-Teaching. While she, too, believed her preservice teacher to be capable, this teacher believed that while co-teaching both she and her preservice teachers were in the lead, as partners. The preservice teacher's view of Taking the Lead differed, however, with the preservice teacher wanting to have a greater say in the happenings of the classroom. A mini-schedule for Taking the Lead was eventually negotiated, however the cooperating teacher exercised her own discretion relative to the pacing and scheduling of the passage.

In the final, seventh, classroom, the cooperating teacher did not view her preservice teacher to be capable and, due to the unscheduled temporal expectations relative to Taking the Lead, was also able to exercise her own discretion. In this classroom the cooperating teacher did not negotiate a mini-schedule with her preservice teacher, nor did she allow her preservice teacher to completely Take the Lead. For her part, the preservice teacher did not attempt to negotiate a mini-schedule as she believed she was, actually, Taking the Lead. 


\section{Desirability.}

"The desirability of a status passage provides the motivational basis for actions that shape that passage...the strategic question about the desirability of a passage is "from whose viewpoint the passage is desirable or undesirable"" (Glaser \& Strauss, 2010, p. 89).

In terms of desirability related to Taking the Lead While Co-Teaching, there are several possible combinations of desirability or undesirability. Table 13 offers a visual representation of the four possible combinations.

Table 13

Desirability or Undesirability of Taking the Lead: Possible Combinations of Viewpoints by Cooperating and Preservice Teachers

\begin{tabular}{c|c}
\hline $\begin{array}{c}\text { Cooperating Teacher } \\
(\text { Agent })\end{array}$ & Preservice Teacher \\
(Passagee) \\
\hline Desirable & Desirable \\
\hline Desirable & Undesirable \\
\hline Undesirable & Desirable \\
\hline Undesirable & Undesirable \\
\hline
\end{tabular}

In the following sections, I will use these combinations to frame the discussion of the desirability, or undesirability, of both agents and passagees related to Taking the Lead While Co-Teaching. 


\section{Desirable/desirable.}

As previously stated, when a passage is desirable by both the agent and the passagee, "cooperation is its dominant characteristic... Both work together to make a desirable passage" (Glaser \& Strauss, 2010, p. 90).

Interestingly, in reexamining the seven co-teaching pairs, only two pairs initially entered into the passage, Taking the Lead While Co-Teaching, with both the agent and the passagee viewing the passage as desirable. In both of these classrooms, the cooperating teachers strongly believed that the preservice teachers should experience full control of the classroom. Said one cooperating teacher: "I really feel...I feel co-teaching is great once we get started, get them in, let them see me...but now I think at this point, I really do think it needs to shift to have, for her to have some time where it's her...her having the feel of having to plan an entire day or an entire week and all the components that go along with it...because sometimes, like, a lot of the stuff she might not even realize I'm doing, like she might not even realize until she has to do it by herself, what it feels like."

Similarly, the preservice teachers assigned to these cooperating teachers also had a strong desire to Take the Lead. Said one preservice teacher: "I feel like I'm losing the attention, respect, of the kids if I'm not fully in charge...I've been with the kids on my own which I love...I feel like I'm in my element."

"When a passage is mutually desirable both to agent and passagee, their cooperation may focus on negotiating mutually acceptable terms of the passage" ( $p$. 94). For these two sets of co-teachers, negotiations relative to the passage centered 
mainly on creating and maintaining mini-schedules, which were related to temporal expectations.

Additionally, when the passage is mutually desirable, "conflicts that might dissolve the passage are avoided" (Glaser \& Strauss, 2010, p. 94). Both the cooperating teachers and preservice teachers offered evidence relative to avoiding conflicts. Said one cooperating teacher: "I try to set up that the candidate feels comfortable and that they feel that they can come to me with anything. Or, um, and that they can, I also try to be very open with my time and feedback...I'm there for them and I'm listening to them." Said one preservice teacher: "This is my time to learn. I don't want to overstep my boundaries.”

\section{Desirable/undesirable.}

In two other classrooms the cooperating teachers, like the teachers above, also wanted their preservice teachers to Take the Lead. In these classrooms, however, the preservice teachers found the passage to be undesirable.

"Whether the agent tries to persuade the passagee to cooperate or forces him to go along with the passage depends upon the kind of power he has at hand and whether the situation is appropriate for its use" (Glaser \& Strauss, 2010, p. 102). In both of these classrooms the cooperating teachers exercised their authority and established the expectation that their preservice teachers would eventually Take the Lead.

"When the status passage is desirable only for the agent, then recalcitrance and conflict are likely to dominate it" (Glaser \& Strauss, 2010, p. 102). Because the passage Taking the Lead was situated within the larger passage of Becoming a Teacher (a passage that was desirable to both the cooperating teacher and the 
preservice teacher) conflicts, which would dissolve the larger passage, were avoided. In other words, despite not necessarily wanting to Take the Lead While Co-Teaching, both preservice teachers, desirable of completing the passage of Becoming a Teacher, complied.

In the first of these classrooms, the cooperating teacher stated, during our second interview: "I feel like she needs at least three to four weeks of being in charge on her own." This same cooperating teacher, however, modified her expectations based on her preservice teacher's resistance.

According to Glaser and Strauss (2010) agents, "even when not allowing complete choice....adjust the degree of choice that pertains to voluntariness or inevitability of the passage on its various dimensions" (p. 105). In our third interview, this same cooperating teacher stated: "She took over for about two full weeks...I really wanted it to be four weeks but she didn't want to do four weeks. But I thought it was really important for her to get the role of the lead teacher and to have that experience...they need to know it's a lot of work."

In the second classroom the cooperating teacher, Heather, did not adjust her expectations based on her preservice teacher's recalcitrance but, instead, asked her preservice teacher to consider her level of commitment. The cooperating teacher, in our second interview, stated: "She seemed very young and some of the things she said, like, "Oh, this is a lot of work" or this and, and I don't remember having to say...to a co-teacher or a student teacher, "Hey listen, this is it...Do you know, I'm s-it's a lot of work being a teacher. I mean I can't, I wish I could tell you differently, you know, but I can't. This is, this is it. I mean, it's a lot of work. Like I come in here on 
weekends sometimes. I'm here late. It just is what it is. You know? And you're gonna (sic) have to think about that and make sure this is really what you want to do."

In this classroom the preservice teacher, then, adjusted her actions based on the cooperating teacher's expectations. During our third interview she described her experience: "At first it was, like, really hard for me to get used to. Um, like everything, the whole teaching environment, getting used to the kids, how, um, to communicate with Heather at first was like a new experience for me. So, um, at the beginning it was rough and I did have one day where I was like, I was so overwhelmed, I left and I cried, I was like, “Oh my God. I can't.” But then I sat down with Heather. We talked about it and after we talked about it I started to, like, loosen up a little bit. I was like so focused on, like, everything needs to be done at once and now I take it day by day."

\section{Undesirable/desirable.}

In the case of one cooperating teacher the passage, Taking the Lead While CoTeaching, was not necessarily undesirable in a negative sense, but undesirable due to her own personality. The cooperating teacher stated: "I'm a take charge person. I'm very (sighs), some things I really like to do and I really want to do and it's very hard to give it up...I really want to do it...It's me, I'm more of a control freak so it's really hard to do."

The degree of desirability related to a passage, however, "is subject to change" (Glaser \& Strauss, 2010, p, 89). In this particular classroom the preservice teacher found the passage to be very desirable and quite openly expressed her desire to Take the Lead to her cooperating teacher. In our second interview the cooperating teacher 
stated: "She's gotten to the point now where she wants more...I think she wants to see if she can do it on her own... I think she wants to feel like she's really the lead."

The cooperating teacher, thus, readjusted her view of Taking the Lead While Co-Teaching to be, more or less, desirable. This co-teaching pair then negotiated the temporal expectations of this passage. In discussing the temporal aspects associated with Taking the Lead, the preservice teacher also eluded to her role in avoiding any potential conflicts, which would dissolve the passage. She said: "Actually, two weeks from now, we set the date, for, um, after parent conferences that I'm going to be doing a lot more of the planning. So I've been going home and I already have a master list going on. Some of them are her ideas, such as, um, symmetry and poetry, those are things she just hasn't gotten to yet. Um, and then a lot of things are my ideas, too...again, we're gonna (sic) keep doing the co-planning but with more, um, my research behind it so I'll kind of present to her, "These are my ideas" and we'll talk together of what we think will and will not work. And then I'm gonna (sic) be more involved in the classroom with actual teaching."

\section{Undesirable/undesirable.}

In the final two classrooms both the cooperating and preservice teachers found the passage, Taking the Lead While Co-Teaching, to be undesirable, but, for different reasons. Both of these classrooms have already been discussed at some length.

In the first of these classrooms, Beth and Yvonne's, the co-teaching pair preferred working as partners. Once Yvonne's college supervisor intervened, however, Beth and Yvonne negotiated a mini-schedule for Taking the Lead. 
In the second classroom the cooperating teacher did not believe her preservice teacher was capable, frequently referring to her as "young" throughout all three interviews. She, therefore, found the passage undesirable, and, as the agent or legitimator, did not allow her preservice teacher to ever completely Take the Lead. In turn, her preservice teacher, although stating that she was doing more and more within the classroom, indicated during interviews and through her actions that, perhaps unconsciously, she did not particularly find Taking the Lead to be desirable.

This preservice teacher, Sarah, was the same preservice teacher who was removed from another student teaching placement during the fall 2015 semester. In our first interview, when discussing that student teaching experience, the preservice teacher stated: “I didn't know I was going to have to take over the entire class eventually. Um, I guess I felt like it was more of, like, a TA position...and then when I found out that I was going to have to, like, take over the whole class, I was kind of surprised in a way...I kind of thought it was going to be like practicum."

I followed up with a question pertaining to what she hoped to gain from the current student teaching experience. Sarah responded: "When I have to, like, stand up in front of everyone even though I, I know them all and I'm like friends with them all, like I, like I'm the, I'm their teacher, I get really, really nervous which affects my performance. Um, so I'm working on being more confident while I'm st—like, standing up there in front." She adds that co-teaching might help her to accomplish this goal "because having another person, another teacher there...who's there with me who sees what's going on and can say, "Oh, why don't you, why don't you do this 
with that person?" or rings the bell to remind the class to settle down, I think is helpful."

In her second interview, referring to planning for mathematics she stated: "I was kind of overwhelmed a little bit and [my cooperating teacher] really helped me, like, sort out, like, my thoughts and, because I was, like, kind of, like lost a little bit." She also added: "When I have to do lessons I still get really nervous on the inside, um, but I think, uh, I'm handling it well outwardly even though I'm like freaking out on the inside."

An excerpt from my field notes also indicates that for Sarah, the passage to Taking the Lead was, perhaps unconsciously, undesirable. Zoe is the cooperating teacher. My thinking is in brackets:

Kids are doing a pre-assessment on "Indigenous Americans" as part of Sarah's TCWS work...Both teachers are circulating room assisting students as needed...A parent comes to the door [Mrs. Brown]...I tell Zoe. Zoe tells Sarah...Sarah says, “Okay, boys and girls. You have five minutes to finish up. ”...Zoe goes to door to greet parent. Let's parent into room. Parent goes to chair in library/rug area... [Parent is there to read?]...Sarah looks at clock at 8:57...Sarah asks Zoe about transition...Zoe tells Sarah to have them leave it on their desk [unfinished work]...Sarah gives students directions to go to rug to see Mrs. Brown. Mrs. Brown asks kids if they have a pen or pencil. Sarah does not say anything...Zoe directs kids to get a clipboard and pen...Zoe and Sarah sit on perimeter of rug...Parent asks if she should start. Zoe says, “Okay!”...Zoe comes to talk to me. At one point kids get loud on rug. Zoe asks me if 
she should intervene. She doesn't. Eventually Sarah claps hands to get kids to calm down...Parent finishes. Zoe tells kids what's next.

Zoe, reflecting on Sarah's role in the classroom during one of our interviews, summed it up. Zoe stated: "She's like, the more I keep thinking about it, she's like the assistant.”

\section{Summary.}

The shaping of a passage "results, in part, from the degree of desirability felt by agent and passagee toward the specific dimensions of direction and timing as they unfold" (Glaser \& Strauss, 2010, p. 89). In the case of these seven classrooms, the degree of desirability or undesirability, felt consciously or unconsciously, by the cooperating and preservice teachers, caused variation across classrooms relative to Taking the Lead While Co-Teaching.

In two classrooms both the cooperating teachers and preservice teachers desired the passage and, therefore, cooperated to negotiate mini-schedules relative to the temporal expectations of the passage and, generally, avoided any conflicts that would dissolve the passage.

In two other classrooms the cooperating teachers, believing it is necessary for student teachers to assume control of the classroom for an extended period of time, were desirable of the passage. Their preservice teachers, however, were undesirable. Both cooperating teachers exercised their authority as agents and legitimators, pushing their preservice teachers to Take the Lead. Both preservice teachers did eventually Take the Lead, but in one of these classrooms, the cooperating teacher adjusted her expectations based on her preservice teacher's level of undesirability. 
In the fifth classroom the cooperating teacher, describing herself as one who likes to be in control, was initially undesirable of the passage. Her preservice teacher, however, was desirable of the passage and openly expressed her desirability. The cooperating teacher, then, adjusted her view of the passage to be, more or less, desirable, and negotiated with her preservice teacher to establish temporal expectations.

In the last two classrooms, both the cooperating and preservice teachers viewed the passage as undesirable. In the first of these classrooms the co-teaching pair preferred teaching as partners. Once the college supervisor intervened, however, the pair negotiated a mini-schedule for Taking the Lead.

In the second of these last two classrooms, the cooperating teacher viewed her preservice teacher as young and incapable and was, therefore, undesirable of the passage. The preservice teacher, through her statements and actions, also indicated a level of undesirability. In this last classroom, the passage to Taking the Lead While Co-Teaching was never really entered.

\section{Reversibility.}

According to Glaser and Strauss (2010), the property of reversibility refers to a change in the shape of a passage. In essence, if we consider the passage as having a direction over time, as in figure 8 , reversibility would change, or reverse, the direction, as represented in figure 9. 
Figure 8

Shape of a Passage

Start of Passage

End of Passage

Figure 9

Shape of a Passage with Reversal

$<$

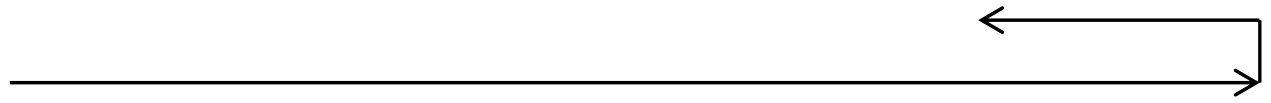

Start of Passage

Reversal of Passage

Passages, which are reversed, may be re-reversed, as in figure 10, or completely abandoned.

Figure 10

Shape of a Passage with Reversal, Re-Reversed

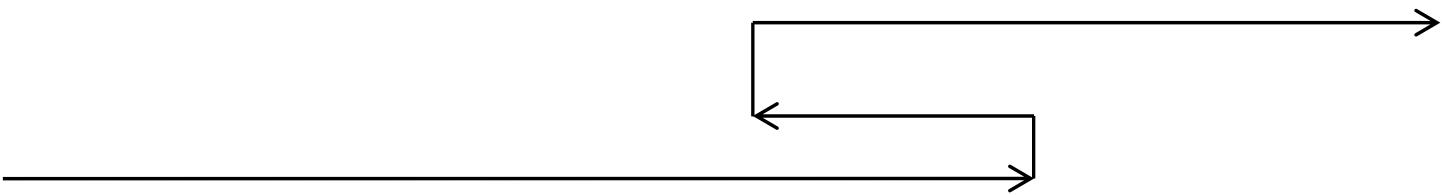

Start of Passage

Reversal of Passage

End of Passage

Glaser and Strauss (2010) tell us that passages may be reversed and re-reversed several times with "reversals that are fairly certain of being re-reversed... hav[ing] relatively little impact on agents and passagees alike" (p. 26). In terms of this research, there were several contextual factors relative to Harold Shipyard, which caused 
frequent reversals and re-reversals, usually with minimal impact, across all of the classrooms. Three main contextual factors emerged which I coded: (a) others in the building; (b) curriculum; and (c) time.

\section{Others in the building.}

As previously mentioned, the faculty, staff, and families at Harold Shipyard frequently welcome practicum students and student teachers. It is not unusual to see groups of practicum students gathered near the main office waiting to teach their practicum lessons, or, to walk into any classroom and see preservice teachers teaching. As such, while very open to their presence in the school, the faculty, staff, and families typically view preservice teachers, even while co-teaching, as students. As a result, when any type of communication is necessary with the teacher, they communicate directly with the cooperating teacher.

Throughout my observations I frequently saw "others" enter into classrooms and communicate with the cooperating teacher, even while the preservice teachers were Taking the Lead. Whether it was the school Interventionist, a parent, or a workstudy student, all bypassed the preservice teachers. While having a minimal impact on the passage to Taking the Lead, these actions, from my viewpoint, represented a minute, but noticeable, reversal in the passage.

\section{Curriculum.}

The curriculum, or lack of a formally defined curriculum, also affected the pacing, or direction, of the passage. Harold Shipyard, as a laboratory school, offers teachers a great deal of freedom in designing their own curriculum. While the preservice teachers often commented that they appreciated this freedom, they also 
indicated that if they were student teaching elsewhere, Taking the Lead may have been easier. Said one preservice teacher during our second interview: "We have the freedom...to go in different directions...from what I've talked about a lot of people [in other placements] are doing scripted teaching. So I think that is actually, possibly easier where you know exactly what you're doing and you're teaching exactly that. Um, as much as I like the freedom of this, I think it is a lot of pressure to really plan every minute of every day." The lack of a formally defined curriculum, then, caused reversals in the passage, Taking the Lead While Co-Teaching; these reversals were minimized in a variety of ways across the classrooms and were, generally, re-reversed with minimal impact on Taking the Lead.

\section{Time.}

Harold Shipyard is a busy place. During the time this study was being conducted, there were several happenings occurring within the school including, but not limited to, (a) practicums, (b) the completion of progress reports, (c) assessments leading up to progress reports, (d) parent conferences, (e) committee meetings, (f) a walk-a-thon, and (g) reading week. All cooperating and preservice teachers frequently referenced limited time both in terms of time together, and time within the classrooms. Table 14 contains excerpts drawn from interviews relative to time.

Table 14

Time Together and Time in the Classroom

ZP: I mean really, as of late, I've, you know I keep apologizing to her because I don't feel as though I have as much time to dedicate to her and the reflective part, and the 
questions, and the feedback because the time that I have is obligated to either a committee or a meeting or, you know, this...

I: An interview. [laughter]

$\mathrm{P}:$...an interview. No, I mean, like it's always something. You know meeting with parents, meetin — and it just seems to be more so with the new programs and things we've taken on and I feel like I'm constantly apologizing to her that I ca-you know, and she's like, "I'm learning." You know, so I think she still feels like she's learning by observing, by participating, but I feel as though that's definitely affecting the amount of time I have to dedicate to being a cooperating teacher. Time

TH: “There's so much to try and keep on top of that I don't feel I have the time I had in the past to sit down with her and have as many discussions as we ordinarily would hav—we've had some, and there will be time to cover everything, but I have so much to do that, um, I feel, it's somewhat affecting it." A lot going on

BN: "Um, I think that we always struggle with time and with planning time. Um, it's really hard to, to find the time to-we have great intentions. Yvonne and I are sitting down and, you know, planning out the week and pl—but, you know, with meetings and everything else it's really hard to come up with a time to do it. And luckily she's really flexible, um, but I think time is one of our biggest issues." Time

KD: "I feel like a lot of the teaching was kind of pushed back because of all the other events that we have at school, like the walk-a-thon or reading week, just different events that are educational that happen here at HSS but that are going in the place of 
other subjects. So then we have to kind of switch the schedule and sometimes, often, like, cut out things that we would normally teach them." No time?

CL: "Some of it's coming to us really last minute and it really hurts the planning time. Or suddenly they throw a "we're having an assembly on Friday." Structure of school.

Although time did emerge as a condition that caused frequent reversals in the passage, Taking the Lead While Co-Teaching, both the cooperating and preservice teachers worked together to mitigate its affect. Time, while limited, did not cause any major reversals in the passage. Like "others in the building" and "curriculum," reversals were generally re-reversed quickly and had minimal impact on the passage.

In the case of this research, all of the passagees, save one, eventually began the passage, Taking the Lead While Co-Teaching. All regularly experienced reversals and re-reversals in the passage due to a variety of structural and personal conditions (Glaser \& Strauss, 2010). In most cases, the reversals had minimal impact. In others, the passage was either blocked or completely abandoned.

In the following sections I will attempt to fully describe each preservice teacher's passage and the various conditions that (a) blocked or arrested the passage, (b) subjected the passage to multiple reversals/re-reversals, or (c) enabled the passage to proceed with a minimum of reversals/re-reversals. 


\section{Sarah.}

Although Sarah never really entered the passage of Taking the Lead While CoTeaching, I feel it is important to at least consider her non-passage. As already discussed, Sarah's cooperating teacher, Zoe, did not feel Sarah was capable and, as a result, blocked Sarah's entry into the passage. The hierarchal nature of the coteaching arrangement offered Zoe the authority to exercise her own discretion based on her own "personal conditions” (Glaser \& Strauss, 2010, p. 27).

Glaser and Strauss (2010) tell us that agents can control the amount of information a passagee receives, relative to the passage, in terms of how it is proceeding. Further, these agents do not need to disclose their personal conditions for exercising their discretion in concealing or distorting information received by the passagee. Passagees, then, may be cooperative or non-cooperative with the agent's actions, with their level of cooperation often directly tied to their understanding of the passage.

Sarah genuinely believed that she was assuming a great deal of responsibility in the classroom and Zoe did very little to correct that assumption. Sarah was, thus, cooperative and, essentially, unaware that she was not Taking the Lead. During one of our interviews Zoe did discuss her personal reasons, with me, for failing to keep Sarah informed: “I feel bad. I think I just feel bad. I think it's because she's so young....and I feel like she just doesn't get it yet. So I feel bad. I almost feel like I kind of have to be like parenting, too. You know, like she's my son's age. I'm like, poor thing." 


\section{Yvonne.}

Yvonne, as previously discussed, was placed with Beth, a cooperating teacher who was in her first year at her particular grade level. Both teachers were similar in age. Beth immediately found Yvonne to be capable and Yvonne was eager to begin working with the children.

During our first interview, Yvonne and I discussed the Preparing to Student Teach Meeting she had previously attended, and her current situation, co-teaching. An excerpt follows:

I: So at that larger meeting, though, when they kind of outlined for you, um-tell me if I have this right — where you know, you're doing so many weeks of observation and then slowly...

YO: $\mathrm{Mm} \mathrm{hmm.}$

I: ...the classroom is turned over to you until you are in charge of the classroom. Is that kind of what you heard at that meeting?

YO: That is what they said. And they said that you can determine that with your cooperating teacher and your supervisors, you can change it, like, like we are now. Um, but I, I felt that that model seemed a little bit unrealistic and so I was really excited about the [co-teaching] opportunity because I, I, I don't know that it's true that most people who are pursuing a teaching career are outgoing, but I'm very outgoing and if I'm in a classroom filled, full of students, it would be difficult to not participate in a way that's appropriate. 
In Beth's classroom, many of the children needed academic support in the form of interventions. Beth described how she and Yvonne were reacting in terms of co-teaching: “They're not [the co-teaching strategies] exactly, um, what I had planned when we started with the co-teacher trainings. Either, I didn't have, I think that, um, the actual kids that you're seeing in my class have dictated, um, the structures that you're looking at more than anything else." In this way, the children were conditions that reversed the passage. In Beth's classroom, Yvonne began co-teaching, or participating in a way that was appropriate, based on the needs of the children. Beth and Yvonne became "partners."

Although in the opening paragraphs of this section I referred to time and curriculum as having a minimal role in terms of reversals, in this classroom they had a greater impact. In terms of time, Beth, still early in her career, was enrolled in an "aspiring leadership program" at New England College. As part of this program, Beth was required to complete internship hours with the Harold Shipyard administration during the school day. Beth generally fulfilled these hours during her preparatory time. Similarly, as an untenured faculty member aspiring to gain tenure, Beth served on a variety of committees at Harold Shipyard which often pulled her from the classroom both during and after the school day. Both of these conditions led to spending less time with Yvonne in terms of planning, and, may have caused reversals in Yvonne's passage to Taking the Lead.

The lack of an existing formal curriculum at Harold Shipyard also had an impact on Taking the Lead in this particular classroom. As already stated, Beth, although in her seventh year of teaching, was in her first year of teaching at this grade 
level. As such, she did not have an existing curriculum that she had used in previous years. The lack of an existing curriculum served may have served as a reversal in Yvonne's passage to Taking the Lead because Beth could not inform Yvonne as to what was next. Instead, Beth and Yvonne figured out the curriculum as partners. Beth and Yvonne would probably have continued as partners throughout the student teaching experience had the college supervisor not stepped in. According to Beth and Yvonne, as previously mentioned, the college supervisor believed Yvonne should Take the Lead While Co-Teaching. Beth and Yvonne, in response to his concerns, negotiated a mini-schedule.

During our third interview, Yvonne stated: "Beth and I, right from the get-go, I felt like did a pretty good job of jumping in and co-teaching. It felt very natural...and then my supervisor said, "Well you know, you need to be, you know, formally taking over this amount of time...at least tell me you're going to be the lead teacher in the coteaching model." And so for the sake of that, for the sake of those observations and for the sake of the TCWS...we were still co-teaching, but not maybe the way we would have had we not had these things, you know, kind of imposing on us."

Glaser and Strauss (2010), however, tell us that "the emergence of a new passage that necessarily takes priority over current central passages" can bring a passage "to a total halt or reversal" (p. 22). In the case of Yvonne, her passage to Taking the Lead was halted due to personal misfortune, which required her to enter into a more personal passage.

During our third interview, Beth explained: "Yvonne had a pretty significant loss...within the last month...It's been heartbreaking to watch...She's been going 
through a grieving process, I guess you could say...She's just been going through a lot, um, and I think it affects her ability to, um, put in a lot of time outside work...So I took back a lot of the planning very abruptly...she couldn't do it...it's been a month...she's been stepping back a lot and taking more time to just kind of take care of the things she needs to take care of."

Yvonne never did re-enter the passage of Taking the Lead. In Yvonne's case, her new personal passage, that emerged as the result of a personal tragedy, took greater priority. Her passage was permanently reversed and, thus, abandoned.

\section{Denise.}

Denise and Celeste, like the other co-teaching pairs, immediately began coteaching from the very first day. Celeste found Denise to be highly capable stating: "I have an excellent student teacher...I think she was very on top of everything, very energetic, very willing to learn, very open to recommendations and suggestions and it just, it just made it very easy. It flowed very easily for us."

Despite Celeste's belief that Denise was capable, however, Celeste was the main cause for reversals in terms of Denise's passage. As previously mentioned, initially, Celeste did not necessarily find the passage desirable, as she preferred to "have control." Denise, however, desired the passage, and, after expressing her feelings to Celeste, Celeste negotiated a min-schedule for Denise to Take the Lead "for a week or two."

During our third interview I asked Celeste to reflect back on the co-teaching experience, especially in terms of anything that made it difficult. Celeste responded: "Me." 
Denise, despite having a very strong desire to Take the Lead, took the lead in in keeping with Celeste's terms. Celeste did allow Denise to do the majority of the planning for three weeks, but she was still very much involved. During our third interview, after I asked Denise about Taking the Lead, she responded: “I wouldn't call it a one-hundred percent take over...I was doing the majority of planning and implementation, but she was still always there with the planning and if I was teaching and things just weren't going right, or, um, I wasn't getting a point across that I was trying to. She would just jump right in."

\section{Lucia.}

Lucia, although viewed as capable by her cooperating teacher, did not necessarily share the same level of desirability to Take the Lead as Denise. Her cooperating teacher, Amy, said during our third interview: "I wanted her to take on more of the responsibility in the classroom... I kind of had to push her along a little bit."

Interestingly, Amy was also enrolled in the "aspiring leadership program" at New England College, but instead of acting as a reversal, her internship hours actually moved Lucia closer to Taking the Lead. Unlike Beth, Amy did a great deal of her internship hours during the school day, which required Lucia to take over the classroom in her absence. During one of our interviews I asked Amy about personal conditions that might affect the implementation of co-teaching. Amy stated: "For me it was doing my 150 hours for my internship ...in the, in the semester. It was nice to have a co-teacher because if there was a meeting going on I could say, "You're gonna (sic) stay here for math. I'm gonna (sic) run to the meeting" ... I had somebody that 
could, she could step up. It was great to have her have the experience of being alone in the classroom, too."

Lucia did Take the Lead for a period of two weeks, although Amy had preferred that she take over for a period of four weeks. Two conditions led to two separate reversals in the passage.

The first condition was an event, specifically, reading week. After I asked Lucia about Taking the Lead, she responded, "Probably four, um, three four weeks...because reading week was during it so it was kind of crazy." This reversal was re-reversed and Lucia resumed the passage. According to Lucia, she assumed about "seventy-five percent" of the responsibility. Amy was still very much involved. The second condition, according to Amy, was the TCWS. Amy stated: "A lot of her time was focused on that when she should have been planning. And then she stopped the takeover because she had to work on the work sample." According to Glaser and Strauss (2010), "a structural condition such as a hierarchy of authority may delegate more control over the passage to an agent than to a passagee; yet personal conditions intervene to explain how one uses his own, or undermines the other's control to reverse the status passage" (p. 27). In this case, Lucia, under the condition of completing the student teaching requirements as defined by the college, reversed the passage and the passage was abandoned.

\section{Veronica.}

Veronica was also highly capable according to her cooperating teacher, Ellen. Additionally, both Veronica and Ellen were both very desirable about having Veronica Take the Lead. 
Ellen, like all of the cooperating teachers at Harold Shipyard, is very dedicated. During our second interview Ellen admitted to feeling stressed, in terms of this dedication, to the students, their families, and to Veronica. At the end of our interview, in fact, Ellen cried with me.

Veronica attempted to help Ellen handle her level of stress by making lists of things each day, for both herself and Ellen, which needed to be accomplished. Veronica stated: "I feel bad. She cried three times today. Because she's just so overwhelmed and so stressed about report cards and conferences...She's so dedicated...she puts so much care and so much thought...she's so incredibly dedicated.”

Veronica also attempted to "fit" into the classroom. She explained: "I tried my best to fit exactly what, into what she was doing rather than implement anything new. Which I think was kind of too bad...Just in terms of real world situation, like, when I am in my own classroom, like, I'm going to need to implement stuff and, kind of see how it goes...I don't think I got the opportunity."

During the course of the semester, Veronica was actively engaged in the classroom and often taught her own lessons. She also said that Ellen was very open to and respectful of her ideas. Veronica, however, expressed frustration relative to her taking over in the classroom. During her third interview Veronica said, "I never felt like I could really take charge of anything." According to Veronica, Ellen could "not let go."

Ellen, like Celeste, was a major condition in terms of reversing the passage of Taking the Lead While Co-Teaching. Unlike Celeste, however, Ellen allowed 
Veronica to assume a greater amount of responsibility and the reversal caused by Ellen was more of a series of mini-reversals that would immediately be re-reversed.

\section{Caroline.}

Caroline was paired with a cooperating teacher who had been teaching for more than forty years. This teacher, Terry, had hosted many student teachers throughout her career and had a very clear vision in terms of Taking the Lead. In our second interview Terry said: "My general tendency though is...for me to start off with most of the responsibility and gradually, um, give up that responsibility to the coteacher in increments. But by the end, as I said, they should have total responsibility, for at least for a short amount of time."

Terry, like most of the other cooperating teachers, also believed her preservice teacher, Caroline, was capable and she and Caroline began co-teaching from the very first day. Terry stated: “Caroline is a very responsible person who takes a lot of initiative for herself. She's motivated to do a good job." She also stated, "She wants to take on increasing responsibility," indicating that Caroline, like Terry, was desirable of the passage, Taking the Lead. Both Terry and Caroline negotiated a mini-schedule for Caroline's passage.

What was different in this classroom was Terry's ability to foresee conditions, which might cause reversals in Caroline's passage, and attempt to prevent them. For example, while all of the other classrooms hosted multiple practicums throughout the semester, Terry hosted only one, stating that he did not believe it was fair to the student teacher. Glaser and Strauss (2010) tell us, “agents in control have several resources for preventing... reversals...if they personally wish to do this” (p. 28). 
Similarly, Terry tried to leave the classroom as much as possible to allow Caroline to fully experience Taking the Lead. Terry stated: "I've been trying to be out of the classroom as much as I can...so as much as possible, [she'1l] be in the classroom without me, so she has experience with how to manage a class on her own and manage time."

According to Glaser and Strauss (2010), an "agent's understanding and control of information, processes, and legitimation allows him to formulate strategies to prevent reversal that achieve a high degree of success" (p. 28). For Caroline and Terry, Terry's experience mentoring student teachers throughout the years, allowed Caroline to more fully Take the Lead While Co-Teaching.

Kelly.

Kelly's passage to Taking the Lead was very similar to Caroline's. The cooperating teacher, Heather, genuinely believed that Kelly needed the opportunity to take control of the classroom. She was desirable of the passage.

Initially, however, Kelly was reticent and doubted her level of capability in light of her other requirements relative to student teaching. She was, at first, undesirable of the passage and expressed her concerns to Heather. Heather, in turn, (a) asked Kelly to re-examine her level of commitment to the profession, (b) more clearly outlined expectations and addressed misconceptions, and (c) helped Kelly to understand that her nervousness was natural.

Kelly, thus, readjusted her level of desirability and began more actively coteaching with Heather. On her passage to Taking the Lead While Co-Teaching she stated: "It was really a mix of her style and my style together, and it worked really 
well, to the point where I was like, I didn't even realize I was teaching, until she was like, "Okay, I'm going to start taking back the class," and I was like, "Whoa." She goes on to say: "From the point [the students] came in in the morning, until the end of the day, I would be directing them and I would teach every single subject. Um, so I would be the lead and she would come in with different, um, like, with different comments or things to add, but for the most part, I was the lead."

Like Terry, Heather also did her part in preventing reversals relative to the passage. In particular, Heather offered Kelly a more significant role in relation to practicum. Kelly explained: "When the math practicum was in I would, um, kind of mirror Heather. I would take notes and she would take notes and...she would conference with me to see if there's anything that she might have missed that I saw...so it kind of was like I was the second teacher in the room giving feedback." In all of the other classrooms, when practicums were occurring, the preservice teachers mainly observed, which resulted in reversals and re-reversals in their passages. By providing Kelly with an alternative, and authoritative role, Heather helped to prevent a reversal in Kelly's passage and actually moved her closer toward Taking the Lead.

\section{Summary.}

"Reversibility in a status passage comes from two general interrelated sources...structural conditions (both contextual and situational)...and personal conditions" (Glaser \& Strauss, 2010, p. 21). In the case of this research, both were present.

Some conditions that caused reversibility, although of concern to participants, had very little impact on the passage Taking the Lead While Co-Teaching. These 
conditions included: (a) others in the building; (b) curriculum; and (c) time. The reversals caused by these conditions were generally allayed by the cooperating and preservice teachers, leading to re-reversals in the passage.

In the case of this research, six of the seven preservice teachers eventually entered the passage, Taking the Lead While Co-Teaching. All regularly experienced reversals and re-reversals, although in some classrooms the reversals were prevented. In most cases, the reversals had minimal impact. In others, the passage was either blocked or completely abandoned.

\section{Summary of question 2.}

Glaser and Strauss (2010) suggested that "anyone who wishes to develop a substantive analysis about any phenomenon that might also be fruitfully conceived of as a status passage can considerably tighten up, as well as make more "dense," his systematic formulation by guiding his research with a sensitivity to the kinds of properties listed above" (p. 9). In the previous sections I have attempted to utilize the properties of status passage including (a) temporality, (b) desirability, and (c) reversibility to analyze the passages of seven preservice teachers, Taking the Lead While Co-Teaching, and to answer my second research question: If differences in implementation are found, why do these differences exist?

While all of the participants indicated that they used a variety of co-teaching strategies within their classrooms, Taking the Lead While Co-Teaching emerged, from the data, as a main concern for participants. This expectation, that preservice teachers would eventually Take the Lead, was clearly articulated at the preparatory co-teaching 
workshop held on day four of the student teaching experience; all participants attended this workshop.

Temporal expectations related to the passage, however, were unscheduled and only loosely defined leaving the rate, transitional statuses, scheduling, and coordination of the passage, largely, in the hands of the cooperating and preservice teachers, which led to great variation when comparing the passages of participants. In terms of desirability, "desirability of a status passage provides the motivational basis for actions that shape that passage" (Glaser \& Strauss, 2010, p. 89). There were four possible combinations of viewpoints by cooperating teachers and preservice teachers related to the desirability, or undesirability, of taking the passage. All four combinations were observed in this study, which, again, led to variability when comparing the passages of passagees.

Reversibility refers to a change in the shape of the passage. Passages can be reversed and re-reversed several times. Reversals "that are fairly certain of being rereversed... have relatively little impact on agents and passagees alike” (p. 26). Some contextual factors relative to Harold Shipyard which caused reverses in all classrooms were (a) others in the building, (b) curriculum, and (c) time. The cooperating and preservice teachers, for the most part, mitigated these reversals, thus, re-reversing the passages.

For some passagees, structural and personal conditions caused passages to be reversed and abandoned, or continually reversed and re-reversed. For other passagees, knowledgeable agents prevented reversals either by foreseeing their potential to reverse the passage, or, by offering alternative options relative to the reversal. 
In sum, in terms of the status passage Taking the Lead, the (a) undefined temporal expectations relative to the passage (b) desirability or undesirability felt by participants toward the passage, and (c) degree of reversibility relative to structural and/or personal conditions experienced by participants caused great variation in terms of each preservice teacher's passage, and, thus, led to differences in implementation of co-teaching, across the seven classrooms.

\section{Summary}

This case study was guided by the following two questions relative to implementation:

1. How is co-teaching implemented in seven elementary and early childhood classrooms?

2. If differences in implementation are found, why do these differences exist?

In an attempt to answer these questions, I systematically used grounded theory analysis to identify the main, or emic, issues of the participants involved in this work. I also sought to identify a core variable, which closely related to the concerns of the participants while they were implementing co-teaching as a student teaching method. As previously stated, I named the core variable: Transitioning from Student to Teacher Alongside the Teacher.

Through the sorting of memos under my identified core variable, and the use of my selected theoretical coding family, "Status Passage," I began to notice two distinct, intersecting passages. The first passage, Becoming a Teacher While CoTeaching, was situated within the larger context of this study, namely, the college setting. This passage, I discovered, was very much related to my first question or how 
co-teaching was implemented across seven elementary and early childhood classrooms.

The second passage, Taking the Lead While Co-Teaching, was more closely situated to the classroom and school context, and, more closely connected to my second question or why differences in implementation exist.

Using three properties of status passage - temporality, desirability, and reversibility - I analyzed each passage separately. In brief, I arrived at the following interpretations:

\section{How is co-teaching implemented in seven elementary and early childhood}

\section{classrooms?}

How co-teaching was implemented, in terms of Becoming a Teacher While Co-Teaching, occurred in much the same way as the more traditional model would have been implemented — embedded in the larger context of student teaching. As such, the temporal expectations of New England College, and the key agents involved, clearly articulated the shape of the passage and ensured its nonreversibility, and, inevitability for this particular case.

\section{If differences in implementation are found, why do these differences} exist?

Differences in implementation, in terms of Taking the Lead While CoTeaching, were due to the (a) undefined temporal expectations relative to the passage (b) desirability or undesirability felt by participants toward the passage, and (c) degree of reversibility relative to structural and/or personal conditions experienced by participants. 


\section{Chapter 5: Conclusions}

\section{Summary of the Study}

\section{Overview.}

Due to the systematic and detailed nature of case study methods, case studies in the area of teacher education can provide a detailed look at complex teacher education activities, illuminating what teacher education programs look like from the perspectives of students and faculty (Zeichner, 1999).

The purpose of this explanatory, instrumental, qualitative, single-case study was to understand, through the use of grounded theory analysis, how co-teaching was implemented in seven elementary and early childhood classrooms in a mid-sized New England city, in an effort to develop substantive theories relative to causal explanations for differences of this particular case.

The case was defined and delimited as: A community of practice, endeavoring to implement co-teaching as a student teaching method during the Spring 2016 semester at an elementary, laboratory school located on a college campus. The community of practice, or unit of analysis - the case - included, as its subsections, seven preservice teachers, the seven cooperating teachers with whom they were paired, and the seven classrooms in which they worked.

The study was guided by the following two questions relative to implementation:

1. How is co-teaching implemented in seven elementary and early childhood classrooms?

2. If differences in implementation are found, why do these differences exist? 
This case study was instrumental in nature (Stake, 1995; Stake, 2005), undertaken to "advance understanding of...[another] interest,"--specifically the implementation of co-teaching as an alternative student teaching method—with the case playing a secondary role (Stake, 2005, p. 445). The case, in instrumental case studies, "facilitates our understanding of something else" (Stake, 2005, p. 445).

The study was organized around the emic "issues" of the participants, or the people who belonged to the case (Stake, 1995). This choice is in keeping with grounded theory methods with the researcher entering the area of study with no problem, but with a keen interest of "what is going on is an issue and how it is handled" (Glaser, 1992, p. 22). In attending to the emic issues, the researcher gains a deeper understanding of the initial etic issue, the implementation of co-teaching, through the perspective of the actors in the setting being studied.

Merriam (1988) tells us that qualitative reliability indicates "the extent to which one's findings can be replicated" (p. 170). Yin (2009) recommends case researchers document their procedures "to make as many steps as operational as possible and to conduct research as if someone were always looking over your shoulder" (p. 45). In an attempt to operationalize my steps, I followed the guidance provided by Yin (2009) in two ways.

First, I created a case study protocol to (a) provide an overview of the study, (b) detail field procedures, and (c) outline the case study report. Second, I maintained a case study database that included transcribed interviews, field notes, assorted relevant documents, artifacts, my methodological and analytical memos, and the case 
study protocol itself. The case study database serves as an evidentiary source for persons wishing to review my evidence directly, or, replicate this study.

My case study protocol also served as a form of initial sampling, directing me as to the type of data I would collect and analyze first. All participants were informed as to the three main types of data to be collected during the study including (1) interviews, (2) observations, and (3) documents. I also engaged in theoretical sampling to (a) determine further data collection sources and procedures, (b) more fully develop "thin areas," and (c) cultivate substantive theory (Glaser, 1992, p. 101). Additional sources of data included informal interviews and the examination of both elicited and extant texts.

During data collection and throughout my analysis, I adhered closely to the methodology of grounded theory analysis as presented by the discoverers of grounded theory, Barney Glaser and Anselm Strauss $(1967,2008)$, and as presented in subsequent texts which further detailed the methodology, as provided by Strauss and Corbin (1998), and Glaser (1978; 1992). Initially, these methods included (a) labeling to establish initial concepts, (b) microanalysis, and (c) selective coding.

Although Strauss and Corbin (1998) recommended grounded theorists utilize axial coding, I adhered more closely to Glaser's (1992) process of analysis "continually coding, comparing, analyzing and memoing...to generate categories" (p. 19). While engaged in this process I continually searched for and was alert to what Glaser (1978) terms the "core variable" or "the main concern or problem for the people in the setting" (p. 94). 
During selective coding I again elected to adhere more closely to Glaser's (1978) analytical recommendations, entering into selective coding only after identifying my core variable. Through my analyses I began to get a sense that, for the participants, the main concern relative to all stakeholders was moving the preservice teacher from student to teacher while co-teaching. I also noticed a distinction between being $a$ teacher versus being the teacher.

I returned to Glaser's (1978) discussion of core variables as basic social processes in an effort to name my core variable. According to Glaser, "a process is something which occurs over time and involves change over time" and, for many analysts, the tendency is to label a process with a gerund (p. 95). I determined that this transition from student to teacher was indeed processual and, therefore, named my core variable Transitioning from Student to Teacher Alongside the Teacher.

I then returned to a study of the theoretical coding families provided by Glaser (1978) and, in doing so, attempted to identify a theoretical coding family that fit with my data and my core variable. According to Glaser and Strauss (1967):

"[This] approach, allowing substantive concepts and hypotheses to emerge first, on their own, enables the analyst to ascertain which, if any, existing formal theory may help him generate his substantive theories. He can then be more faithful to his data, rather than forcing it to fit a theory. He can also be more objective and less theoretically biased" (p. 34).

In my review of coding families, I centered upon what Glaser calls "The Mainline Family" of theoretical codes. 
Of particular interest to me, within the Mainline Family, was the code "status passage" which Glaser describes as "moving people along and getting them through" (Glaser, 1978, p. 77). To me, the idea of status passage fit with my core variable. Through further theoretical sampling I sought out extant texts related to my chosen theoretical code and came upon Glaser and Strauss's (2010) text, Status Passage.

Through the sorting of memos under my identified core variable, and the use of my substantive codes and selected theoretical coding family, "Status Passage," I began to notice two distinct, intersecting passages: Becoming a Teacher While CoTeaching and Taking the Lead While Co-Teaching. I initially utilized the properties of passage offered by Glaser and Strauss (2010) to establish similarities and differences, and to visually compare these two distinct passages.

It was through the identification of these two separate but intersecting passages, as well as through the comparison of their properties using my theoretical coding family and the further sorting of my memos, that I began to understand how co-teaching was implemented and why variations existed, in this particular case.

The first passage, Becoming a Teacher While Co-Teaching, was situated within the larger context of this study, namely, the college setting. This passage, I discovered, was very much related to my first question or how co-teaching was implemented across seven elementary and early childhood classrooms.

The second passage, Taking the Lead While Co-Teaching, was more closely situated to the classroom and school context, and, more closely connected to my second question or why differences in implementation exist. 
Using three properties of status passage — temporality, desirability, and reversibility - I analyzed each passage separately and arrived at the following interpretations:

\section{How is co-teaching implemented in seven elementary and early childhood classrooms?}

How co-teaching was implemented, in terms of Becoming a Teacher While Co-Teaching, occurred in much the same way as the more traditional model would have been implemented — embedded in the larger context of student teaching. As such, the temporal expectations of New England College, and the key agents involved, clearly articulated the shape of the passage and ensured its nonreversibility, and, inevitability, for this particular case.

\section{If differences in implementation are found, why do these differences exist? \\ Differences in implementation, in terms of Taking the Lead While Co-} Teaching, were due to the (a) undefined temporal expectations relative to the passage (b) desirability or undesirability felt by participants toward the passage, and (c) and reversals in the passage relative to structural and/or personal conditions experienced by participants.

\section{Interpretations}

Although I identified the main issue of the participants, or my core variable, as Transitioning from Student to Teacher Alongside the Teacher, my discussion thus far has centered mainly on two sub-passages, Becoming a Teacher While Co-Teaching and Taking the Lead While Co-Teaching. My reasoning for doing so was to more 
adequately and thoroughly answer my research questions. I return now to my core variable to (a) consider how it was identified, and (b) to offer a brief analysis and my interpretations as related to this particular case.

\section{Identifying the core variable.}

While engaged in analysis, Strauss and Corbin (1998) were instrumental in helping me identify my core variable. First, their words reassured me as I struggled to objectively identify the main theme of my research. They stated, "Sometimes students, especially those in practitioner fields, become caught up in the descriptive details...or... are so flooded with data that they are unable to obtain the distance necessary to commit to a central idea" (p. 147). Second, they offered several strategies to assist the researcher in identifying the core variable. One of these strategies is to write a descriptive story about "what seems to be going on here?" (p. 148). In keeping with their recommendations, I crafted an analytical memo outlining my interpretation of the descriptive story.

A section of my descriptive story is presented here:

What keeps striking me during the observations and interviews is that the cooperating teacher is the main teacher, no matter what, and that the preservice teachers are in a subordinate role. This is no surprise really. But, their roles differ in that some take on more responsibility. To explore the idea further of the main teacher, there seem to be conditions in place that keep these preservice teachers in the subordinate role. Existing conditions such as program requirements, or access to tools, or communication, or the roles of stakeholders. In some ways the preservice teachers maintain that subordinate role by "going with the flow" or "being careful 
not to step on toes." These decisions are conscious. Other preservice teachers unconsciously keep themselves in that role by doubting their own capability or needing someone to tell them what to do. Some actually perceive themselves as the main teacher (at least for a portion of the time) without realizing how much they are not doing. What is this all about? Is it navigating through the co-teaching experience? None of the preservice teachers ever do become, really, the teacher and there are many reasons. Like Veronica, for example. She's highly capable and yet, her cooperating teacher couldn't let go. Even if she had let go, there are still existing conditions that would not allow the preservice teacher to be the main teacher. Maybe I am just hooked on the idea of the teacher and can't see around it. What else is going on then?...The cooperating teachers are almost conditions! I hadn't realized that. So, what's it all about? What was happening during implementation? Maybe it's "Becoming a teacher with a teacher." Or "Becoming a teacher with the teacher: Variations within Co-Teaching Experiences" or "Becoming a teacher with the teacher: ????" What gets at all that is going on? I just can't get at that core category but it's right there...

Through the further coding of my data, the continued writing of analytical memos, and through the sorting of my memos, I eventually chose a core variable that, I believed, had the "power...to form an explanatory whole...able to account for considerable variation within categories" (Strauss \& Corbin, 1998, p. 146).

Once I had identified my core variable, I separated the variable into two intersecting passages, Becoming a Teacher While Co-Teaching and Taking the Lead While Co-Teaching, which I have already discussed at some length. In the next section 
I will again use the properties of status passage - temporality, desirability, and reversibility - to analyze the larger passage, or my core variable, Transitioning from Student to Teacher Alongside the Teacher, and will offer my interpretations.

\section{Analysis and interpretations.}

Temporal expectations, including the rate, transitional statuses, scheduling, and coordination, of the status passage Transitioning from Student to Teacher Alongside the Teacher (henceforth abbreviated to Transitioning), were legitimized by New England College. These temporal expectations were understood with a fair degree of certainty by the various agents involved in this study and by the preservice teachers, due to either (a) prior knowledge (as in the case of the agents), or (b) the Preparing to Student Teach Meeting or the Student Teaching Handbook (New England College, 2010).

The preservice teachers in this study, in my interpretation, focused on the temporal expectations of which they were certain, such as the duration of the student teaching experience, and the various program requirements such as the OPRs and TCWS. Interestingly, outside of these temporal expectations, the preservice teachers eluded to having few other expectations of the student teaching experience and were taking a "wait and see" approach.

All agents, including the college supervisors, seminar instructors, and cooperating teachers were also familiar with and adherent to the college requirements, although one of the college requirements, the phasing of the student teaching experience —immersion, inclusion, and culmination — was susceptible to interpretation. 
Under the heading "Phases of Student Teaching," the Student Teaching Handbook (New England College, 2010) includes the following caveat:

Each teacher candidate is an individual and there will be differences in how he/she will assume duties and responsibilities. Cooperating teachers and college supervisors are cautioned against comparing a current teacher candidate with former individuals they mentored. The phases of student teaching....are presented as guidelines. The cooperating teacher, in collaboration with the college supervisor and student teacher, determines the rate progression through each phase of student teaching (p. 36).

This understanding, although not explicitly stated by key agents, was, in my interpretation, implicitly present in their actions.

Temporal expectations related to phasing, especially as related to having the preservice teacher assume full responsibility for the classroom—even though established in the Student Teaching Handbook (New England College, 2010) and during the preparatory co-teaching workshop — became unscheduled and undefined. As a result, some preservice teachers Transitioned more quickly toward becoming teachers, some never Transitioned, and some fell somewhere in between.

The preservice teachers in this study obviously would not be student teaching if they did not find Transitioning to be desirable. Likewise, the key agents involved, as part of their professional responsibilities, would find the Transition to be desirable.

In my interpretation Transitioning, however, had two separate components.

The first component was more tightly connected to Transitioning in terms of gaining professional licensure. This component, in keeping with the discussion above, had 
highly defined temporal expectations and I tied it directly to Becoming a Teacher While Co-Teaching. This component was desirable.

The second component, in my view, was Transitioning in terms of the preservice teachers asserting themselves as teaching professionals, moving from the program requirements of New England College, toward the requirements as presented in the classroom. This second component was related to Taking the Lead While CoTeaching, and, due to its loosely defined temporal expectations was prone to different levels of desirability or undesirability. When both the cooperating teachers and preservice teachers found this component of Transitioning desirable, the preservice teacher Transitioned more quickly toward asserting herself as a teaching professional. When both the cooperating and preservice teachers found Transitioning undesirable, the preservice teacher did not make the Transition. And, when the cooperating and preservice teachers differed in terms of their level of desirability, the Transition for the preservice teacher fell somewhere in between.

Both components of Transitioning, in my view, were vulnerable to conditions that caused reversibility. As already discussed, poorly defined temporal expectations and varying degrees of desirability were more likely to lead to the reversal of the passage Transitioning as related to asserting oneself as a teaching professional, or, Taking the Lead While Co-Teaching.

Additionally, contextual factors relevant to Harold Shipyard, including (a) access to the building and information, (b) practicums, held within the classrooms, and (c) events such as reading week, led to reversals. In terms of access, preservice teachers eager to Transition to teaching professionals, or, Taking the Lead, expressed 
feelings of frustration relative to their inability to conduct their work in efficient ways. In terms of practicum, these same teaching professionals (save one) were susceptible to reversals, even if well on their way through the Transition, as they were positioned squarely back as students/silent observers during the practicum sessions held in their classrooms.

Other structural and personal conditions played a role in causing or preventing reversals. In terms of causing reversals, the inability for some cooperating teachers to "let go" caused reversals for preservice teachers desirable of Transitioning. Additionally, other status passages outside of Transitioning such as personal passages due to life-changing circumstances, or, due to aspiring to lead in other areas of education, caused reversals. Interestingly, the second of these outside status passages also prevented reversibility.

The college requirements, namely the OPRs and TCWS were conditions that also either prevented or caused reversibility as related to Transitioning. In terms of causing reversals, for preservice teachers who were undesirable of Taking the Lead, the TCWS acted as an available excuse for the preservice teacher to assume less responsibility for work outside of the classroom (i.e., planning, correcting, etc.). In terms of preventing the reversal, for preservice teachers who desired the passage, who were paired with cooperating teachers who were undesirable, the OPRs and TCWS enabled the preservice teachers to Take the Lead, and Transition.

Some conditions prevented reversibility. The college supervisors and seminar leaders, in carefully orchestrating the program requirements, were instrumental in helping the preservice teachers transition, especially as related to Becoming a Teacher. 
It should be noted, however, that some cooperating teachers in this study commented on the disconnect they felt in relation to the college supervisors. Mainly, their concerns were related to the preservice teachers with whom they were paired, feeling that the college supervisor who was completing the OPR did not really know the preservice teacher.

Other conditions that prevented reversibility, especially in terms of Taking the Lead, were the ability to foresee conditions that might cause reversals, or, the ability to reframe these conditions.

Finally, perhaps the most crucial condition affecting the reversal of the status passage Transitioning, was what I initially coded as "holding back." This condition was directly related to the cooperating teachers. In the analytical memo above, I began to understand the cooperating teacher's role as a "condition" in that all of the cooperating teachers in this study admitted to holding back certain aspects of the teaching profession. Let it be understood that, in terms of this research, the cooperating teachers were not holding back this information to impede their preservice teachers in terms of making the Transition. Instead, these cooperating teachers, as agents, were attempting to prevent reversibility.

Holding back aspects of the profession (i.e., completing progress reports, correcting, assembling homework, communicating with families, etc.), for the cooperating teachers, allowed the preservice teachers the time they needed to fulfill the temporal expectations of New England College, or, to Become Teachers. Additionally, for these cooperating teachers, holding back, from their view, made the Transition to Taking the Lead easier. This point is vital in that, many of the preservice 
teachers remained completely unaware of "what was behind the curtain" and, thus, were unable to completely make the Transition both in terms of Becoming a Teacher While Co-Teaching or Taking the Lead While Co-Teaching. For their part, the cooperating teachers remained largely unaware that their attempt at preventing reversals in Transitioning from Student to Teacher Alongside the Teacher may have, ultimately, been the greatest reversal of them all.

\section{Implications.}

\section{Harold Shipyard.}

As previously mentioned, all of the preservice teachers in this study reported feeling welcomed at Harold Shipyard. However, some contextual conditions caused reversals in the passage Transitioning from Student to Teacher Alongside the Teacher. These reversals could be minimized.

First, although safety and security is a primary concern in all schools, arrangements should be made to give preservice teachers early morning access to the building. Similarly, provisions should be made to allow preservice teachers access to important information, such as upcoming school events.

Second, although it is recognized that Harold Shipyard is a laboratory school on a college campus established to provide a place for preservice teachers to practice, in classrooms where student teachers are placed, practicums should be kept to a minimum. Alternatively, student teachers placed at Harold Shipyard could be put in a position of greater authority by establishing a clear role for them while practicums are occurring in the classrooms in which they are placed. 
Third, cooperating teachers should be selected with care. Although every cooperating teacher at Harold Shipyard has, at a minimum, a master's level degree, and, all have been teaching for a number of years, cooperating teachers with (a) outside commitments, (b) limited experience teaching at their particular grade level, or (c) the inability to "let go," should be exempt from taking on a preservice teacher.

Fourth, if Harold Shipyard were to continue to host student teachers as coteachers, the administration and cooperating teachers should clearly define temporal expectations including scheduling, rates, and transitional statuses for Taking the Lead, while positioning these expectations within the larger temporal expectations of the student teaching experience as established by New England College. These expectations should emphasize that while co-teaching does enable both participants (a) the opportunity to collaborate in the classroom, (b) incorporate different co-teaching approaches (Heck et al., 2010), and (c) learn from each other through collective praxis (Tobin, 2006), there is the requirement that the preservice and cooperating teacher "gradually shift the roles" (Picanco \& Darragh, 2011, p. 140) with the preservice teacher ultimately assuming (a) "full responsibility of the classroom by leading the planning, organization, delivery and assessment of instruction" and (b) "effectively manag[ing] human resources by directing other adults, including the cooperating teacher" (Heck et al., 2010, p. 94).

In this vein, and perhaps most importantly, the cooperating teachers should consider aspects of the profession that are essential, which may, unless clearly defined in advance, stay hidden from the preservice teachers. Temporal expectations, which include these essential aspects of the profession, should be clearly established at the 
beginning of the student teaching experience, for both cooperating and preservice teachers, and be monitored throughout.

\section{New England College.}

The pre-student teaching requirements, OPRs, and TCWS were instrumental in Transitioning Student to Teacher Alongside the Teacher. As such, these program requirements should remain part of the temporal expectations at New England College, even if New England College chooses to more widely utilize the co-teaching model. If and when these requirements are revised, wording relative to co-teaching in terms of these program requirements would be helpful in establishing for all stakeholders - the preservice teachers, cooperating teachers, college supervisors, and seminar leaders - specific expectations.

Similarly, the Student Teaching Handbook, if revised, should include clearly defined temporal expectations for co-teaching, should New England College decide to adopt the model. These temporal expectations should be designed to be less susceptible to interpretation, and, if created in tandem with the temporal expectations created by Harold Shipyard, could also include essential aspects of the teaching profession which, without being explicitly stated, may be held back.

And finally, although the Student Teaching Handbook (New England College, 2010) is very accessible and a Preparing to Student Teach Meeting was held prior to the experience, it was surprising that the preservice teachers, in this particular case, had limited expectations relative to student teaching. For this reason, every effort should be made to make them more aware—-perhaps through meetings with recent 
graduates - of what the student teaching expectations are within both the larger context of the college, and the smaller context—namely the classroom.

\section{Limitations}

The case study's strengths outweigh its limitations, offering a means of studying multifaceted real-life situations involving multiple variables of potential significance, resulting in a rich and complete account of the phenomenon being studied (Merriam, 2009). However, all research, including case studies, is susceptible to concerns related to validity and reliability (Merriam, 1988).

In an effort to address my own subjectivity, and remain more objective in my analyses, I steadily undertook techniques recommended by Glaser and Strauss (1967, 2008), Strauss and Corbin (1998), and Glaser $(1978 ; 1992)$ while conducting this

research. Specifically, I attempted to think comparatively by constantly comparing data with data and by examining my developing thoughts against existent literature and my own biases. Next, I struggled to see and capture events through the eyes of the participants while collecting multiple sources of data-interviews, observations, and documents—-systematically.

I also attempted to enhance the internal validity of this study through the use of triangulation, through the collection of multiple forms of data, the utilization of "multiple methods to confirm the emerging findings" (Merriam, 1988, p. 169), and, through the use of member-checks throughout the study to offer participants the opportunity to comment on my findings and validate my own emergent thinking (Creswell, 2014). 
Additionally, to strengthen the reliability of this research, I created a case study protocol to (a) provide an overview of the study, (b) detail field procedures, and (c) outline the case study report. The protocol served as a guide in defining initial data collection procedures, helped me to maintain focus, and allowed me to be reflective about potential concerns, including the preparation of this dissertation. Second, I maintained a case study database that included transcribed interviews, field notes, assorted relevant documents, artifacts, and the case study protocol itself. The case study database serves as an evidentiary source for persons wishing to review my evidence directly, or, replicate this study.

In addition to internal validity threats, critics of case study methods also claim that case studies lack generalizability. However, Yin (2009) informs us that case studies "rely on analytic generalization [with] the investigator striving to generalize a particular set of results to some broader theory" (p. 43). Replication, therefore, is important so theories generated can be tested (Creswell, 2014). "Once such direct replications have been made, the results might be accepted as providing strong support for the theory...this replication logic is the same that underlies the use of experiments" (Yin, 2009, p. 44). Fraenkel et al, (2012) concur, reminding researchers and readers of case studies alike that the reader judges the applicability of the findings and determines whether they fit his or her own situation, understanding that the findings in case study are "less definitive, less certain...intended to be heard, discussed, and further investigated" (p. 437). 


\section{Further Research}

As stated in the opening pages of this dissertation, research related to student teaching is a "'black box"; we know what goes in... and what comes out...but not what occurs in the interim" (Guyton and McIntyre, 1990 p. 524). This case study attempted to explore that "black box;" specifically, this case study attempted to explore the implementation of co-teaching as an alternative student teaching method, and, through a grounded theory approach, identify the emic issues of the participants.

Future research should continue to use case studies to explore the student teaching experience, whether that experience include co-teaching or some other alternative method. "By accumulating what might be called cases of understanding, we can have an ever-expanding source of examples from which others can learn" (Sirotnik, 1999, p. 610) and, as a result, construct tentative hypotheses that can help to structure future research and advance the field's knowledge base (Merriam, 2009).

On a more practical level, in terms of this research as related to the implementation of co-teaching, additional research is needed.

First, this case study took place during the spring semester and, as such, preservice teachers were entering already established classrooms. It would be interesting to replicate this study at Harold Shipyard during the fall semester to determine the main issues of participants and to compare the results to this particular study.

And second, while I am appreciative to Harold Shipyard and New England College for allowing me to conduct this study, this study should be replicated in a multitude of settings implementing co-teaching as an alternative student teaching 
method, with an emphasis on conducting this work within (a) a variety of public school settings, and (b) across multiple grade levels.

\section{Conclusion.}

Through the systematic use of grounded theory, analysts develop substantive theories based on "perceptions...personal experiences, and...hard-won analyses" (Glaser \& Strauss, 1967, p. 225). The analyst is aware that his or her explanations are not the only plausible explanations, but that, based on his or her work in the field and the ongoing relationship between the data and the analysis, the substantive theories developed can be reported with conviction.

While Stake (2010) observed that there can be many explanations, or causes, related to an event, and that as qualitative researchers we cannot be certain...when offering explanations, he also acknowledges, "whether we are quantitative or qualitative researchers, we do need to search for causes, for influences, for preconditions, for correspondences" keeping in mind that our interpretations of the data "stand not as proof but as persuasion of one meaning more than another" (p. 25).

In attempting to interpret the data and locate hypothetical causes, I stayed grounded in the data, building substantive theories through grounded theory analysis (Glaser \& Strauss, 1967, 2008; Strauss \& Corbin, 1998). The substantive theories generated are not meant as generalizations, but refer to "the limited, local, particular place and time" (Stake, 2010, p. 26) of this individual, single case, and add to the limited research relative to teacher education. 
Appendix A

Definition of Co-Teaching Approaches

\begin{tabular}{|l|l|}
\hline Co-Teaching Strategy & Definition \\
\hline One Teach, One Observe & $\begin{array}{l}\text { One teacher has the primary responsibility while the } \\
\text { other gathers specific observational information on } \\
\text { students or the instructing teacher. }\end{array}$ \\
\hline One Teach, One Assist & $\begin{array}{l}\text { One teacher has primary instructional responsibility, } \\
\text { while the other assists students with their work. }\end{array}$ \\
\hline Station Teaching & $\begin{array}{l}\text { The co-teaching pair divides the instructional content } \\
\text { into parts and the students into groups. Groups spend a } \\
\text { designated time at each station. }\end{array}$ \\
\hline Parallel Teaching & $\begin{array}{l}\text { Each teacher instructs half the students. The same } \\
\text { instructional material is addressed using the same } \\
\text { teaching strategy. }\end{array}$ \\
\hline Supplemental Teaching & $\begin{array}{l}\text { One teacher works with students at their expected } \\
\text { grade level while the other teacher works with those } \\
\text { students who need the information and/or materials re- } \\
\text { taught, extended, or remediated. }\end{array}$ \\
\hline Aeam Teaching & $\begin{array}{l}\text { One teacher uses alternative teaching strategies to } \\
\text { provide students with different approaches to learning } \\
\text { the same information. }\end{array}$ \\
\hline Both teachers are actively involved in the lesson.
\end{tabular}

Bacharach, N. \& Heck, T. W. (2010) 
Appendix B

\section{Permission Document}

Rhode Island College/University of Rhode Island

$\mathrm{PhD}$ in Education

Rhode Island College

School of Education, Horace Mann Hall

Providence, RI 02908

Title of Project: An Explanatory Case Study of the Implementation of Co-Teaching as a Student Teaching Method

\section{CONSENT FORM TO CONDUCT RESEARCH}

I am a doctoral student in the Ph.D. in Education Joint Program with the University of Rhode Island and Rhode Island College. The reason I am meeting with you is to obtain your permission to conduct my dissertation research at the Henry Barnard School.

My research proposal (attached) is to conduct a single-case study, utilizing an embedded design, which will encompass five elementary classrooms including the preservice and cooperating teachers contained within, to examine the implementation of co-teaching as an alternative student teaching method. The study will entail the ability to observe in each classroom on 3 occasions to gather information related to the implementation of co-teaching. Interviews with the participants will occur outside of the school environment and school hours.

The study participants will be given an informed consent letter to sign that outlines the specifics of the research and their part in the study.

This study will pose no risks to the teachers (preservice or inservice/cooperating) or the students.

The records of this research will be kept private. In any sort of report that might be published, the researcher will not include any information that will make it possible to identify any participant. Research records will be kept in a sealed file, and access will be limited to the researcher. If there are any problems with the study, the research records may be viewed by the Rhode Island review board responsible for protecting human participants and other government agencies that protect human participants in 
research. All data will be kept for a minimum of three years, after which it will be destroyed.

\section{$\underline{\text { Statement of Consent }}$}

I have read and understand the information above, and I agree to have the Henry Barnard School participate in the "Explanatory Case Study of the Implementation of Co-Teaching as a Student Teaching Method."

Print Name:

Signature:

Name of Researcher Obtaining Permission: 
Appendix C

\section{CONSENT DOCUMENT}

\section{Rhode Island College}

An Explanatory Case Study of the Implementation of Co-Teaching as a Student Teaching Method

You are being asked to be in a research study about the implementation of co-teaching as a student teaching method. You are being asked because you will be student teaching during the Spring 2016 semester at Henry Barnard School. Please read this form and ask any questions that you have before choosing whether to be in the study.

Karen Capraro, an associate professor and doctoral candidate at Rhode Island College, is doing this study. Dr. Patricia Cordeiro is the faculty advisor.

\section{Why this Study is Being Done (Purpose)}

We are doing this study to learn about the ways co-teaching is implemented as a student teaching method. We are also looking at why differences in implementation may exist.

\section{What You Will Have to Do (Procedures)}

If you choose to be in the study, we will ask you to:

- First, you'll talk with me and answer questions I have about your student teaching experience. I will ask about the ways co-teaching is being implemented as a student teaching method. We will meet three times. Each time will take about thirty minutes.

- Second, I will observe you and your cooperating teacher in the classroom in which you are student teaching three times. Each time will take about one hour.

- Third, I will read the written reflections you provide to your seminar leader about your student teaching experience.

- Fourth, I will observe three seminar meetings.

\section{Risks or Discomforts}

The risks are minimal and are about the same as what you would experience during your typical daily activities.

\section{Benefits of Being in the Study}

Being in this study will not benefit you directly.

\section{Deciding Whether to Be in the Study}

Being in the study is your choice to make. Nobody can force you to be in the study. You can choose not to be in the study, and nobody will hold it against you. You can change your mind and quit the study at any time, and you do not have to give a reason. If you decide to quit later, nobody will hold it against you. 


\section{How Your Information will be Protected}

Because this is a research study, results will be summarized across all participants and shared in a dissertation. Your name will not be used in any reports. We will take several steps to protect the information you give us so that you cannot be identified. Instead of using your name, your information will be given a code number. The information will be kept in a locked office file, and seen only by myself and other researchers who work with me. The only time I would have to share information from the study is if it is subpoenaed by a court, or if you are suspected of harming yourself or others, then I would have to report it to the appropriate authorities. Also, if there are problems with the study, the records may be viewed by the Rhode Island College review board responsible for protecting the rights and safety of people who participate in research. The information will be kept for a minimum of three years after the study is over, after which it will be destroyed.

\section{Who to Contact}

You can ask any questions you have now. If you have any questions later, you can contact Karen Capraro at kcapraro@ric.edu, (401) 339-6602 or Dr. Patricia Cordeiro at pcordeiro@,ric.edu, (401) 456-8626.

If you think you were treated badly in this study, have complaints, or would like to talk to someone other than the researcher about your rights or safety as a research participant, please contact Cindy Padula at IRB@ric.edu, by phone at 401-456-9720.

You will be given a copy of this form to keep.

\section{Statement of Consent}

I have read and understand the information above. I am choosing to be in the study "An Explanatory

Case Study of the Implementation of Co-Teaching as a Student Teaching Method". I can change my mind and quit at any time, and I don't have to give a reason. I have been given answers to the questions I asked, or I will contact the researcher with any questions that come up later. I am at least 18 years of age.

I___agree __ do not agree to be audiotaped for this study.

Print Name of Participant:

Signature of Participant: Date:

Name of Researcher Obtaining Consent: 


\section{Appendix D}

\section{Case Study Protocol}

\section{An Explanatory Case Study of the Implementation of Co-Teaching as a Student Teaching Method}

\section{A. Overview of the Case Study Project}

1. Background Information

This case study is part of the researcher's doctoral work. Specifically, this case study encompasses the researcher's culminating work - the dissertation -

as part of her doctoral program.

2. Issues Being Investigated

a. Purpose

The purpose of this case study, entitled "An Explanatory Case Study of the Implementation of Co-Teaching as a Student Teaching Method," is to elucidate how co-teaching, after being formally introduced to participants hrough two co-teaching workshops (Bacharach \& Heck, 2010), is implemented in seven early childhood and elementary classrooms in a small laboratory school located on a college campus in a mid-sized New England city, to illuminate what differences, if any, exist in the implementation and why those differences may exist.

b. Case Study Questions

1. How is co-teaching implemented in seven early childhood and elementary classrooms?

2. If differences in implementation are found, why do these differences exist?

c. Theoretical Framework This case study will utilize grounded theory, as discovered by Barry Glaser and Anselm Strauss (1967) as its theoretical framework.

d. Setting

This case study will be conducted at the Henry Barnard School, located on the Rhode Island College campus in Providence, Rhode Island. 
3. Role of Protocol in Guiding the Case Study Investigator The case study protocol will be utilized as a standard agenda in the investigator's line of inquiry. The case study protocol (1) contains the procedures and general rules to be followed, (2) guides the investigator in carrying out the data collection, (3) keeps the investigator targeted on the topic of the case study, and (4) increases the reliability of case study research.

4. Relevant Readings: See Dissertation Proposal/References Location of Dissertation Proposal/References: Case Study Database/Documents

\section{B. Field Procedures}

1. Protection of Human Subjects

a. Institutional Review Board Approval

Approval \#: 1516-1291

Location of Approval: Case Study Database/Documents

2. Names of Site to be Visited \& Contact Person

a. Henry Barnard School/Principal: Jeannine Magliocco

Location of Permission Document: Case Study Database/Documents

3. Classrooms to be Visited \& Contact Persons
a. Kindergarten/ Room \# 117
b. First Grade/ Room \# 102
c. First Grade/ Room \# 107
d. Fourth Grade/Room \# 167
e. Fourth Grade/ Room \# 169
f. Fifth Grade/ Room \# 175

Location of Consent Forms: Case Study Database/Documents

3. Data Collection Plan

a. Interviews

Individual interviews will be scheduled and conducted by the researcher according to the availability of the interviewees (Yin, 2009). All individual 
interviewees will be interviewed during weeks two and three of the student teaching experience (January 25-February 5, 2016), during the seventh week of the student teaching experience (March 7-11, 2016), and within one week of the conclusion of the student teaching experience (May 2-6, 2016. All interviews will be audio-recorded. The first set of interviews will be transcribed verbatim by the researcher. Interviews two and three will be transcribed in parts, based on relevance, by the researcher. Additionally, written notes will be taken during the interview to record the reactions of the interviewer, to signal importance of answers given, and/or to pace the interview (Merriam, 2009).

The interviews will follow the structure recommended by Steidman (2006). Specifically, three interviews will be conducted with each participant. Interview One will focus on the participant's life history as related to the topic; Three will ask participants to reflect on the meaning of their experience. All interviews will last about 45 minutes and will be conducted at Henry Barnard School. Specific locations (i.e., room numbers) are impossible to determine in advance. The standardized, open-ended interview approach will be utilized (Patton, 2002).

Location of Transcribed Interviews: Case Study Database/Documents

b. Observations

Using the researcher's theoretical framework, the operational definition of coteaching, and the seven methods of co-teaching to narrow the researcher's focus, observations will be conducted in each classroom three times during the course of the student teaching experience - once within weeks two and three of student teaching (January 25-Frbruary 5, 2016), once between weeks six through eight (February 9-March 18, 2016), and once within the last week (May 2-6, 2016) -each lasting one hour in duration. The researcher will assume the role of complete observer during the classroom observations. Descriptive field notes will be recorded during and after each observation. Location of Observational Field Notes: Case Study Database/Documents 


\section{c. Documents}

For the purposes of this research, documents will include parts five and six of the Teacher Candidate Work Sample, produced by the individual preservice teachers, as required by the Feinstein School of Education and Human Development and the seminar supervisor.

Contact persons:

Lorraine Cotti, Leslie Sevey, Carolyn Obel-Omia, Madeline Nixon

Location of Teacher Candidate Work Sample/Parts 5 \& 6: Case Study

Database/Documents

d. Notes

The investigator will take notes (both typed and handwritten) throughout the study. Notes will be dated and kept chronologically.

Location of Notes: Case Study Database/Notes

\section{Case Study Questions}

a. What am I noticing about implementation? Is it systematic or the result of other circumstances? Is it planned or haphazard? Who plans? Is the cooperating teacher making all of the decisions regarding implementation? What co-teaching approaches are being utilized? Again, systematic or in reaction to other circumstances? Planned or haphazard? Are some used more often than others? Why?

b. How do the histories of the participants affect implementation?

c. What questions am I NOT asking myself, that I should be asking?

\section{Dissertation/Case Study Report}

\section{ORDER OF ELEMENTS/Dissertation}

See also: http://web.uri.edu/graduate-school/formatting/

For a thesis in Standard Format, the elements must appear in the following order, and follow the indicated numbering scheme: 
Preliminary material is numbered in lower case Roman numerals, starting with the Approval Page. However, the Approval Page and the Abstract do not have page numbers on them. The elements must appear in this order:

1. Blank Page

2. Title Page

3. Library Rights Statement (only in the "Original Copy")

4. Approval Page

5. Abstract

6. Acknowledgements (optional)

7. Dedication (optional)

8. Preface (optional)

9. Table of Contents

10. List of Figures

11. List of Tables

The main text is numbered in Arabic numerals starting with 1 on the first page of the text, and ending with the last page of the Bibliography. These elements must appear in this order:

1. Text

2. List of References (optional)

3. Appendices (optional)

4. Bibliography

5. Blank Page (not numbered) 
Appendix E

IRB Approval

rom:

"NoReplyRIC_Elements@topazti.net<mailto:NoReplyRIC_Elements@ topa zti.net>"

$<$ NoReplyRIC_Elements@topazti.net<mailto:NoReplyRIC_Elements@top azti.net $>>$

> Date: December 23, 2015 at 1:02:04 PM EST

$>$ To: Institutional Review Board - Rhode Island College

<irb@ric.edu<mailto:irb@ric.edu>>, "Cordeiro, Patricia A."

$<$ PCordeiro@ric.edu<mailto:PCordeiro@ric.edu>>, "Capraro, Karen L."

$<$ kcapraro@ric.edu<mailto:kcapraro@ric.edu $>>$

$>$ Subject: IRB: \#1516-1291 (Cordeiro, Patricia) approved

$>$

$>$

$>$ Greetings,

$>$

$>$ The proposal for the project referenced below has been APPROVED by the Institutional Review Board (IRB).

$>$

$>$ Project title: An explanatory case study of the implementation of coteaching as a student teaching method

$>$

$>$ Approval \#: 1516-1291

$>$ Type of review: Follow-up by Chair

$>$ Proposal type: Original

$>$ Principle Investigator: Cordeiro, Patricia

$>$ Fees received: 1 . No fees -- RIC supervised or sponsored

$>$ Funding status:

$>$

$>$ Approval date: 12/23/2015

$>$ Expiration date: 12/23/2016

$>$ A request to renew this protocol must be received by $11 / 25 / 2016$.

$>$ 
Appendix $F$

Individual Interview Questions \#1

Where:

When:

With whom:

1. What experiences have you had co-teaching, prior to this experience?

2. Tell me a little bit about your experiences in school.

Probing questions:

a. How does what you know about school differ from what you have been taught about school?

3. How would you describe the "ideal" classroom?

4. How would you describe the "ideal" teacher?

5. Tell me about what you expect from this student teaching experience.

6. Describe your understanding of co-teaching. 
Appendix G

Individual Interview Questions \#2

Where:

When:

With whom:

1. Tell me about how things are going.

Probing questions:

a. Do you feel as though you were prepared to enter into student teaching?

b. Do you feel your cooperating teacher (to student teacher)/student teacher (to cooperating teacher) was prepared?

c. How has your teaching changed?

d. How is it like your cooperating teacher/student teacher?

e. How is it different?

f. Why is it different?

2. Of the seven methods of co-teaching, which do you use most?

Probing questions:
a. Least?
b. Why?

3. Describe a typical day in your classroom.

4. Has your understanding of co-teaching changed? 
Appendix H

Individual Interview Questions \#3

Where:

When:

With whom:

1. What made co-teaching easy?

2. What made co-teaching difficult?

3. Has your understanding of co-teaching changed?

4. If you could offer advice to someone preparing to co-teach, what advice would you give?

5. What other question(s) do you wish I had asked? 


\section{Bibliography}

Allen, D.S., Perl, M., Goodson, L. \& Sprouse, T. (2014). Changing traditions: Supervision, co-teaching, and lessons learned in a professional development school partnership. Educational Considerations, 42(1), 19-29.

American Psychological Association (2010). Publication manual of the American Psychological Association. Washington, DC: American Psychological Association.

Bacharach, N., \& Heck, T. W. (2012). Voices from the field: Multiple perspectives on a co-teaching in student teaching model. Educational Renaissance, 1(1), 49-61.

Bacharach, N., Heck, T. W., \& Dahlberg, K. (2010). Changing the face of student teaching through coteaching. Action In Teacher Education, 32(1), 3-14.

Bacharach, N., Heck, T., \& Dank, M. (2003). Co-teaching: A partnership in the classroom. Paper presented at the annual meeting of the Association of Teacher Educators, Jacksonville, FL.

Badiali, B., \& Titus, N. E. (2010). Co-Teaching: Enhancing student learning through mentor-intern partnerships. School-University Partnerships, 4(2), 74-80.

Bassey, M. (1999). Case study research in educational settings. Philadelphia, PA: Open University Press.

Berliner, D.C. \& Biddle, B.J. (1995). The manufactured crisis: Myths, fraud, and the attack on America's public schools. Cambridge, MA: Perseus Books.

Charmaz, K. (2006). Constructing grounded theory: A practical guide through qualitative analysis. Thousand Oaks, CA: Sage Publications.

Christiansen, E. (2016). Rhode Island College: Meeting the state's needs through time. Retrieved July 25, 2016, from http://www.ric.edu/aboutric/pdf /RICHISTORYBOOK2016.pdf

Cochran-Smith, M. \& Fries, K. (2005). The AERA panel on research and teacher education: Context and goals. In M. Cochran-Smith \& K. Zeichner (Eds.), Studying teacher education: The report of the AERA panel on research and teacher education (pp.37-68). Washington, DC: American Educational Research Association.

Cochran-Smith, M., \& Zeichner, K. M. (Eds.). (2005). Studying teacher education: The report of the AERA panel on research and teacher education. Washington, DC: American Educational Research Association. 
Cook, L., \& Friend, M. (1995). Co-teaching: Guidelines for creating effective practices. Focus On Exceptional Children, 28(3), 1-16. Retrieved July 25, 2016, from http://0-web.ebscohost.com.helin.uri.edu/ehost/detail?sid $=58 \mathrm{dd} 61 \mathrm{~d} 2-95 \mathrm{a} 7-49 \mathrm{cc}-\mathrm{be} 38-74243286 \mathrm{dcca} \% 40$ sessionmgr4001\&vid $=6 \&$ hid $=4214 \&$ bdata $=$ JnNpdGU9ZWhvc3QtbGl2ZQ $\% 3 \mathrm{~d} \% 3 \mathrm{~d} \# \mathrm{db}$ $=$ eric $\& \mathrm{AN}=\mathrm{EJ} 545936$

Council of Chief State School Officers. (2012). Our responsibility, our promise: Transforming educator preparation and entry into the profession.

Creswell, J.W. (2014). Research design: Qualitative, quantitative, and mixed methods approaches $\left(4^{\text {th }}\right.$ ed.). Thousand Oaks, CA: Sage Publications.

Darling-Hammond, L. (2006). Constructing $21^{\text {st }}$ century teacher education. Journal of Teacher Education 57(3), 300-314. doi: 10.1177/0022487105285962

Darling-Hammond, L., \& Baratz-Snowden, J. (2007). A good teacher in every classroom: Preparing the highly qualified teachers our children deserve. Educational Horizons, 85(2), 111-132.

Darragh, J. J., Picanco, K. E., Tully, D., \& Henning, A. S. (2011). "When teachers collaborate, good things happen": Teacher candidate perspectives of the coteach model for the student teaching internship. AILACTE Journal, 8, 83-104.

Diana, T. J. (2014). Co-teaching: Enhancing the student teaching experience. Kappa Delta Pi record, 50, 76-80. DOI: 10.1080/00228958.2014.900849

Duncan, A. (2009). Teacher preparation: Reforming the uncertain profession. Remarks of Secretary Arne Duncan at Teachers College, Columbia University. Retrieved July 25, 2016 from http://www.ed.gov/news/speeches/teacherpreparation-reforming-uncertain-profession

Feinstein School of Education and Human Development (2014). Teacher candidate work sample. Providence, RI: Rhode Island College. Retrieved July 25, 2016 from https://www.ric.edu/feinsteinschooleducationhumandevelopment /pdf/TCWS_Rubric_Task.pdf

Feinstein School of Education and Human Development (2016). Roles and responsibilities of the team. Retrieved July 25, 2016 from: https://www.ric.edu/FeinsteinSchoolEducationHuman Development/pdf/Roles-and-Responsibilities-of-the-Team.pdf

Fennessey, S. (2004). Henry Barnard School: A tradition in education for lifelong learning. Providence, RI: Rhode Island College. 
Forzani, F. M. (2014). Understanding "core practices" and "practice-based" teacher education: Learning from the past. Journal of Teacher Education, (65)4, 357368.

Fraenkel, J. R., Wallen, N. E., \& Hyun, H. H. (2012). How to design and evaluate research in education ( $4^{\text {th }}$ ed.). New York, NY: McGraw-Hill.

Friend, M. (1993). Co-Teaching: An overview of the past, a glimpse at the present, and considerations for the future. Preventing School Failure, 37(4), 6-10.

Glaser, B.G. (1978). Theoretical sensitivity. Mills Valley, CA: The Sociology Press.

Glaser, B.G. (1992). Basics of grounded theory analysis: Emergence vs. forcing. Mill Valley, CA: Sociology Press.

Glaser, B.G. \& Strauss, A.L. (1967). The discovery of grounded theory: Strategies for qualitative research. New York, NY: Aldine Publishing.

Glaser, B.G. \& Strauss, A.L. (2008). The discovery of grounded theory: Strategies for qualitative research ( $3^{\text {rd }}$ printing). New Brunswick, NJ: Transaction Publishers.

Glaser, B.G. \& Strauss, A.L. (2010). Status Passage. New Brunswick, NJ: Aldine Transaction.

Goldstein, D. (2014). Teacher wars: A history of America's most embattled profession. New York, NY: Doubleday.

GoNoodle (Producer). (2016). Available from https://www.gonoodle.com

Goodlad, J.I. (1990). Teachers for our nation's schools. San Francisco, CA: JosseyBass.

Goodlad, J. I. (1999). Whither schools of education?. Journal Of Teacher Education, 50(5-), 325-38.

Graziano, K. J., \& Navarrete, L. A. (2012). Co-teaching in a teacher education classroom: Collaboration, compromise, and creativity. Issues In Teacher Education, 21(1), 109-126.

Guyton, E. \& McIntyre, D.J. (1990). Student teaching and school experiences. In W.R. Houston, M. Haberman, \& J. Sikula (Eds.), Handbook of research on teacher education: A project of the Association of Teacher Educators (514- 534). New York, NY: Macmillan. 
Heck, T. W., Bacharach, N., \& Dahlberg, K. (2008). Co-teaching: Enhancing the student teaching experience. Paper presented at the Eighth Annual IBER \& TLC Conference, Las Vegas, NV.

Heck, T.W., Bacharach, N., Dahlberg, K., Ofstedal, K. \& Mann, B. (2010). Mentoring teacher candidates through co-teaching: Collaboration that makes a difference. St. Cloud, MI: Teacher Quality Enhancement Center.

Henry Barnard School (2016). The Henry Barnard School History. Retrieved July 25, 2016 from http://henrybarnardschool.org/index.php/about-us/history

Hodge, S. (2014). Transformative learning as an "inter-practice" phenomenon. Adult Education Quarterly: A Journal of Research and Theory, 64(2), 165-181.

Hollins, E.R. \& Guzman, M.T. (2005). Research on preparing teachers for diverse populations In M. Cochran-Smith \& K.M. Zeichner (Eds.), Studying teacher education: The report of the AERA panel on research and teacher education. Washington, DC: American Educational Research Association.

Holmes Group (1986). Tomorrow's teachers: A report of the Holmes Group. Retrieved July 25, 2016 from http://files.eric.ed.gov/fulltext/ED270454.pdf

Kohlberg, L. \& Mayer, R. (1972). Development as the aim of education. Harvard Educational Review, 42(4), 449-496.

Lave, J. (1991). Situating learning in communities of practice. In L. Resnick, J. Levine, \& S. Behrend (Eds.), Perspectives on socially shared cognition. Washington, DC: American Psychological Association.

Lave, J., \& Wenger, E. (1991). Situated learning: Legitimate peripheral participation. Cambridge, England: Cambridge University Press.

Levine, A. (2006). Will universities maintain control of teacher education? Change: The Magazine of Higher Learning, 38(4), 36-43.

Levine, A. (2010). Teacher education must respond to changes in America. Phi Delta Kappan, 92(2), 19-24.

Lofland, J. (1971). Analyzing social settings: A guide to qualitative observation and analysis. Belmont, CA: Wadsworth Publishing.

Merk, H., Waggoner, J., \& Carroll, J. (2013). Co-learning: Maximizing learning in clinical experiences. AILACTE Journal, 10(1), 79-95.

Merriam, S.B. (1988). Case study research in education: A qualitative approach. San Francisco, CA: Jossey-Bass Publishers. 
Merriam, S.B. (2009). Qualitative research: A guide to design and implementation (Rev. ed.). San Francisco, CA: Jossey-Bass Publishers.

Merriam, S.B. \& Bierema, L.L. (2014). Adult learning: Linking theory and practice. San Francisco, CA: Jossey-Bass.

Merriam-Webster (2016). Agent. Retrieved July 25, 2016 from: http://www.merriamwebster.com/dictionary/agent

Murphy, C., \& Beggs, J. (2010). A five-year systematic study of co-teaching science in 120 primary schools. In C. Murphy \& K. Scantlebury (Eds.) Co-teaching in international contexts: Research and practice (pp. 11-34).

National Council for Accreditation of Teacher Education, W. C. (2006). What makes a teacher effective? A summary of key research findings on teacher preparation. National Council for Accreditation of Teacher Education.

National Council for Accreditation of Teacher Education (NCATE). (2010). Transforming teacher education through clinical practice: A national strategy to prepare effective teachers. Report of the Blue Ribbon Panel on Clinical Preparation and Partnerships for Improved Student Learning. National Council for Accreditation of Teacher Education.

Patton, M.Q. (1986). Utilization-focused evaluation ( $2^{\text {nd }}$ ed.). Beverly Hills, CA: Sage Publications.

Patton, M.Q. (2002). Qualitative research and evaluation methods $\left(3^{\text {rd }}\right.$. ed.). Thousand Oaks, CA: Sage Publications.

Patton, M.Q. (2008). Utilization-focused evaluation (4 ${ }^{\text {th }}$ ed.). Thousand Oaks, CA: Sage Publications.

Picanco, K., \& Darragh, J. (2011). Reimagining partnerships: Using the co-teach model to prepare 21st century teachers. Northwest Passage Journal, 9, 139146.

Rhode Island College (2010). Student teaching handbook. Retrieved July 25, 2016 from https://www.ric.edu/feinsteinschooleducationhumandevelopment/ pdf/CPP_StudentTeachingHandbook.pdf

Rhode Island College (2016) Teacher Candidates. Retrieved July 25, 2016 from https://www.ric.edu/feinsteinschooleducationhumandevelopment/st teachingteacherCandidates.php 
Rivers, J. \& Sanders, W. (2002). Teacher quality and equity in educational opportunity: Findings and policy implications. In L. Izumi \& W. Evers (Eds.), Teacher Quality (pp. 13-23). Stanford, CA: Hoover Institution.

Roth, W. M. \& Tobin, K. (2002). At the elbow of another: Learning to teach by coteaching. New York, NY: Peter Lang.

Roth, W., Tobin, K., Carambo, C., \& Dalland, C. (2004). Coteaching: Creating resources for learning and learning to teach chemistry in urban high schools. Journal of Research in Science Teaching, 41(9), 882-904.

Rotherham, A. J., Mitchel, A. L. (2014). Genuine progress, greater challenges: A decade of teacher effectiveness reforms. Bellwether Education Partners. Retrieved July 25, 2016 from http://files.eric.ed.gov /fulltext/ED545140.pdf

Seidman, I. (2006). Interviewing as qualitative research: A guide for researchers in education and the social sciences ( $3^{\text {rd }}$ ed.). New York, NY: Teachers College Press.

Seidman, I. (2013). Interviewing as qualitative research: A guide for researchers in education and the social sciences $\left(4^{\text {th }}\right.$ ed.). New York, NY: Teachers College Press.

Sirotnik, K. A. (1999). Making sense of educational renewal. Phi Delta Kappan, 80(8), 606-10.

Siry, C. (2011). Emphasizing collaborative practices in learning to teach: coteaching and cogenerative dialogue in a field-based methods course. Teaching Education 22(1), 91-101.

Stake, R.E. (1995). The art of case study research. Thousand Oaks, CA: Sage Publications.

Stake, R.E. (2005). Qualitative case studies. In N.K. Denzin \& Y.S. Lincoln (Eds.), The Sage handbook of qualitative research ( $3^{\text {rd }}$ ed., pp. 443-466). Thousand Oaks, CA: Sage Publications.

Stake, R.E. (2010). Qualitative research: Studying how things work. New York, NY: Guilford Press.

Strauss, A. \& Corbin, J. (1998). Basics of qualitative research: Techniques and procedures for developing grounded theory ( $2^{\text {nd }}$ ed.). Thousand Oaks, CA: Sage Publications. 
Tobin, K. (2006). Learning to teach through coteaching and cogenerative dialogue. Teaching Education, 17(2), 133-142.

United States. Department of Education. (2011). Our future, our teachers: The Obama administration's plan for teacher education reform and improvement US Department of Education.

Villa, R.A., Thousand, J.S., \& Nevin, A.I. (2013). A guide to co-teaching: Strategies to facilitate student learning ( $3{ }^{\text {rd }}$ ed.). Thousand Oaks, CA: Corwin.

Wassell, B. \& LaVan, S. (2009). Revisiting the dialogue on the transition from coteaching to inservice teaching: New frameworks, additional benefits and emergent issues. Cultural Studies of Science Education, 4(2), 477-484.

Wenger, E., McDermott, R. \& Snyder, W.M. (2002). Cultivating communities of practice: A guide to managing knowledge. Boston, MA: Harvard Business School Press.

Williams, W. (1976). Implementation analysis and assessment. In W. Williams \& R.F. Elmore (Eds.), Social program implementation. New York, NY: Academic Press.

Yin, R. K. (1989). Case study research: Design and methods. Newbury Park, CA: Sage Publications, Inc.

Yin, R.K. (2003). Case study research: Design and methods $\left(3^{\text {rd }}\right.$ ed.). Thousand Oaks, CA: Sage Publications.

Yin, R. K. (2009). Case study research: design and methods ( $4^{\text {th }}$ ed.). Thousand Oaks, CA: Sage Publications, Inc.

Yin, R.K. (2014). Case study research: Design and Methods $\left(5^{\text {th }}\right.$ ed.). Thousand Oaks, CA: Sage Publications.

Zeichner, K. M. (1999). The new scholarship in teacher education. Educational Researcher, 28(9), 4-15.

Zeichner, K. M. (2002). Beyond traditional structures of student teaching. Teacher Education Quarterly, 29(2), 59-64.

Zeichner, K. M. (2010). Rethinking the connections between campus courses and field experiences in college-and university-based teacher education. Journal of Teacher Education, 61(1-2), 89-99. 
Zeichner, K.M. \& Conklin, H.G. (2005). Teacher education programs. In M. CochranSmith \& K. Zeichner (Eds.), Studying teacher education: The report of the AERA panel on research and teacher education (pp. 645-735). Washington, DC: American Educational Research Association. 